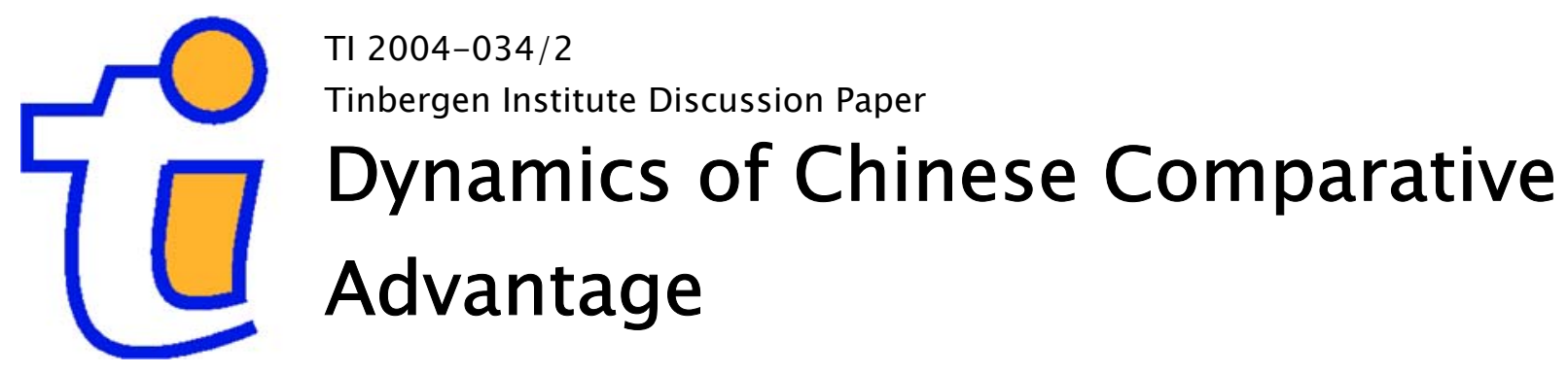

Jeroen Hinloopen ${ }^{1}$

Charles van Marrewijk²

Tinbergen Institute, and Departments of Economics of

' Universiteit van Amsterdam,

2 Erasmus Universiteit Rotterdam. 


\section{Tinbergen Institute}

The Tinbergen Institute is the institute for economic research of the Erasmus Universiteit Rotterdam, Universiteit van Amsterdam, and Vrije Universiteit Amsterdam.

Tinbergen Institute Amsterdam

Roetersstraat 31

1018 WB Amsterdam

The Netherlands

Tel.: $\quad+31(0) 205513500$

Fax: $\quad+31(0) 205513555$

Tinbergen Institute Rotterdam

Burg. Oudlaan 50

3062 PA Rotterdam

The Netherlands

Tel.: $\quad+31(0) 104088900$

Fax: $\quad+31(0) 104089031$

Please send questions and/or remarks of nonscientific nature to driessen@tinbergen.nl.

Most TI discussion papers can be downloaded at http://www.tinbergen.nl. 


\title{
Dynamics of Chinese comparative advantage ${ }^{1}$
}

\author{
Jeroen Hinloopen ${ }^{2}$
}

University of Amsterdam, Tinbergen Institute, and

Economics Network for Competition and Regulation (ENCORE)

Charles van Marrewijk ${ }^{3}$

Erasmus University Rotterdam and Tinbergen Institute

March 2004

\begin{abstract}
$\underline{\text { Abstract }}$
We analyze the dynamics of Chinese comparative advantage as measured by export shares and the Balassa index using 3-digit and 4digit sectors for the period $1970-1997$. We use novel tools to identify periods of rapid structural change and the persistence of comparative advantage, such as Galtonian regressions, probability-probability (p-p) plots, and the Harmonic Mass index, to supplement the usual descriptive statistical methods and mobility indicators associated with Markov transition matrices.
\end{abstract}

Keywords: Balassa index, distribution dynamics, Galtonian regression, Markov matrices, P-P plots, and the HM index.

JEL codes: E63, F14, F40, N95, O10, O53, P30, R11

\footnotetext{
${ }^{1}$ We would like to thank Robert Feenstra, Joe Francois, Jaime de Melo, Jan Willem Gunning, and seminar participants at the Institute of Social Studies and the University of Amsterdam for useful comments and suggestions. The usual disclaimer applies.

${ }^{2}$ Correspondence: University of Amsterdam, Department of Economics, Roetersstraat 11, 1018 WB

Amsterdam; J.Hinloopen@uva.nl; www.fee.uva.nl/io/jhinloopen.

${ }^{3}$ Correspondence: Erasmus University Rotterdam, Department of Economics, P.O. Box 1738, 3000

DR Rotterdam; vanmarrewijk@few.eur.nl; www.few.eur.n1/few/people/vanmarrewijk.
} 


\section{Introduction}

The rapid development of China's economy over the last few decades has attracted much attention. Many nations, firms, and opinion leaders look in awe and envy at these developments, particularly when realizing that China is already the most populous nation on earth and the second-largest economy after correction for purchasing power. It is clear that China's income growth would not have been possible without opening up to the world economy and using foreign knowledge, either directly or indirectly. Virtually all aspects of China's economy are part of ongoing research and debate, for example regarding its business environment (Tse et al., 2003), its friction with Japan over safeguards (Yoshimatsu, 2002), its friction with the United States regarding its bilateral trade balance (Fung and Lau, 2001), and its role in the world economy (Deckers, 2004).

We analyze the dynamics of revealed comparative advantage for three Chinese economies, namely China, Hong Kong, and Taiwan, inter alia on the basis of three innovations. ${ }^{4}$ First, we use Galtonian regressions to identify the most suitable lag period for analyzing changes in comparative advantage. Second, we introduce probability-probability ( $p-p)$ plots as an alternative means to avoid the discretization problem associated with estimating Markov transition matrices. Third, we apply the Harmonic Mass (HM) index developed by Hinloopen and Van Marrewijk (2004c) on the basis of p-p plots to identify peculiarities in the data and periods of rapid structural change. Along the way we also describe basic developments in Chinese export flows and the statistical and stability properties of the distribution of comparative advantage, estimate decile Markov transition matrices with associated mobility indices, and give a description of the structural changes in the Chinese exports which enabled the rapid development process.

The concept of 'revealed' comparative advantage, introduced by Liesner (1958) but refined and popularized by Balassa (1965) and therefore known as the 'Balassa index', is widely used empirically to identify a country's weak and strong export sectors. Porter (1990) uses it to identify strong sectoral clusters, Amiti (1999) analyzes specialization patterns in Europe, Proudman and Redding (1998, 2000) focus on the dynamics of comparative advantage, Bojnec (2001) analyzes agricultural trade, Hinloopen and Van Marrewijk (2001) study the (dynamics of the) empirical distribution of European trade, and Fertö and Hubbard (2003) analyze competitiveness in Hungarian agrifood sectors. The theoretical basis for the Balassa index as an indicator of comparative advantage was provided by Hillman (1980), who developed a necessary and sufficient condition for the correspondence between the Balassa

\footnotetext{
${ }^{4}$ We use the term 'Chinese' always in reference to the combination China, Hong Kong, and Taiwan.
} 
index and pre-trade relative prices, which can be verified empirically (see Marchese and Nadal de Simone, 1989, and Hinloopen and Van Marrewijk, 2004a).

We use a combination of the CID UC Davis / Feenstra (2000) data set, consisting of annual observations on bilateral trade flows for 4 digit sectors, 183 countries, and 28 years, with a total of slightly less than 18.4 million positive observations. ${ }^{5}$ In line with the recommendation in Hinloopen and Van Marrewijk (2004a), we only report results for those sectors that satisfy the Hillman condition. In this particular case, however, all sectors for all three countries satisfy the Hillman condition throughout the entire time period. The most important aspect of the data set to take into consideration for this study on the dynamics of Chinese comparative advantage is the role of Hong Kong as a transshipment center for many goods from China, as discussed by Fung (1998), Feenstra et al. (1999), and Feenstra (2000). Since the data set partially uses export data, as explained in Appendix I, re-exports of China's goods to other countries, such as the United States, through Hong Kong tend to be underestimated. In 1996, for example, China reported direct exports to the USA of \$ 14.2 billion and indirect exports to the USA via Hong Kong of \$ 12.5 billion, a total value of \$ 26.7 billion. The USA, however, reported an import value from China of $\$ 51.5$ billion in 1996, a discrepancy of $\$ 24.8$ billion. Although a substantial part of this discrepancy can be attributed to the value-added of the transshipped goods in Hong Kong, estimated by Feenstra et al. (1999) to be $\$ 7.6$ billion, most of the remainder reflects a failure of China's authorities to track the 'final destination' of its exports.

Figure 1 Evolution of China's exports relative to Hong Kong's exports, 1970-1997

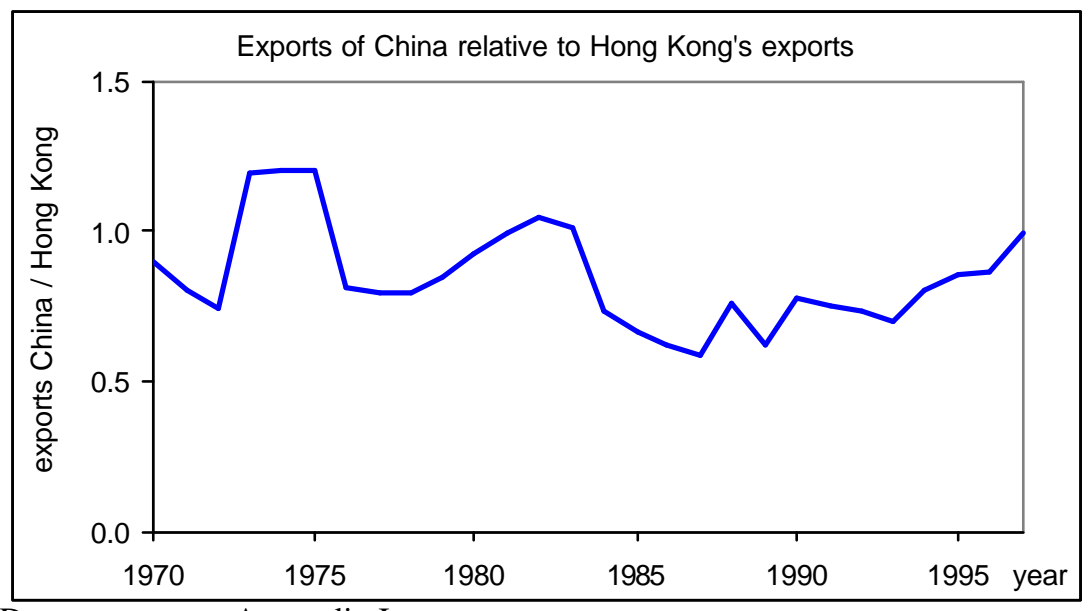

Data source: see Appendix I

\footnotetext{
${ }^{5}$ See the eta - center website for details regarding the sector classification and the top 40 Balassa indices: www.few.eur.nl/few/people/vanmarrewijk/eta . See Appendix I for data details.
} 
What does this imply for our study of comparative advantage? As China's reported exports are classified to a too large extent as exports to Hong Kong rather than other countries, but comparative advantage is concerned with the sectoral and not the geographic composition of trade flows, the impact for the measured comparative advantage of China is limited. This does not hold, however, for the measured comparative advantage of Hong Kong. Its role as a transshipment center for re-exports from China implies that Hong Kong's measured exports partially reflect its own comparative advantage (caused by Hong Kong's production factors) and partially reflect China's comparative advantage (caused by China's production factors). Under the assumption that Hong Kong's role as an entrepôt is similar for all sectors and leads to similar mark-ups for services rendered in Hong Kong, the reported comparative advantages for Hong Kong in this study therefore reflect a weighted average of China's comparative advantages and Hong Kong's 'true' comparative advantages. Although there is considerable fluctuation in China's exports relative to Hong Kong's exports, see Figure 1, for the period as a whole there is neither an upward nor a downward trend, indicating that Hong Kong's role as an entrepôt has not changed substantially over the period under investigation.

Section 2 gives a brief overview of the structure and history of the Chinese economies. Section 3 discusses basic trade developments regarding major export markets and trade composition. Section 4 reviews the largest initial and ultimate trade sectors at the 4digit level. Section 5 discusses comparative advantage as measured by the Balassa index and reviews its main distributional and stability aspects. Section 6 discusses the evolution over time of the strong Chinese export sectors at the 4digit level, ordered at the 1-digit level. To get an estimate of the most appropriate time lag for analyzing dynamics of comparative advantage, section 7 estimates Galtonian regressions and concludes that a five year lag is a suitable choice. Section 8 estimates five-year difference Markov transition matrices for the deciles of the distribution of comparative advantage. To avoid the discretization problem of Markov matrices, section 9 introduces p-p plots and the HM index as an indicator for structural differences. We identify three main peaks in China's HM index (in 1972, 1980, and 1985), and a related peak in Taiwan's HM index in the mid-1980s. Section 10 provides a factor-abundance oriented approach of the evolution of comparative advantage at the 3-digit level, with a classification in five broader categories: primary products, naturatresource intensive products, unskilled-labor intensive products, technology intensive products, and human-capital intensive products. We relate the discussion of structural changes in these categories with the peaks identified by the HM index. Section 11, finally, concludes. 


\section{The Chinese economies}

Our study concentrates on the dynamics of comparative advantage for three Chinese economies: the People's Republic of China, Hong Kong special administrative region of China, and the Republic of China, henceforth referred to as China, Hong Kong, and Taiwan, respectively. At present, Hong Kong is the smallest of the three, both in terms of land area $\left(1000 \mathrm{~km}^{2}\right)$ and in terms of population (6.8 million inhabitants), followed by Taiwan $(36,000$ $\mathrm{km}^{2}$ and 22 million inhabitants) and China (9.3 million $\mathrm{km}^{2}$ and 1,262 million inhabitants). Over the past 40 years the population of China has almost doubled, of Hong Kong has slightly more than doubled, and of Taiwan has nearly tripled, see Figure 2.

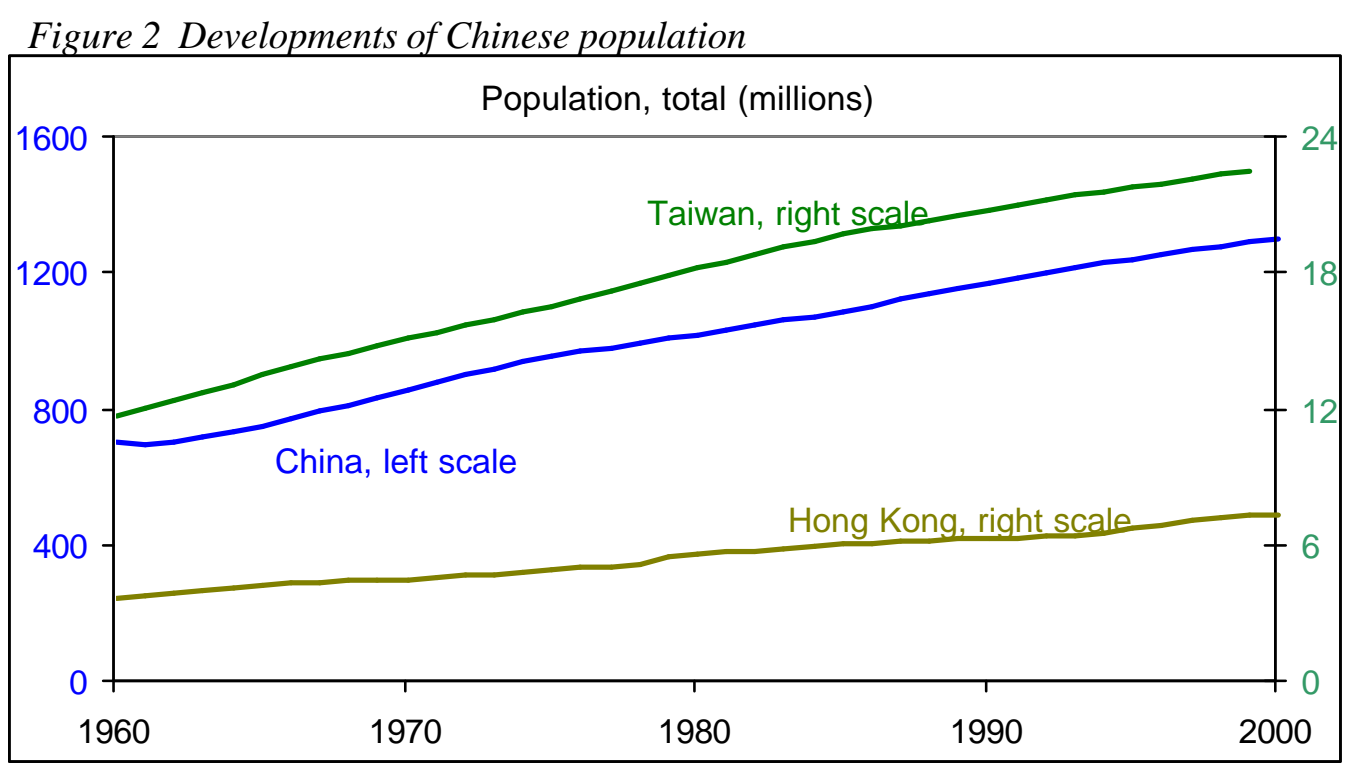

Data source: see Appendix I

As indicated by some of the tools found in North and central China left behind by homo erectus, the history of China dates back some 1.3 million years. The earliest Chinese settlements on Taiwan began in the $7^{\text {h }}$ century. It was reached in 1590 by the Portuguese, who named it Formosa ('beautiful'), followed by the Dutch in 1624 (who assumed control from 1641 to 1662), who were in turn expelled by Koxinga, a general of the Ming dynasty. Japan acquired Taiwan in 1895 after the first Sino-Japanese war, and kept control until 1945, when it was returned to China. From 1949 on the Nationalist government of Chiang Karshek took refuge on, and control of, the island. One century earlier, the British occupied Hong Kong, which had long been barren, rocky, and sparsely settled, during the Opium War (183942). After a brief occupation by the Japanese (1941-45), Hong Kong returned to Britain until 1997 when it became a special administrative region of China: 'one country, two systems'. China has been under communist rule since 1949 and has eventually managed to replace Taiwan in most international organizations (the United Nations in 1971, and the International 
Monetary Fund and the World Bank in 1980), although both countries are now a member of the World Trade Organization.

Figure 3 Developments in Chinese income and trade flows
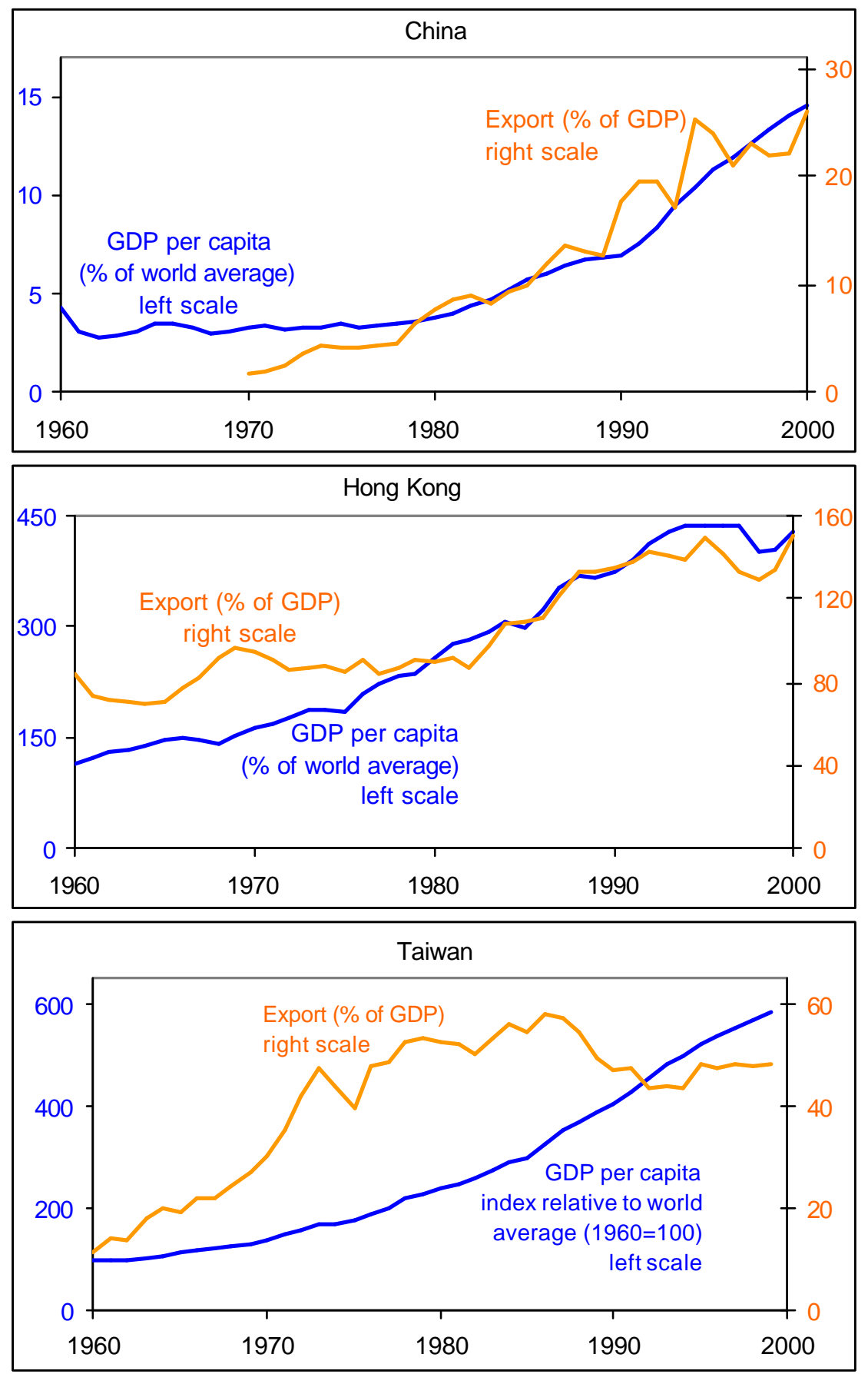

Data source: see Appendix I

As illustrated in Figure 3, all three economies have witnessed a tremendous increase in income levels and international trade flows in the recent past, although the timing and levels differ. Hong Kong is the richest economy in per capita terms, followed by Taiwan and China. In the period 1960-2000, and starting from an income level above the world average, per 
capita income in Hong Kong increased relatively steadily by 274 percent more than per capita income in the world as a whole. At the same time, trade openness in Hong Kong increased and exports as a percentage of GDP reached 150 percent in 2000. Between 1960 and 2000 the per capita income level in Taiwan rose almost 500 percent more than the per capita income level in the world as a whole. Simultaneously, Taiwan's trade openness increased, particularly in the period 1960-80. Exports reached about 50 percent of GDP in 2000. China, too, managed to achieve some 242 percent more rapid per capita income growth than the world average in the period 1960-2000. Unlike the more steady developments in the other two Chinese economies, however, this increase was exclusively achieved in the last two decades of the $20^{\text {th }}$ century, in conjunction with economic reform and opening up of the economy since 1978, leading to exports as a percentage of GDP reaching almost 26 percent in 2000.

\section{Basic trade developments ${ }^{6}$}

The current geographic distribution of the international trade flows for the three Chinese economies is remarkably similar, see Table 1 . The ten largest export markets account for more than $75 \%$ of total exports in all cases. The other two Chinese economies are always in the top ten, as are the USA, Japan, Germany, UK, Singapore, and the Netherlands. For China and Hong Kong the list is completed by South Korea and France, while Malaysia and Thailand complete the Taiwanese list. Political changes have affected the geographic distribution over time, as illustrated in Figure 4. Exports from China have risen gradually in the past 30 years, while exports from China to South Korea started at the end of the 1980s, as did exports from Taiwan to China. Similarly, exports from Hong Kong to China increased substantially since the end of the 1970s.

Table 1 Largest export markets in 1997 (\% of total exports)

\begin{tabular}{lr|lr|lr}
\hline \hline China & export & Hong Kong & export & Taiwan & export \\
\hline Hong Kong & 24.1 & China & 34.4 & USA & 24.9 \\
USA & 18.6 & USA & 21.8 & China & 12.2 \\
Japan & 17.8 & Japan & 6.0 & Hong Kong & 11.9 \\
South Korea & 5.0 & UK & 3.9 & Japan & 9.2 \\
Germany & 4.1 & Germany & 3.6 & Singapore & 4.2 \\
Singapore & 2.3 & Singapore & 2.8 & Germany & 3.8 \\
UK & 1.9 & Taiwan & 2.5 & UK & 2.8 \\
Taiwan & 1.8 & Netherlands & 1.7 & Malaysia & 2.8 \\
France & 1.8 & South Korea & 1.5 & Netherlands & 2.2 \\
Netherlands & 1.5 & France & 1.5 & Thailand & 2.1
\end{tabular}

\footnotetext{
${ }^{6}$ Appendix II provides more details, see also www.few.eur.nl/few/people/vanmarrewijk/eta.
} 
Figure 4. Geographic trade distribution, highest export markets in 1997 (\% of total)
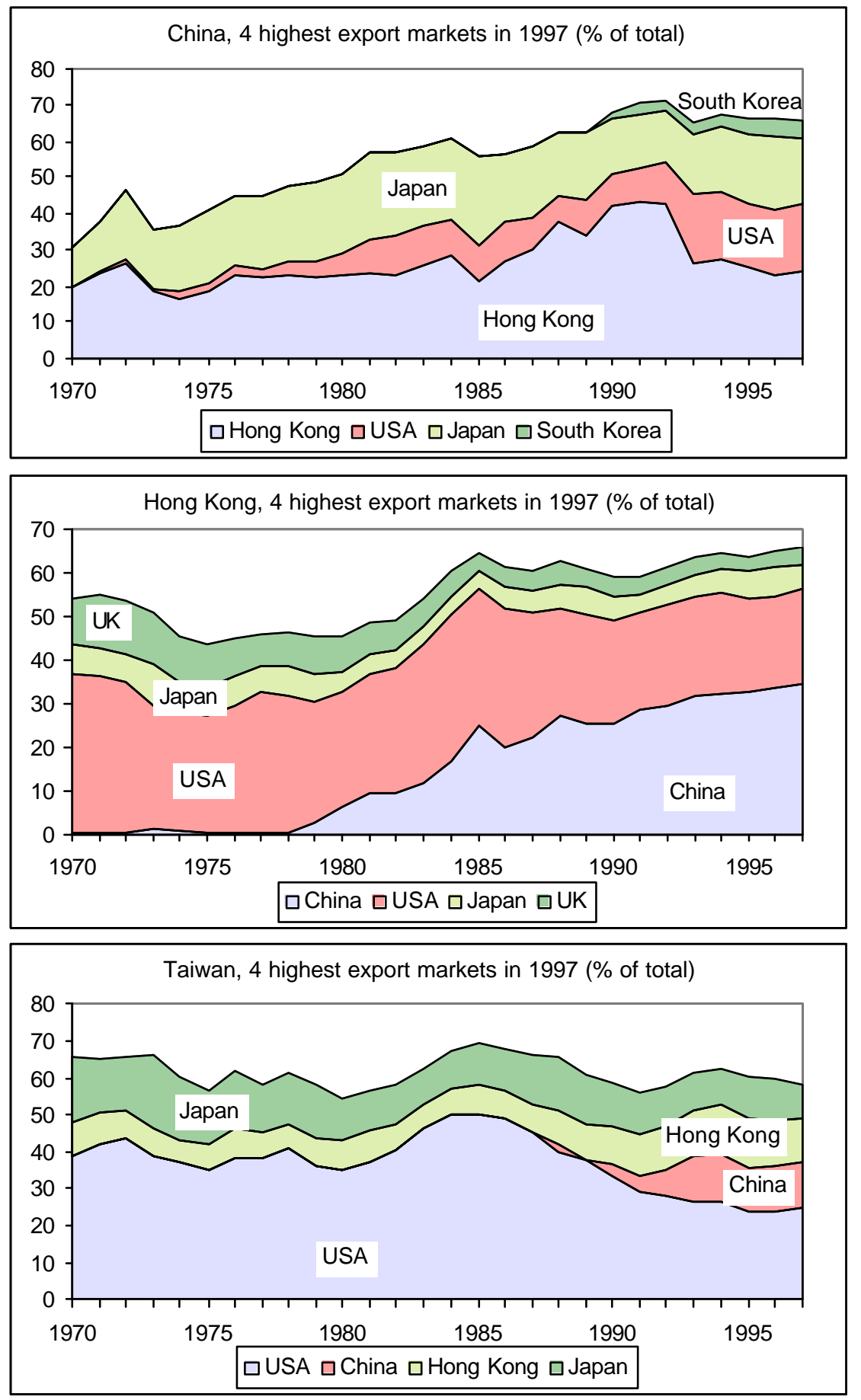

Our analysis focuses on the dynamics of the sectoral distribution of comparative advantage, rather than on its geographic distribution. The sectors are classified in increasing detail in digits; there are ten 1-digit sectors (0-9), each in principle subdivided in ten 2-digit sectors, etc. We have data available at the 4digit level, which in theory could be 10,000 sectors, but in practice amounts to 'only' 1,249 different sectors. Of these we classify 747 as truly 4digit sectors, see below. This section briefly describes the main export composition at the 1-digit level, the sequel of the paper analyzes 3-digit and 4-digit sectors. As summarized in Table 2, 
the sectoral composition has significantly changed in the three Chinese economies over the past 30 years. This is illustrated in more detail in Figure 5.

Table 2 Main export composition; 1-digit export categories, values (\% of total)

\begin{tabular}{c|rrr|rrr|rrr}
\hline \hline & \multicolumn{3}{|c|}{ China } & \multicolumn{3}{|c|}{ Hong Kong } & \multicolumn{3}{c}{ Taiwan } \\
Cat. & 1970 & 1985 & 1997 & 1970 & 1985 & 1997 & 1970 & 1985 & 1997 \\
\hline 0 & 22.96 & 15.85 & 6.03 & 3.14 & 2.60 & 1.67 & 22.15 & 5.57 & 1.62 \\
1 & 0.58 & 0.45 & 0.57 & 0.49 & 1.09 & 0.89 & 0.23 & 0.04 & 0.03 \\
2 & 14.69 & 11.08 & 2.29 & 2.60 & 3.01 & 1.54 & 4.80 & 1.85 & 1.33 \\
3 & 0.58 & 29.60 & 3.81 & 0.27 & 0.47 & 1.15 & 0.84 & 1.76 & 0.33 \\
4 & 0.75 & 0.53 & 0.35 & 0.09 & 0.04 & 0.21 & 0.05 & 0.01 & 0.02 \\
5 & 4.16 & 5.56 & 5.50 & 3.93 & 3.89 & 5.57 & 2.85 & 2.48 & 6.17 \\
6 & 18.85 & 18.89 & 19.13 & 19.97 & 16.86 & 16.52 & 26.62 & 21.74 & 19.27 \\
7 & 2.21 & 3.18 & 23.41 & 11.34 & 24.87 & 32.44 & 15.90 & 27.64 & 48.72 \\
8 & 7.52 & 14.87 & 38.71 & 57.89 & 46.21 & 39.38 & 25.63 & 38.58 & 13.00 \\
9 & 27.71 & 0.00 & 0.21 & 0.28 & 0.94 & 0.62 & 0.94 & 0.34 & 9.51 \\
\hline
\end{tabular}

$0=$ food and live animals; $1=$ beverages and tobacco; $2=$ crude materials; $3=$ mineral fuels; $4=$ animal \& vegetable oils; $5=$ chemicals; $6=$ manufactured goods; $7=$ machinery $\&$ transport eq.; $8=$ misc. manufactured articles; $9=$ comm. not classified elsewhere

The initial importance of sector 0 (food and live animals) in China and Taiwan has drastically reduced in China and virtually disappeared in Taiwan. The same holds for sector 2 (crude materials) in China. Sectors 6, 7, and 8 are currently the dominant export sectors in all three Chinese economies, the developments over time and the degree of importance of individual sectors differs. In all three countries, the share of sector 6 (manufactured goods) has been substantial and relatively stable throughout the period, although declining slightly in Hong Kong and Taiwan. Similarly, in all three countries, the share of sector 7 (machinery \& transport eq.) has increased significantly over time. The rising importance of sector 7 started in China around 1987 and took place in Hong Kong and Taiwan throughout the period. In Taiwan it is by far the largest sector, accounting for almost half of all exports. Sector 8 (misc. manufactured articles) has become the dominant sector in China over time. In Hong Kong and Taiwan, on the other hand, sector 8 was the dominant sector initially, but has clearly become less important over time, notwithstanding the observation that it is still an important sector in all three countries.

A peculiar feature regarding China's trade flows is apparent in Table 3 and partially reflected in Figure 5: the share of sector 9 (comm. not classified elsewhere) declines from no less than 27.71 percent in 1970 to 0.00 percent in 1985. Although sector 9 includes such fascinating items as 'armored fighting vehicles, arms of war \& ammunit.' and 'gold, non-monetary' the reduction is almost exclusively caused by a change in sub-item 9999: 'non-identified products', which may refer to clandestine trade, arms deals, trade with nations without official 
trade ties, trade flows which have not been properly classified, etc. A whopping 27.61 percent of China's trade flows in 1970 involved 'non-identified' products, which was matched onefor-one in terms of trade partner, identified as 'unknown partner'. China's trade share of nonidentified products to unknown partners is particularly high in the first half of the 1970s (about 20 percent), declines in the second half of the 1970s (about 10 percent) and completely disappears from 1984 onwards. A reverse development occurs in Taiwan, where trade flows of non-identified products to unknown partners are completely absent until 1989 and rise to 8.25 percent in 1997. The political sensitivity of some of the trade connections and trade deals are undoubtedly responsible for a fair share of these observations, which should be kept in mind when analyzing China's trade flows in the 1970s and, to a lesser extent, Taiwan's trade flows in the 1990s. Hong Kong does not have any non-identified trade flows with unknown partners in the entire time period.

Figure 5 Dynamics of main export composition, 1-digit sectors

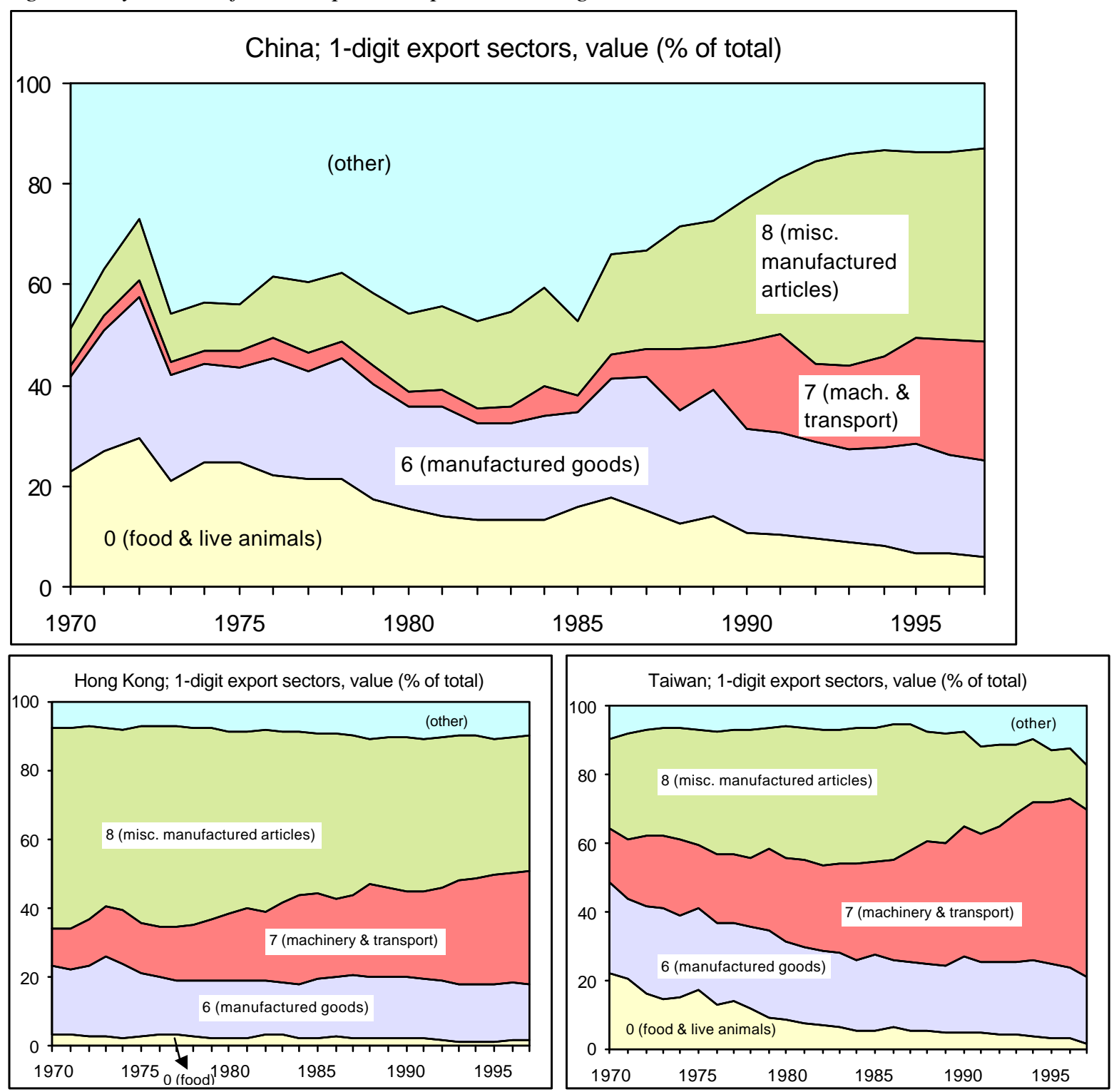




\section{Important 4-digit trade shares}

As is evident from the above section, the composition of international trade flows changed drastically for the three Chinese economies at the 1-digit level within a period of just three decades. Most of the remainder of the paper focuses on the dynamics at the most detailed 4 digit level available to us. To make these comparisons as accurately as possible we indeed concentrate on the 4digit level as such, indicating that we ignore (i) the "non-identified products' category 9999 (although the size of these trade flows is taken into account for comparative calculations, see the next section) and (ii) trade flows effectively classified only at the 3-digit level, such as category $752 \mathrm{~A} / \mathrm{X}$ 'automatic data processing machines \& units thereof' which could refer to trade flows in any of the more detailed 4digit categories 7521, $7522,7523,7524,7525$ or 7528 .

Table 3 Four highest identified 4-digit sectors in 1970 and 1997, value

\begin{tabular}{|c|c|c|c|}
\hline \multicolumn{2}{|c|}{ Panel a Four highest in 1970} & \multicolumn{2}{|c|}{ export (\% of total) } \\
\hline code & & 1970 & 1997 \\
\hline & China & & \\
\hline 0422 & Rice semi-milled or wholly milled, broken rice & 3.702 & 0.128 \\
\hline 2613 & Raw silk (not thrown) & 3.124 & 0.152 \\
\hline 6522 & Cotton fabrics, woven, bleach. merceriz. dyed, printed & 2.931 & 1.243 \\
\hline \multirow[t]{2}{*}{2919} & Other materials of animal origin, n.e.s & 2.929 & 0.364 \\
\hline & Hong Kong & & \\
\hline 8999 & Manufactured goods, n.e.s. & 9.213 & 0.635 \\
\hline 8942 & Children's toys, indoor games, etc. & 7.312 & 6.357 \\
\hline 8429 & Other outer garments of textile fabrics & 5.712 & 2.038 \\
\hline \multirow[t]{2}{*}{8451} & Jerseys, pull-overs, twin sets, cardigans, knitted & 5.037 & 2.217 \\
\hline & Taiwan & & \\
\hline 0565 & Vegetables, prepared or preserved, n.e.s. & 5.973 & 0.031 \\
\hline 6342 & Plywood consisting of sheets of wood & 5.071 & 0.083 \\
\hline 6521 & Cotton fabrics, woven, unbleached, not mercerized & 4.241 & 0.049 \\
\hline 8451 & Jerseys, pull-overs, twin sets, cardigans, knitted & 3.859 & 0.537 \\
\hline \multirow{2}{*}{\multicolumn{2}{|c|}{$\begin{array}{l}\text { Panel b Four highest in } 1997 \\
\text { code I }\end{array}$}} & \multicolumn{2}{|c|}{ export (\% of total) } \\
\hline & & 1970 & 1997 \\
\hline & China & & \\
\hline 8942 & Children's toys, indoor games, etc. & 0.286 & 3.837 \\
\hline 8429 & Other outer garments of textile fabrics & 0.532 & 3.227 \\
\hline 8461 & Under garments, knitted or crocheted of wool & 0.069 & 2.817 \\
\hline \multirow[t]{2}{*}{7649} & Parts of apparatus of division 76- & 0.010 & 2.639 \\
\hline & Hong Kong & & \\
\hline 8942 & Children's toys, indoor games, etc. & 7.312 & 6.357 \\
\hline 7649 & Parts of apparatus of division 76- & 0.051 & 4.414 \\
\hline 7512 & Calculating machines, cash registers. ticket \& sim. & 0.016 & 4.210 \\
\hline \multirow[t]{2}{*}{8851} & Watches, watch movements and cases & 1.625 & 2.358 \\
\hline & Taiwan & & \\
\hline 7512 & Calculating machines, cash registers. Ticket \& sim. & 0.000 & 7.618 \\
\hline 6531 & Fabrics, woven of continuous synth. textil. materials & 1.534 & 2.002 \\
\hline 7649 & Parts of apparatus of division 76- & 1.029 & 2.002 \\
\hline 7852 & Cycles, not motorized & 0.194 & 1.527 \\
\hline
\end{tabular}


In some cases, unfortunately, the 3-digit trade flows account for a sizeable share of total trade flows, as is the case, for example, for Taiwan, where 'automatic data processing machines \& units thereof' accounted for 9.8 percent of Taiwanese exports in 1997 (up from 0.00 in 1980). Ignoring them therefore implies that we exclude a substantial part of total exports in some cases. The alternative, however, is to aggregate all trade flows to the 3 -digit level, which introduces aggregation problems and destroys the rich details of the data available to us. Table 3, therefore, lists the share of the four highest identified 4 digit export sectors for the three Chinese economies in 1970 and 1997. Some of the initially important export sectors became much less important over time. In China, for example, the export of rice reduced from 3.7 to 0.1 percent and the export of raw silk from 3.1 to 0.1 percent. In Taiwan, similarly, the export of prepared vegetables reduced from 6.0 to 0.0 percent, of plywood from 5.1 to 0.1 percent, and of cotton fabrics from 4.2 to 0.0 percent. Some other initially important export sectors remained important over time. This holds specifically for Hong Kong, where children's toys represented 7.3 percent of exports in 1970 and 6.3 percent in 1997, and similarly for outer garments (from 5.7 to 2.0 percent) and jerseys (from 5.0 to 2.2 percent).

Taking the four highest 4-digit categories together as an indicator, it appears that Hong Kong, where this total share changed from 27.3 percent in 1970 to 11.2 percent in 1997 , was initially the most specialized economy and that its trade developments have been most stable. China, where this share changed from 12.7 percent in 1970 to 1.9 percent in 1997, appears to be less specialized initially and undergoing more dramatic changes over time. In Taiwan, where this share changed from 19.1 percent in 1970 to 0.7 percent in 1997, the initial degree of specialization appears to be intermediate and the changes over time most dramatic. We will investigate in the sequel whether these heuristic impressions are good indicators of actual developments, or not.

The reverse pattern occurs if we look at the currently most important export sectors, as illustrated in Figure 6. In China the most important sectors are children's toys, outer garments, under garments, and parts of apparatus of division 76 (telecommunications and sound recording app.), combined rising from 0.9 percent in 1970 to 12.5 percent in 1997. In Hong Kong they are children's toys, parts of apparatus of division 76, calculating machines, and watches, combined rising from 9 percent to 17.3 percent. In Taiwan, finally, the most important sectors are calculating machines, synthetic fabrics, parts of apparatus of division 76 (note the dramatic rise and fall of this sector in Figure 6), and bicycles, combined rising from 2.8 percent to 13.1 percent. Again, the current degree of specialization appears highest in Hong Kong, intermediate in Taiwan, and lowest in China, while the developments are most stable in Hong Kong and the changes most dramatic in China and Taiwan. 
Figure 6 Development of the 4 highest 4-digit sectors in 1997, value

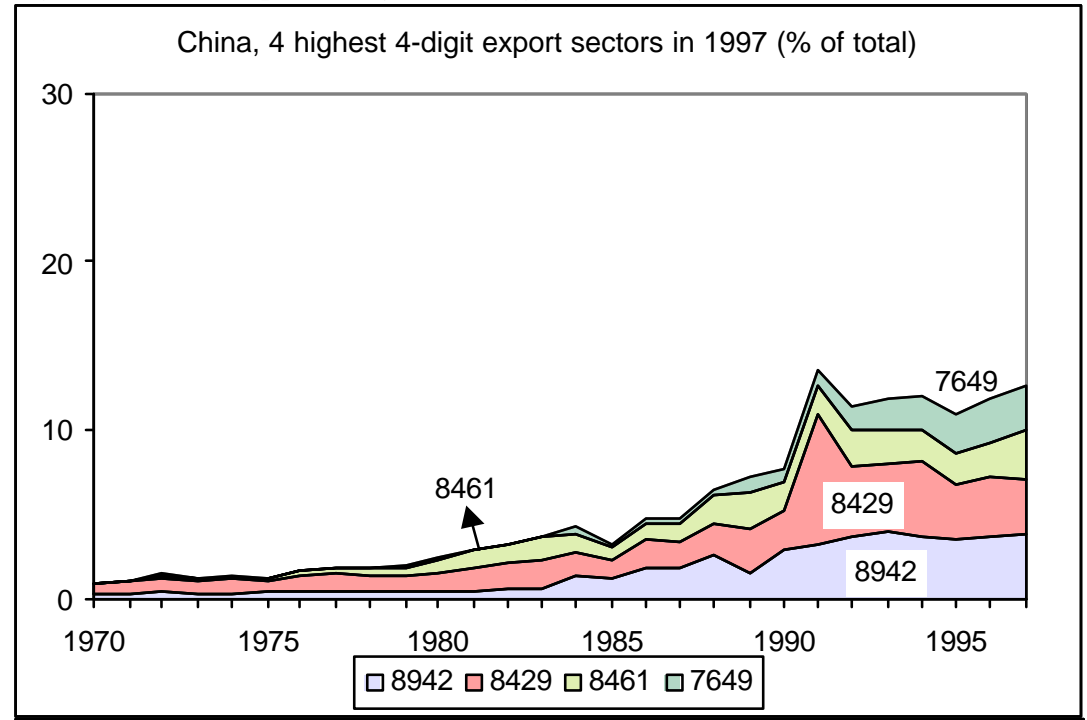

Hong Kong, 4 highest 4-digit export sectors in 1997 (\% of total)
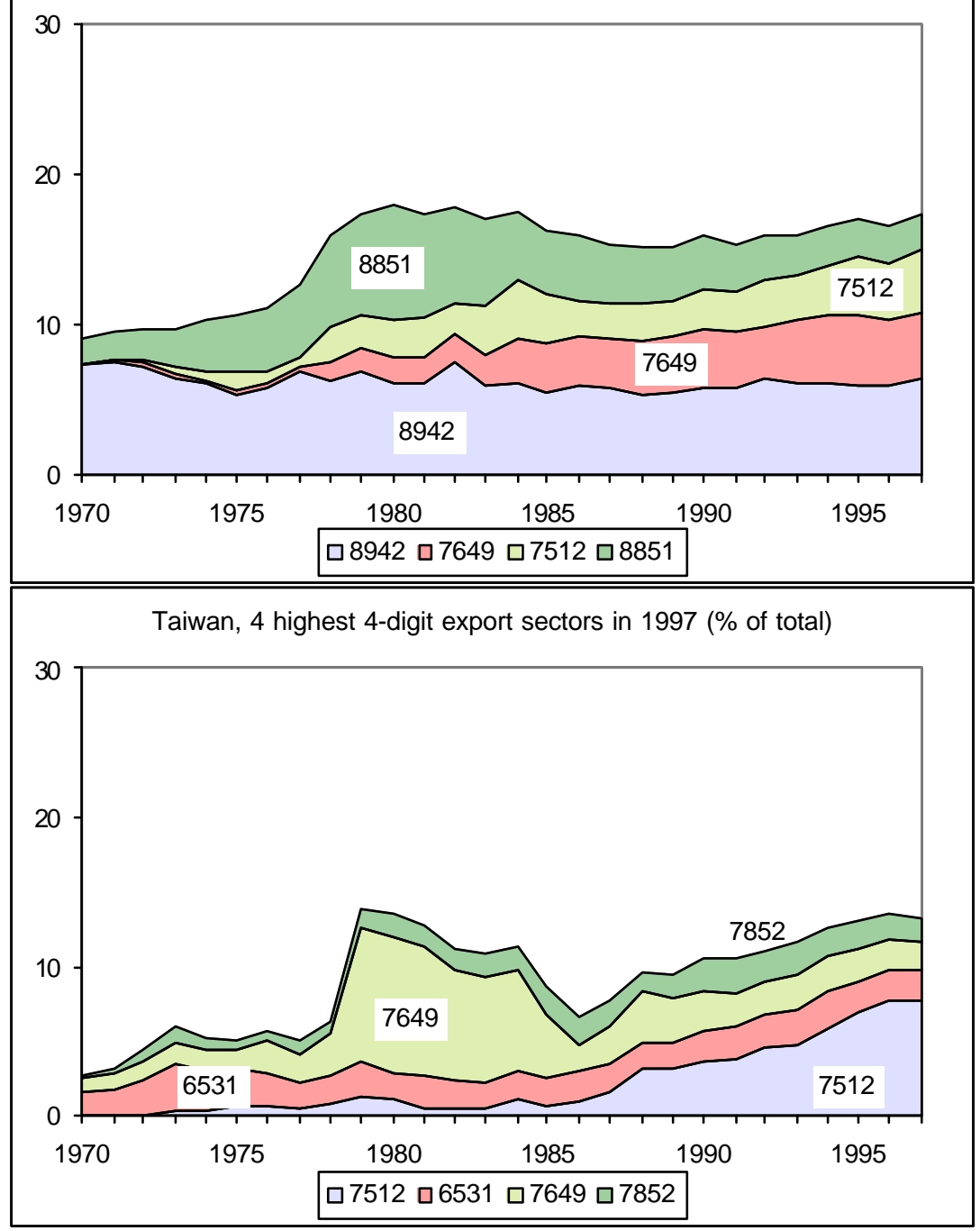

\section{Revealed Comparative Advantage: the Balassa Index}

An advantage of the analysis in section 4, which focuses on the shares of sectors in total exports, is the rapid identification of those sectors of substantial importance to a country's 
export revenue. A disadvantage is partially associated with the aggregation problem: even if a sector's share in total exports is large, this does not necessarily indicate that the sector as such performs well. Perhaps we have lumped together so many types of goods or services in this particular sector that it is a large sector for all countries. Take, for example, sector 7649 (parts of apparatus of division 76). In 1997 its share is ranked $2^{\text {nd }}$ in Hong Kong (4.4 percent of total exports), $3^{\text {rd }}$ in Taiwan ( 2 percent of total exports), and $4^{\text {h }}$ in China (2.6 percent of total exports). One could argue that Taiwan's export performance for sector 7649 is 'bad' relative to the other two Chinese economies, despite the fact that it is the $3^{\text {rd }}$ largest sector in Taiwan. In short, without a frame of reference it is hard to gauge the importance of individual sectors. Bela Balassa (1965) acknowledged this and introduced normalized export shares as an indicator of revealed comparative advantage, now known as the Balassa index, defined as:

$$
B I_{i, t}^{j}=\frac{\text { share sector } j \text { in country } i \text { 's export, period } t}{\text { share sector } j \text { in reference countries 's export, period } t} .
$$

If the Balassa index is above unity, that is $B I_{i, t}^{j}>1$, country $i$ is said to have a comparative advantage in the production of commodity $j$ in time period $t$ relative to the group of reference countries as its export share for product $j$ is larger than the export share in the reference countries. Our discussion focuses on the comparative advantage of the three Chinese economies taking all countries in our data set as the reference countries (see Appendix I). In fact, for example, Taiwan does not have a comparative advantage in sector 7649 in 1997 as its export share is lower than the world average in that year of 2.24 percent of total trade.

Table 4 gives the main statistical properties of the empirical distribution of the Balassa index for the three Chinese economies for a selection of years (see Appendix II for a complete listing). The table is subdivided into three parts. The first part lists the percentile points $p-z$, where $z$ varies from 1 to 99 . In China in 1970, for example, the p-10 point occurs at 0.022 , indicating that 10 percent of China's sectors had a Balassa index below 0.022, and the p-75 point occurs at 1.864, indicating that 75 percent of China's sectors had a Balassa index below 1.864. The second part of the table gives basic statistical properties, such as the maximum, the mean, the standard deviation, the number of observations, etc. The third part of the table indicates the Balassa index point $B I-z$, where $z$ varies from 1 to 8. In Hong Kong in 1985, for example, the table indicates that the BI-1 point occurs at 0.711 , indicating that 71.1 percent of Hong Kong's sectors had a Balassa index below 1, and the BI-4 point occurs at 0.882, indicating that 88.2 percent of Hong Kong's sectors had a Balassa index below 4 . 
Table 4 Empirical cumulative distribution function of the Balassa Index, selected years*

\begin{tabular}{|c|c|c|c|c|c|c|c|c|c|}
\hline & \multicolumn{3}{|c|}{ China } & \multicolumn{3}{|c|}{ Hong Kong } & \multicolumn{3}{|c|}{ Taiwan } \\
\hline & 1970 & 1985 & 1997 & 1970 & 1985 & 1997 & 1970 & 1985 & 1997 \\
\hline p-1 & 0.003 & 0.001 & 0.001 & 0.003 & 0.001 & 0.000 & 0.003 & 0.000 & 0.000 \\
\hline p-2.5 & 0.007 & 0.002 & 0.006 & 0.008 & 0.004 & 0.001 & 0.008 & 0.001 & 0.001 \\
\hline p-5 & 0.013 & 0.007 & 0.027 & 0.013 & 0.008 & 0.004 & 0.021 & 0.003 & 0.003 \\
\hline p-10 & 0.022 & 0.017 & 0.060 & 0.021 & 0.021 & 0.017 & 0.032 & 0.013 & 0.009 \\
\hline$p-25$ & 0.087 & 0.071 & 0.200 & 0.057 & 0.099 & 0.093 & 0.111 & 0.084 & 0.056 \\
\hline p-50 & 0.457 & 0.442 & 0.598 & 0.216 & 0.426 & 0.364 & 0.430 & 0.434 & 0.286 \\
\hline p-75 & 1.864 & 2.675 & 2.064 & 1.010 & 1.262 & 1.119 & 2.166 & 1.810 & 0.895 \\
\hline p-90 & 8.338 & 12.282 & 4.254 & 5.087 & 4.309 & 2.877 & 8.250 & 4.728 & 2.170 \\
\hline p-95 & 16.290 & 30.585 & 6.158 & 15.031 & 6.723 & 3.671 & 12.125 & 7.661 & 3.608 \\
\hline p-97.5 & 26.081 & 43.250 & 7.714 & 19.864 & 10.440 & 4.803 & 27.674 & 10.768 & 5.392 \\
\hline p-99 & 56.682 & 64.718 & 10.810 & 19.977 & 12.694 & 7.789 & 78.015 & 14.108 & 8.628 \\
\hline Max & 81.390 & 77.032 & 19.204 & 55.591 & 16.981 & 11.873 & 184.909 & 50.828 & 25.261 \\
\hline Mean & 3.457 & 4.594 & 1.572 & 1.954 & 1.433 & 0.950 & 3.926 & 1.788 & 0.933 \\
\hline Std & 9.745 & 11.388 & 2.287 & 5.147 & 2.665 & 1.489 & 14.724 & 4.125 & 2.308 \\
\hline Obs & 470 & 546 & 470 & 397 & 440 & 449 & 418 & 408 & 475 \\
\hline $\mathrm{Sk}$ & 2272 & 1307 & 670 & 1547 & 718 & 753 & 4439 & 3635 & 3888 \\
\hline Kur & 22172 & 5502 & 2889 & 18715 & 2108 & 3550 & 100390 & 93069 & 73841 \\
\hline Nor & 24444 & 6809 & 3559 & 20262 & 2826 & 4304 & 104829 & 96704 & 77728 \\
\hline$B I-1$ & 0.604 & 0.597 & 0.594 & 0.748 & 0.711 & 0.731 & 0.636 & 0.659 & 0.773 \\
\hline$B I-2$ & 0.755 & 0.709 & 0.743 & 0.841 & 0.818 & 0.849 & 0.739 & 0.762 & 0.893 \\
\hline$B I-4$ & 0.851 & 0.813 & 0.885 & 0.882 & 0.882 & 0.960 & 0.830 & 0.870 & 0.962 \\
\hline$B I-8$ & 0.896 & 0.859 & 0.977 & 0.929 & 0.955 & 0.991 & 0.897 & 0.956 & 0.987 \\
\hline
\end{tabular}

* The Balassa index (BI) is based on annual bilateral export flows of 182 countries for the period 1970 through 1997; p- $z$ reports the BI for the $z$-th percentile, for $z=1,2.5,5,10,25,50,75,90,95,97.5$, and 99; $\max =$ maximum; std $=$ standard deviation; obs $=$ number of observations; sk $=$ skewness, kur $=$ kurtosis; nor = normality; $B I-z$ reports the share of sectors with a BI lower than $z$, for $z=1,2,4,8$.

Figure 7 Cumulative distribution of the Balassa index for the Chinese economies

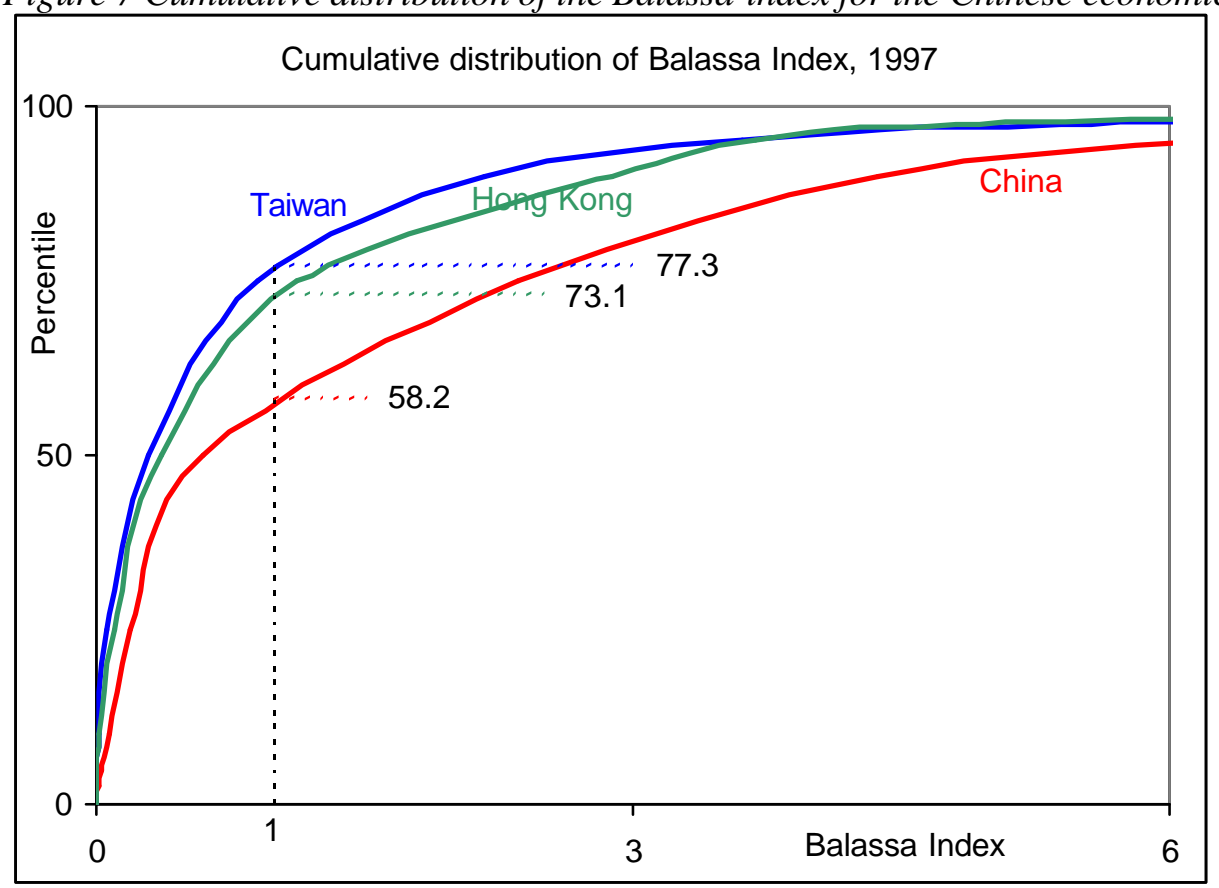


As indicated by the entries in Table 4 and in accordance with our findings for the European Union, the distribution of the Balassa index differs markedly from one country to the other. This is illustrated for the year 1997 in Figure 7. Evidently, and in accordance with the suggestions of section 4, the economies of Taiwan and Hong Kong are more specialized in their exports than China's economy, as fewer sectors in those two countries achieve a high Balassa index than in China. In the figure this is illustrated for the share of sectors unable to achieve a comparative advantage in international trade (Balassa index below 1), which is above 73 percent in Hong Kong and Taiwan and below 60 percent in China. A similar observation holds for almost the entire domain. The figure suggests that the distribution for Hong Kong more closely resembles that of Taiwan than of China, which of course does not indicate that the sectors for which Hong Kong achieves a comparative advantage more closely resembles that of Taiwan than of China.

Figure 8 Comparative advantage and median value of the Balassa index

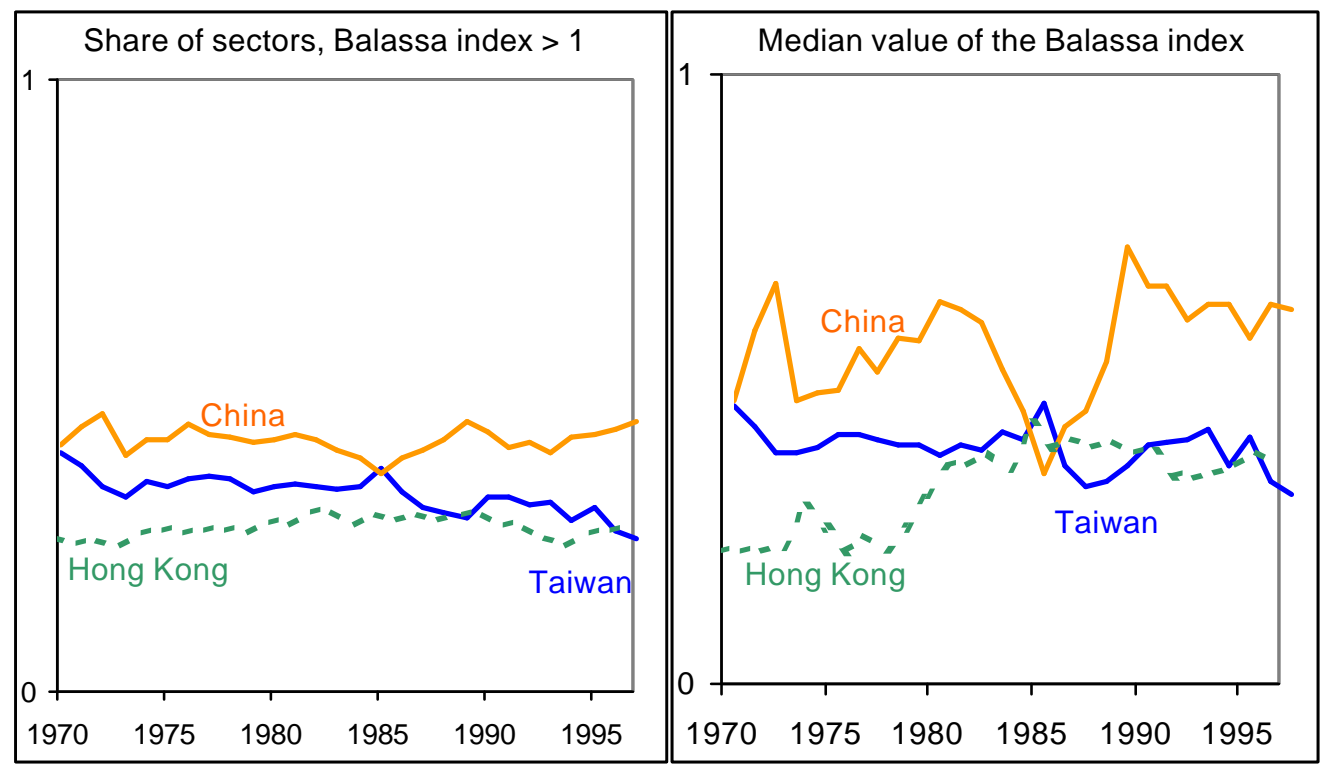

Also in accordance with our earlier findings for the European Union, we find that the distribution is very skewed to the right for all countries, with a few very high observations. As a result the mean is a poor indicator for the statistical properties of the distribution and it is better to focus on the distribution of the percentiles $(p-z$ in Table 4) and the extent of comparative advantage ( $B I-z$ in Table 4 ). Unlike our earlier findings for the European Union, however, the distribution of the Balassa index is not very stable over time. This is, perhaps, most effectively illustrated for the two most robust statistical properties of this distribution: the share of sectors with a comparative advantage and the median value of the Balassa index, see Figure 8. The share of sectors with a comparative advantage is consistently higher in China than in Hong Kong and Taiwan. The latter two economies therefore display a greater 
degree of international specialization. For China and Hong Kong no obvious trend in the degree of specialization is visible at this level of detail, whereas Taiwan seems to increasingly specialize in its exports as the share of sectors with a comparative advantage is gradually declining. Our formal analysis in the sequel indicates that the same is true for China and Hong Kong. Although not fluctuating wildly, the degree of variation in the share of sectors with a comparative advantage is clearly larger than in our earlier analysis for Europe. This holds particularly for the median value of the Balassa index, which appears to have no trend for China, a slightly downward trend for Taiwan and an upward trend for Hong Kong at the end of the 1970s and early 1980s. These changes relative to our European findings reflect, of course, the longer time period under investigation, the more detailed level of aggregation, and the more dramatic structural changes for the Chinese economies during the sample period.

\section{Chinese comparative advantage, 4 -digits}

Table 5 lists the four sectors with the highest Balassa index in 1970 and in 1997 for the Chinese economies. In view of the fact that there are 747 different sectors, the table provides some indication that comparative advantage, once obtained, tends to last, see also section 7 . Sector 2613 (raw silk [not thrown]), which ranked highest in China in 1970 and in 1997, had the highest Balassa index in China almost throughout the period, while sector 0013 (swine, live) was consistently in the top $40 .{ }^{7}$ The other two initially highly ranked sectors in China disappeared from the top 40; sector 0129 (Meat \& edib. offals, etc.) rather gradually in 1982, and sector 2235 (castor dil seeds) very abruptly in 1995 (when exports dropped to \$1.5 million [representing 10 percent of the world market], from $\$ 10.3$ million the year before [representing 67 percent of the world market]). ${ }^{8}$ Three of the four highest ranked sectors in China in 1997 were consistently in the top 40 throughout the period. The exception is sector 6712 (pig iron, etc.), which gradually became more important and entered the top 40 in 1980.

Similar observations hold for Hong Kong, where sectors 8999 (manufactured goods nes) and 8942 (children's toys, indoor games, etc.) were ranked first and second in Hong Kong both in 1970 and in 1997, while both were in the top 40 throughout the period. The other two initially highly ranked sectors (6521 [cotton fabrics, etc.] and 8442 [under garments, etc.]) held on to their comparative advantage, but gradually faded in the rankings. The reverse occurred for sectors 8851 (watches, etc.) and 8852 (clocks, etc.), ranked third and fourth in Hong Kong in 1997, respectively; these sectors gradually rose in the rankings, particularly in the 1970s.

\footnotetext{
${ }^{7}$ See the eta-center website (www.few.eur.nl/few/people/vanmarrewijk/eta) for the top 40 lists.

${ }^{8}$ Chinese exports of castor oil seeds virtually stopped in 1997 (falling to \$32,000 and representing 0.2 percent of the world market), such that China no longer has a comparative advantage. Note, however, that data for 1997 are preliminary, see Feenstra (2000).
} 
Table 5 Balassa index: four highest identified 4-digit sectors in 1970 and 1997

\begin{tabular}{l|lc}
\hline \hline \multicolumn{2}{c}{$\begin{array}{l}\text { Panel a Four highest BI in } 1970 \\
\text { code }\end{array}$} & Balassa index \\
\hline & China & \\
\hline 2613 & Raw silk (not thrown) & 78.7 \\
2235 & Castor oil seeds & 36.3 \\
0013 & Swine, live & 33.4 \\
0129 & Meat \& edib. offals, n.e.s. salt. in brine dried/smok. & 32.0 \\
\hline & Hong Kong & \\
\hline 8999 & Manufactured goods, n.e.s. & 55.6 \\
8942 & Children's toys, indoor games, etc. & 25.5 \\
6521 & Cotton fabrics, woven, unbleached, not mercerized & 21.7 \\
8442 & Under garments, excl. shirts, of textile fabrics & 20.1 \\
\hline & Taiwan & 31.8 \\
\hline 0565 & Vegetables, prepared or preserved, n.e.s. & 28.1 \\
6521 & Cotton fabrics, woven, unbleached, not mercerized & 25.9 \\
6342 & Plywood consisting of sheets of wood & 23.5 \\
0586 & Fruit, temporarily preserved & \\
\hline \hline
\end{tabular}

\begin{tabular}{l|lc}
\multicolumn{2}{l}{$\begin{array}{l}\text { Panel } \\
\text { code }\end{array}$} & Four highest BI in 1997 \\
\hline & China & Balassa index \\
\hline 2613 & Raw silk (not thrown) & 19.2 \\
2614 & Silk worm cocoons suitable for reeling \& silk waste & 13.5 \\
2683 & Fine animal hair, not carded or combed & 12.3 \\
6712 & Pig iron, cast iron and spiegeleisen, in pigs, blocks & 12.0 \\
\hline & Hong Kong & \\
\hline 8999 & Manufactured goods, n.e.s. & 11.9 \\
8942 & Children's toys, indoor games, etc. & 10.3 \\
8851 & Watches, watch movements and cases & 8.4 \\
8852 & Clocks, clock movements and parts & 7.8 \\
\hline & Taiwan & 6.6 \\
\hline 7852 & Cycles, not motorized & 6.6 \\
7511 & Typewriters; cheque-writing machines & 6.5 \\
6573 & Coated/impregnated textile fabrics \& products nes. &
\end{tabular}

There appears to have been a more structural transition in Taiwan, where all four highest ranking sectors in 1970 disappeared from the top 40 list by 1994. Moreover, none of the four highest ranking sectors in Taiwan in 1997 made it to the top 40 in 1970. The initial Taiwanese strongholds, such as vegetables, cotton fabrics, plywood, and fruit, are replaced by the more technically advanced current strongholds, such as bicycles, typewriters, textile fabrics, and hand tools. In all three Chinese economies, however, the value of the highest Balassa index has fallen considerably over time, in conjunction with economic development. 
Table 6 Distribution of share of sectors with comparative advantage (BI $\geq 1)$, 4-digit level

\begin{tabular}{|c|c|c|c|c|c|c|c|c|c|c|c|c|}
\hline & \multicolumn{6}{|c|}{ percentage of \# of sectors } & \multicolumn{6}{|c|}{ percentage of export value } \\
\hline \multicolumn{13}{|c|}{ China } \\
\hline sect. & 1970 & 1975 & 1980 & 1985 & 1990 & 1997 & 1970 & 1975 & 1980 & 1985 & 1990 & 1997 \\
\hline 0 & 11.5 & 11.2 & 8.5 & 8.2 & 7.0 & 6.6 & 22.0 & 27.1 & 15.8 & 15.6 & 9.6 & 5.7 \\
\hline 1 & 0.3 & 1.1 & 0.0 & 0.0 & 0.3 & 0.0 & 0.2 & 0.6 & 0.0 & 0.0 & 0.1 & 0.0 \\
\hline 2 & 5.5 & 6.1 & 5.9 & 6.6 & 7.0 & 4.0 & 14.7 & 9.9 & 10.4 & 13.6 & 6.3 & 2.3 \\
\hline 3 & 0.9 & 0.0 & 1.9 & 1.6 & 1.1 & 1.1 & 0.2 & 0.0 & 9.6 & 12.4 & 2.0 & 1.7 \\
\hline 4 & 0.9 & 0.8 & 0.3 & 0.3 & 0.5 & 0.8 & 0.8 & 0.6 & 0.1 & 0.7 & 0.1 & 0.4 \\
\hline 5 & 2.0 & 2.9 & 4.3 & 3.0 & 4.0 & 4.0 & 2.8 & 2.8 & 3.6 & 4.7 & 4.0 & 3.5 \\
\hline 6 & 6.9 & 6.9 & 9.0 & 6.9 & 10.2 & 11.6 & 14.7 & 16.6 & 20.6 & 23.6 & 20.8 & 18.5 \\
\hline 7 & 1.2 & 1.1 & 1.1 & 0.0 & 1.9 & 4.0 & 0.6 & 1.0 & 0.8 & 0.0 & 11.6 & 11.3 \\
\hline 8 & 8.7 & 8.5 & 7.7 & 6.9 & 7.8 & 10.0 & 5.5 & 8.5 & 15.0 & 17.8 & 29.8 & 40.7 \\
\hline 9 & 0.3 & 0.3 & 0.3 & 0.0 & 0.0 & 0.0 & 29.9 & 21.6 & 12.1 & 0.0 & 0.0 & 0.0 \\
\hline total & 38.0 & 38.8 & 38.8 & 33.4 & 39.9 & 41.8 & 91.4 & 88.8 & 87.9 & 88.3 & 84.2 & 84.0 \\
\hline \multicolumn{13}{|c|}{ Hong Kong } \\
\hline sect. & 1970 & 1975 & 1980 & 1985 & 1990 & 1997 & 1970 & 1975 & 1980 & 1985 & 1990 & 1997 \\
\hline 0 & 2.1 & 1.7 & 1.2 & 1.4 & 1.1 & 0.8 & 0.7 & 0.5 & 0.6 & 0.9 & 0.7 & 0.6 \\
\hline 1 & 0.3 & 0.3 & 0.3 & 0.3 & 0.3 & 0.3 & 0.4 & 0.3 & 0.3 & 1.0 & 2.1 & 0.8 \\
\hline 2 & 2.4 & 1.7 & 2.9 & 3.4 & 3.6 & 3.3 & 1.9 & 1.7 & 2.3 & 2.2 & 1.6 & 1.1 \\
\hline 3 & 0.0 & 0.0 & 0.0 & 0.0 & 0.3 & 0.3 & 0.0 & 0.0 & 0.0 & 0.0 & 0.0 & 1.2 \\
\hline 4 & 0.0 & 0.0 & 0.0 & 0.0 & 0.3 & 0.6 & 0.0 & 0.0 & 0.0 & 0.0 & 0.1 & 0.2 \\
\hline 5 & 1.8 & 2.0 & 1.7 & 2.0 & 1.9 & 0.6 & 2.9 & 2.5 & 1.2 & 1.5 & 1.5 & 0.7 \\
\hline 6 & 6.1 & 6.6 & 8.1 & 7.3 & 8.1 & 7.2 & 19.1 & 17.9 & 16.1 & 15.1 & 16.3 & 13.1 \\
\hline 7 & 1.2 & 2.9 & 2.9 & 3.1 & 3.9 & 4.5 & 3.2 & 5.3 & 9.4 & 14.9 & 15.5 & 22.2 \\
\hline 8 & 10.6 & 11.1 & 10.8 & 11.0 & 10.6 & 10.3 & 61.2 & 61.9 & 59.6 & 51.9 & 49.5 & 43.1 \\
\hline 9 & 0.0 & 0.0 & 0.0 & 0.0 & 0.0 & 0.0 & 0.0 & 0.0 & 0.0 & 0.0 & 0.0 & 0.0 \\
\hline total & 24.6 & 26.2 & 27.9 & 28.5 & 30.0 & 27.9 & 89.3 & 90.1 & 89.4 & 87.4 & 87.1 & 83.0 \\
\hline \multicolumn{13}{|c|}{ Taiwan } \\
\hline sect. & 1970 & 1975 & 1980 & 1985 & 1990 & 1997 & 1970 & 1975 & 1980 & 1985 & 1990 & 1997 \\
\hline 0 & 7.1 & 6.4 & 4.7 & 4.5 & 3.3 & 0.8 & 25.6 & 21.0 & 9.3 & 5.3 & 5.7 & 1.6 \\
\hline 1 & 0.0 & 0.0 & 0.0 & 0.0 & 0.0 & 0.0 & 0.0 & 0.0 & 0.0 & 0.0 & 0.0 & 0.0 \\
\hline 2 & 2.8 & 2.0 & 1.6 & 1.5 & 1.6 & 0.8 & 4.2 & 1.5 & 0.6 & 0.8 & 0.7 & 0.6 \\
\hline 3 & 0.3 & 0.0 & 0.0 & 0.3 & 0.0 & 0.0 & 0.3 & 0.0 & 0.0 & 0.2 & 0.0 & 0.0 \\
\hline 4 & 0.0 & 0.0 & 0.0 & 0.0 & 0.0 & 0.0 & 0.0 & 0.0 & 0.0 & 0.0 & 0.0 & 0.0 \\
\hline 5 & 1.6 & 1.4 & 1.0 & 0.3 & 0.0 & 0.5 & 1.0 & 0.4 & 0.3 & 0.0 & 0.0 & 0.8 \\
\hline 6 & 8.4 & 9.0 & 12.0 & 11.8 & 9.2 & 7.8 & 27.2 & 24.3 & 22.1 & 22.8 & 21.1 & 16.8 \\
\hline 7 & 3.7 & 3.4 & 4.7 & 5.7 & 5.4 & 5.9 & 6.9 & 8.3 & 23.0 & 20.8 & 27.3 & 32.2 \\
\hline 8 & 9.9 & 10.9 & 7.9 & 11.1 & 8.7 & 4.9 & 24.6 & 32.7 & 33.6 & 35.2 & 28.0 & 12.1 \\
\hline 9 & 0.0 & 0.0 & 0.0 & 0.0 & 0.0 & 0.3 & 0.0 & 0.0 & 0.0 & 0.0 & 0.0 & 14.2 \\
\hline total & 33.9 & 33.1 & 31.9 & 35.2 & 28.2 & 20.8 & 89.8 & 88.3 & 88.8 & 85.1 & 82.8 & 78.1 \\
\hline
\end{tabular}

$0=$ food and live animals; 1 = beverages and tobacco; $2=$ crude materials; $3=$ mineral fuels; $4=$ animal $\&$ vegetable oils; $5=$ chemicals; $6=$ manufactured goods; $7=$ machinery $\&$ transport eq.; $8=$ misc. manufactured articles; $9=$ comm. not classified elsewhere.

As already noted in section 5, if a country has a high export share in a certain sector, this does not necessarily indicate that it has a revealed comparative advantage as measured by the Balassa index using normalized export shares. The two measures are, however, positively correlated. This can be illustrated for the four sectors with the highest export shares in the 
Chinese economies in 1997 as reported in Table 3. In China, sector 8942 (children's toys) entered the Balassa index top 40 in 1988 and gradually increased to $23^{\text {rd }}$ place in 1997 , sector 8429 (outer garments) entered the Balassa index top 40 in 1992 and hovers around $25^{\text {th }}$ place since then, while sector 8461 (under garments) sporadically enters the Balassa index top 40.

In Hong Kong, similarly, children's toys are always in the Balassa index top 4, sector 8851 (watches, etc.) rapidly increased in the Balassa index from rank 31 in 1970 to number 1 in 1980 (and has remained in the top 4 ever since), while sector 7512 (calculating machines) occasionally enters the Balassa index top 40.

In Taiwan, finally and again similarly, calculating machines entered the Balassa index top 40 in 1991 and rapidly increased to $12^{\text {th }}$ place in 1997, sector 6531 (fabrics, woven, etc.) was continuously in the Balassa index top 40 since 1978 (and sporadically before), gradually increasing to $7^{\text {th }}$ place in 1997, while sector 7852 (cycles) increased gradually in the Balassa index top 40 until it reached first place in 1989, where it solidly remained ever since. Nonetheless, it is, of course, easier to achieve a high Balassa index in a small sector than in a large sector. China's \$ 42.1 million exports of silk worm cocoons (2614) in 1997 (44.3 percent of the world market), for example, gave it a Balassa index of 13.5, while its 170 times larger exports of children's toys in the same year (\$7.2 billion, or 20.4 percent of the world market) gave it a Balassa index of only 6.2. These issues on sectoral differences are analyzed by Hinloopen and Van Marrewijk (2004d).

As a first, more complete indication of the development of Chinese comparative advantage over time than indicated by the examples above, Table 6 reports the distribution of shares with a comparative advantage $(\mathrm{BI} \geq 1)$ at the 4digit level, organized along the 1-digit sector composition, both as a percentage of the total number of sectors and as a percentage of the export value. The table shows that for Hong Kong, for example, 24.6 percent of the number of export sectors at the 4digit level achieved a comparative advantage in 1970, which together accounted for 89.3 percent of Hong Kong's 4-digit export value in that year. The table also shows the distribution of the sectors at the 1-digit level. In 1970 in Hong Kong, for example, of the 24.6 percent of the number of sectors with a comparative advantage, 10.6 were classified as a subdivision of sector 8 (misc. manufactured articles) and 6.1 percent as a subdivision of sector 6 (manufactured goods classified chiefly by material), accounting for 61.2 and 19.1 percent of Hong Kong's 4-digit export value in 1970, respectively. 
Figure 9 Development of sectoral distribution of comparative advantage
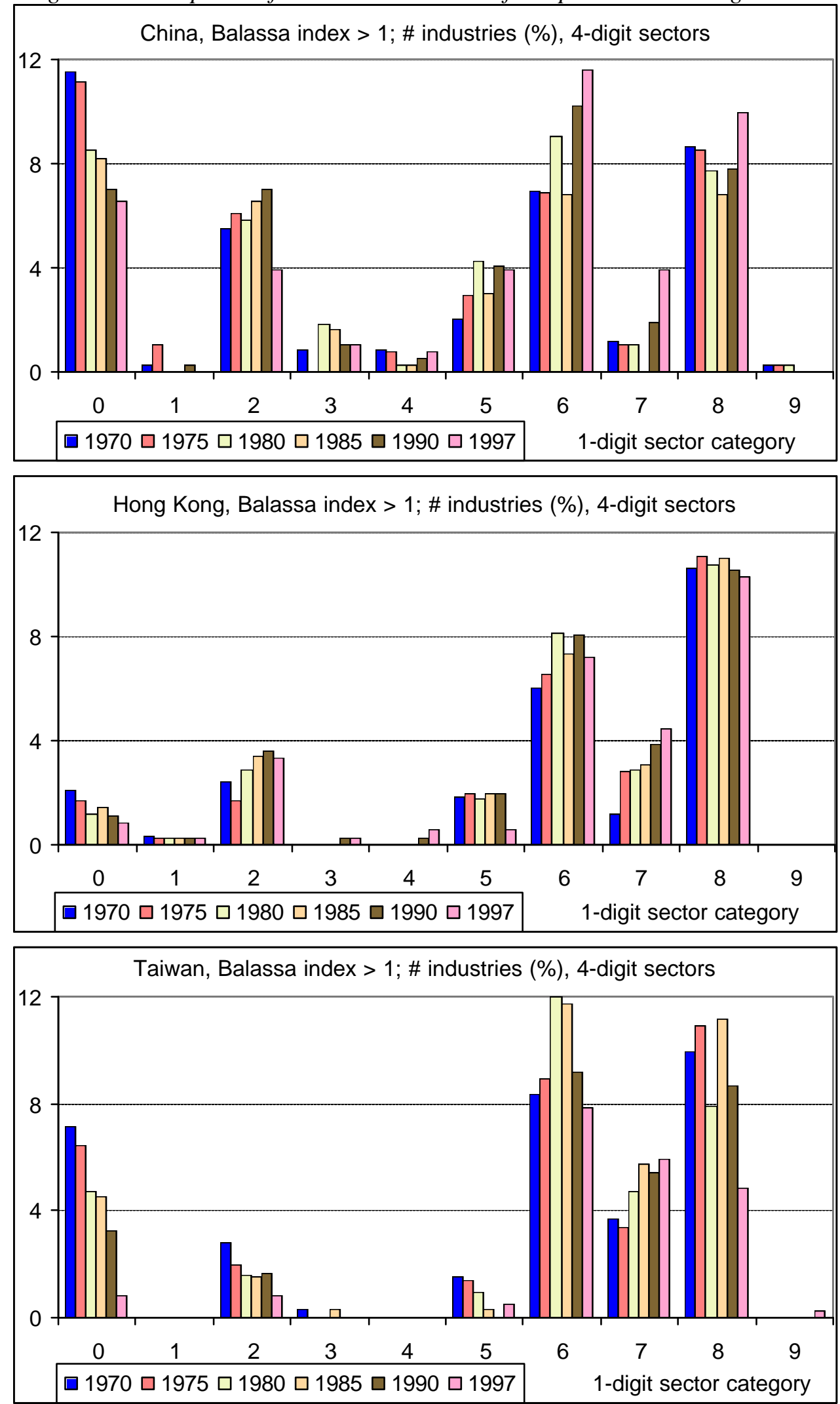

For all three Chinese economies, initial comparative advantage in 1970 is strong for subdivisions of sectors 0 (food and live animals), 2 (crude materials), 6 (manufactured goods), and 8 (misc. man. articles) when measured as a share of the number of sectors. For China and 
Taiwan this translates into a substantial share of export value in all cases. The comparative advantage export value for Hong Kong, however, is much more concentrated in sectors 6 and 8 , and consequently very low in sectors 0 and 2 . The dynamic developments are illustrated in Figure 9 for the share of the number of sectors with comparative advantage. As is clear from Figure 9, China was initially strong in exporting food and live animals (0) and crude materials (2), but switched its comparative advantage from those sectors to subdivisions of sectors 5-8, particularly towards 6 and 8 . Hong Kong was initially already very focused on subdivisions of sectors 6 and 8. It maintained those positions, and additionally grew strong in subdivisions of sectors 2 and 7 (machinery and transport equipment). Taiwan's initial position was somewhere in between China's and Hong Kong's. Over time, however, it drastically shifted away from comparative advantages in sectors 0,2 , and 5, almost exclusively towards subdivisions of sectors 6-8. Taiwan, therefore appears to be the most specialized of the three Chinese economies, as also illustrated in Figure 7. Moreover, and as explained in the introduction, Hong Kong's reported comparative advantage to a substantial extent reflects developments in China's comparative advantage.

\section{Galtonian regressions}

With his conjecture that the height of a father is equal to the average height of his sons, Galton lay the foundation of what has become known as Galtonian regressions; linear models where the independent variable is a time-lagged value of the dependent variable. Estimates of these models not only indicate to what extent phenomena are correlated through time, they also allow for an assessment of convergence through time. Recall that $B I_{i, t}^{j}$ is the value of the Balassa index for sector $j$, country $i$, period $t$. Let $b i_{i, t}^{j}=\ln \left(B I_{i, t}^{j}\right)$ and let $\overline{b i}$ denote the median value of $b i_{i, t}^{j}$. In view of the shape of the distribution of Balassa indices as described in section 5, we focus on the median rather than the mean value in the analysis below as the median is a more robust indicator. We apply Galton's framework to Balassa indices through a slight generalization of Hart's (1995) procedure:

$$
\begin{aligned}
& \left(b i_{i, t}^{j}-\overline{b i_{t}}\right)=\alpha_{k}+\beta_{k}\left(b i_{t-k}^{j}-\overline{b i_{t-k}}\right)+e_{i j t} \\
& k=1, . .27 ; \quad t=1971, . ., 1996 ; \quad t-k \geq 1970
\end{aligned}
$$

Assuming that the distribution is approximately log-normal, but possibly dependent on the lag, yields errors in equation (2) with an approximate normal distribution $N\left(0, \sigma_{k}^{2}\right)$. From equation (2) it follows that the dispersion of the Balassa index over time, as measured by the variance, changes according to

$$
V\left(b i_{t}\right)=\beta_{k}^{2} V\left(b i_{t-k}\right)+\sigma_{k}^{2} .
$$


Table 7 Galtonian regressions of the Balassa index for the Chinese economies, lag 1-14

\begin{tabular}{|c|c|c|c|c|c|c|c|}
\hline lag & China & Taiwan & Hong Kong & lag & China & Taiwan & Hong Kong \\
\hline$\beta$ & 0.92 & 0.91 & 0.94 & $\beta$ & 0.70 & 0.68 & 0.72 \\
\hline t-value & 175.32 & 148.59 & 191.70 & t-value & 82.68 & 69.55 & 91.67 \\
\hline $1 ?$ & 0.94 & 0.91 & 0.94 & $8 ?$ & 0.78 & 0.72 & 0.80 \\
\hline Adj. $R^{2}$ & 0.88 & 0.83 & 0.89 & Adj. $\mathrm{R}^{2}$ & 0.61 & 0.52 & 0.64 \\
\hline \# obs. & 10134 & 9435 & 9519 & \# obs. & 7324 & 6472 & 6807 \\
\hline$\beta$ & 0.87 & 0.86 & 0.90 & $\beta$ & 0.68 & 0.65 & 0.70 \\
\hline t-value & 143.09 & 120.06 & 163.09 & t-value & 76.42 & 63.38 & 89.90 \\
\hline $2 ?$ & 0.90 & 0.87 & 0.92 & $9 ?$ & 0.76 & 0.69 & 0.78 \\
\hline Adj. $R^{2}$ & 0.82 & 0.76 & 0.84 & Adj. $R^{2}$ & 0.58 & 0.49 & 0.62 \\
\hline \# obs. & 9718 & 8980 & 9112 & \# obs. & 6940 & 6069 & 6434 \\
\hline$\beta$ & 0.84 & 0.83 & 0.87 & $\bar{\beta}$ & 0.65 & 0.62 & 0.67 \\
\hline t-value & 124.16 & 107.01 & 144.12 & t-value & 70.95 & 61.73 & 82.64 \\
\hline $3 ?$ & 0.87 & 0.84 & 0.90 & $10 ?$ & 0.74 & 0.68 & 0.77 \\
\hline Adj. $\mathrm{R}^{2}$ & 0.77 & 0.71 & 0.81 & Adj. $\mathrm{R}^{2}$ & 0.55 & 0.47 & 0.60 \\
\hline \# obs. & 9296 & 8576 & 8721 & \# obs. & 6536 & 5726 & 6064 \\
\hline$\beta$ & 0.80 & 0.80 & 0.84 & $\beta$ & 0.64 & 0.60 & 0.65 \\
\hline t-value & 108.38 & 94.92 & 131.18 & t-value & 66.61 & 58.24 & 76.01 \\
\hline $4 ?$ & 0.85 & 0.81 & 0.88 & $11 ?$ & 0.73 & 0.67 & 0.76 \\
\hline Adj. $\mathrm{R}^{2}$ & 0.72 & 0.67 & 0.77 & Adj. $R^{2}$ & 0.53 & 0.45 & 0.58 \\
\hline \# obs. & 8900 & 8135 & 8338 & \# obs. & 6163 & 5440 & 5720 \\
\hline $\bar{\beta}$ & 0.77 & 0.78 & 0.81 & $\beta$ & 0.62 & 0.59 & 0.63 \\
\hline t-value & 99.73 & 86.02 & 115.57 & t-value & 64.28 & 57.09 & 71.95 \\
\hline $5 ?$ & 0.83 & 0.79 & 0.86 & $12 ?$ & 0.72 & 0.66 & 0.74 \\
\hline Adj. $R^{2}$ & 0.69 & 0.63 & 0.73 & Adj. $R^{2}$ & 0.52 & 0.45 & 0.56 \\
\hline \# obs. & 8499 & 7718 & 7947 & \# obs. & 5784 & 5162 & 5367 \\
\hline$\beta$ & 0.74 & 0.74 & 0.78 & $\beta$ & 0.61 & 0.58 & 0.61 \\
\hline t-value & 90.76 & 81.53 & 106.77 & t-value & 60.96 & 54.30 & 68.72 \\
\hline $6 ?$ & 0.81 & 0.77 & 0.84 & $13 ?$ & 0.71 & 0.66 & 0.73 \\
\hline Adj. $\mathrm{R}^{2}$ & 0.65 & 0.59 & 0.71 & Adj. $\mathrm{R}^{2}$ & 0.50 & 0.44 & 0.54 \\
\hline \# obs. & 8110 & 7284 & 7564 & \# obs. & 5417 & 4870 & 5021 \\
\hline $\bar{\beta}$ & 0.72 & 0.71 & 0.75 & $\bar{\beta}$ & 0.60 & 0.56 & 0.59 \\
\hline t-value & 88.29 & 73.08 & 99.94 & t-value & 55.76 & 53.08 & 63.12 \\
\hline $7 ?$ & 0.80 & 0.74 & 0.82 & $14 ?$ & 0.70 & 0.65 & 0.72 \\
\hline Adj. $R^{2}$ & 0.64 & 0.55 & 0.67 & Adj. $R^{2}$ & 0.49 & 0.43 & 0.53 \\
\hline \# obs. & 7715 & 6883 & 7186 & \# obs. & 5046 & 4598 & 4684 \\
\hline
\end{tabular}

If the estimated value of $\beta_{k}$ is 'low enough', dispersion over time could decrease. Obviously, any estimate of $\beta_{k}$ exceeding unity implies an increase in dispersion over time. To be more precise, using the correlation between $b i_{t}$ and $b i_{t-k}$ as given by $\rho_{k}=1-\sigma_{k}^{2} / V\left(b i_{t}\right)$, equation (3) can be reduced to:

(4) $\frac{V\left(b i_{t}\right)}{V\left(b i_{t-k}\right)}=\frac{\beta_{k}^{2}}{\rho_{k}^{2}}$. 
Accordingly, if $\beta_{k}$ is below 1 and smaller than $\rho_{k}$ dispersion over time has decreased, while the dispersion stays the same if $\beta_{k}=\rho_{k}$.

Figure 10 Galtonian regression results and base choice, lag 1-27 years*
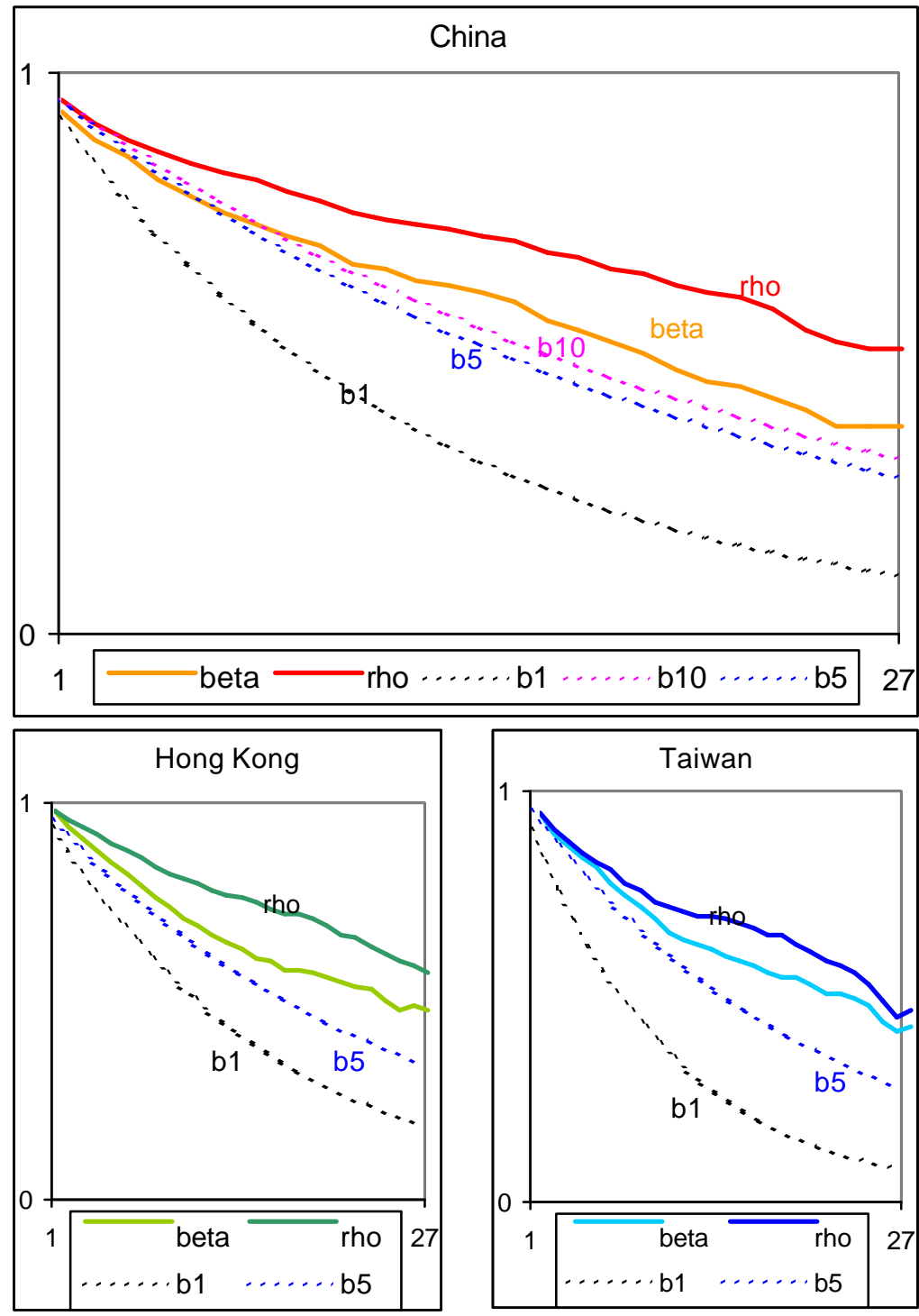

* The beta and rho estimates are given in Table 7 , the $b_{1}, b_{5}$, and $b_{10}$ lines are computed estimates using a 1, 5, and 10 year lag, respectively, as base choice. See section 7 for further details.

Table 7 reports the pooled Galtonian regression results for China, Hong Kong, and Taiwan for lags of 1 to 14 years. Appendix II reports the pooled results for lags of 15 to 27 years, while the results for individual annual estimates are available on the ETA website. Obviously, the regression performs well on a statistical basis for all three countries for all lags in Table 7. All estimates are highly significant and explain a substantial share of the variance in the deviation from the median. This underlines the non-transitory nature of values of the Balassa index. Note that the absolute size of the estimated value of $\beta_{k}$ decreases more or less monotonically with the number of years in between the periods to which the two cross sections pertain. In 
theory there is a close link between these estimates, which we will use as a first indicator for the appropriate lag period (base choice) regarding the degree of persistence. Suppose that we take the one year lag as the basis. Repeated use of equation (2) then gives

$$
\beta_{k}=\beta_{1}^{k}, \quad k=1, . ., 27
$$

The estimated value of $\beta_{1}$, say $b_{1}$, can then be used as a second estimate of $\beta_{k}, k=2, . ., 27$, and compared to the estimate obtained in Table 7. Similarly, suppose that we take the two year lag as the basis. Repeated use of equation (2) then implies

$$
\beta_{2 k}=\beta_{2}^{k}, \quad k=1, . ., 13
$$

The estimated value of $\beta_{2}$, say $b_{2}$, can then be used as a direct second estimate for the even lags and compared to the estimate obtained in Table 7. Moreover, we can get implied indirect estimates for the odd lags by computing $b_{2}^{k / 2}$ for the odd periods. And so on for the choice of a $3,4,5$, etc. year lag as the basis.

Figure 10 summarizes the findings on the Galtonian regressions for the three Chinese economies and the computed estimates taking a one year, five year, or ten year lag as the basis. Evidently, taking a one year lag as the basis results in a gross underestimate of the degree of persistence in comparative advantage: there is substantially more 'memory' in the system after a number of years than suggested by repeated use of a one year lag. The empirical estimate for the 20 year lag for China using actual data is 0.46 , more than twice the calculated estimate of 0.19 taking a one year lag as the basis. As we take a longer lag as the basis for our calculations, the deviation with the empirical estimate diminishes. With a five year lag as the basis, for example, the calculated estimate for China's 20 year lag is 0.35 . With a ten year lag it is 0.42 , very close to the actual 0.46 .

Figure 11 Base choice and goodness-of-fit

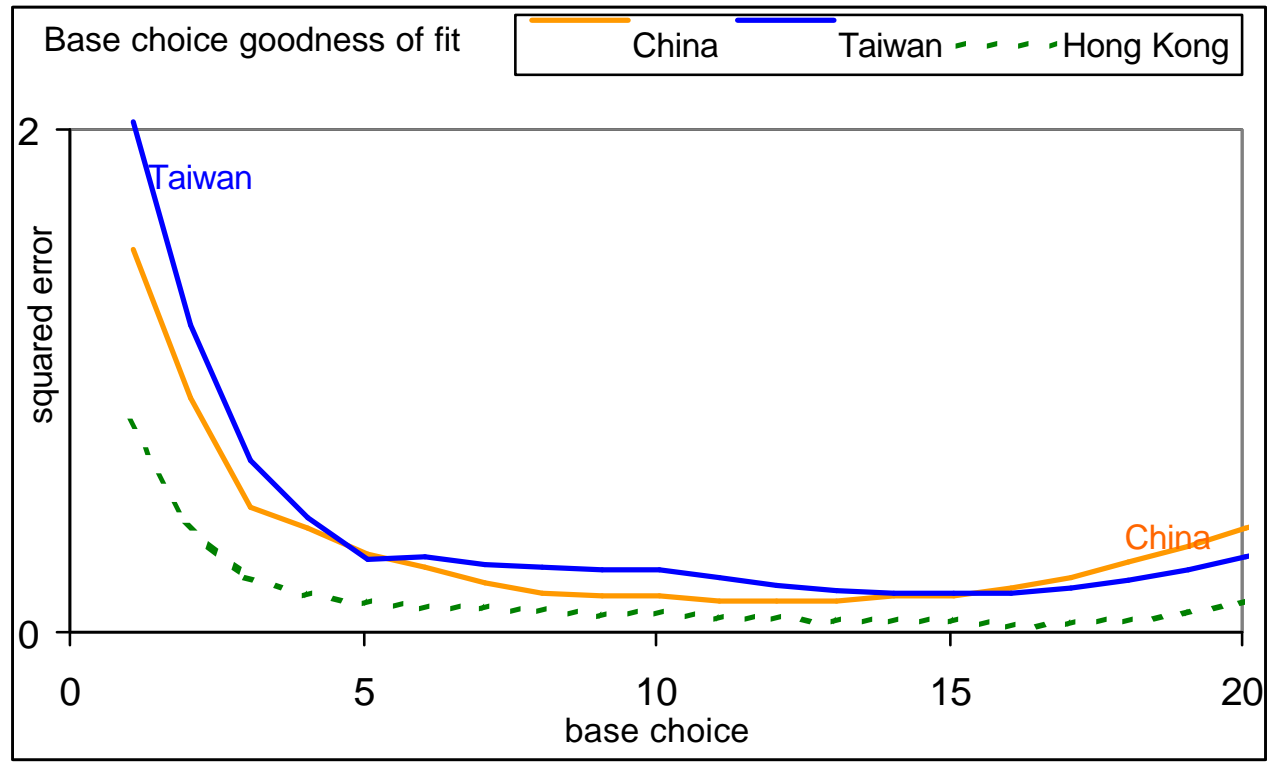


Applying a mechanical rule, such as minimizing the mean squared error of the deviation between the empirical estimate and the calculated estimate for a particular base choice, leads to rather long lags as the 'optimal' base choice. Including all observations for the sample period in this calculation would lead to a base choice of 12 years for China, 15 years for Taiwan, and 16 years for Hong Kong. This ignores, however, three points. First, persistence calculations are most often used for forecasting purposes, in which case the goodness-of-fit for the first 5 or 10 years is most important. We could deal with this issue, of course, in several ways. Second, by extending the base choice we are increasing the number of indirectly implied estimates relative to the number of directly theoretically implied estimates. For that reason we should, other things equal, prefer a low lag over a high lag in our base choice. Third, and most importantly, as illustrated in Figure 11 using all observations as a comparison, most improvement in the goodness-of-fit is achieved after extending the base choice from one year to about five years. Although, as indicated above, the mean squared error reaches its absolute minimum only much later, the improvements are very small compared to the cost of extending the base period and putting too much emphasis on far-away forecasts. For these reasons a five year lag seems to be a suitable base choice.

A final remark on Figure 10 before we continue. As derived in equation (4) the dispersion of the distribution diminishes over time if, and only if, $\beta_{k}<\rho_{k}$. Based on the regression results depicted in Figure 10 there is some evidence that this occurred for the three Chinese economies in the sample period, as also suggested in sections 5,6 , and 8 below.

\section{Markov transitions and mobility indicators}

Empirical research into the persistence and mobility of revealed comparative advantage over time using transition probability matrices is pioneered by Proudman and Redding (1998, 2000), see also Brasili, Epifani, and Helg (2000), and Hinloopen and Van Marrewijk (2001). Most studies into the dynamics of comparative advantage classify the data endogenously into several categories, such as quartiles or quintiles. The number of categories is usually determined in an ad hoc manner, depending on data availability. In Hinloopen and Van Marrewijk (2004b), we provide a structural analysis for choosing the number of categories using the entire data set, that is including all countries, years, and sectors, for different levels of aggregation (1-4 digits). In that paper, which also discusses some methodological and estimation issues, we argue that an analysis of the dynamics of comparative advantage at the 4-digit sectoral level should identify about 10 different classes. Accordingly, this section analyzes the transition dynamics of the deciles of the Balassa index, while Appendix II provides information on the quintiles for comparison. 
Figure 12 Markov 5-year transition matrix; Taiwan, deciles, pooled estimate

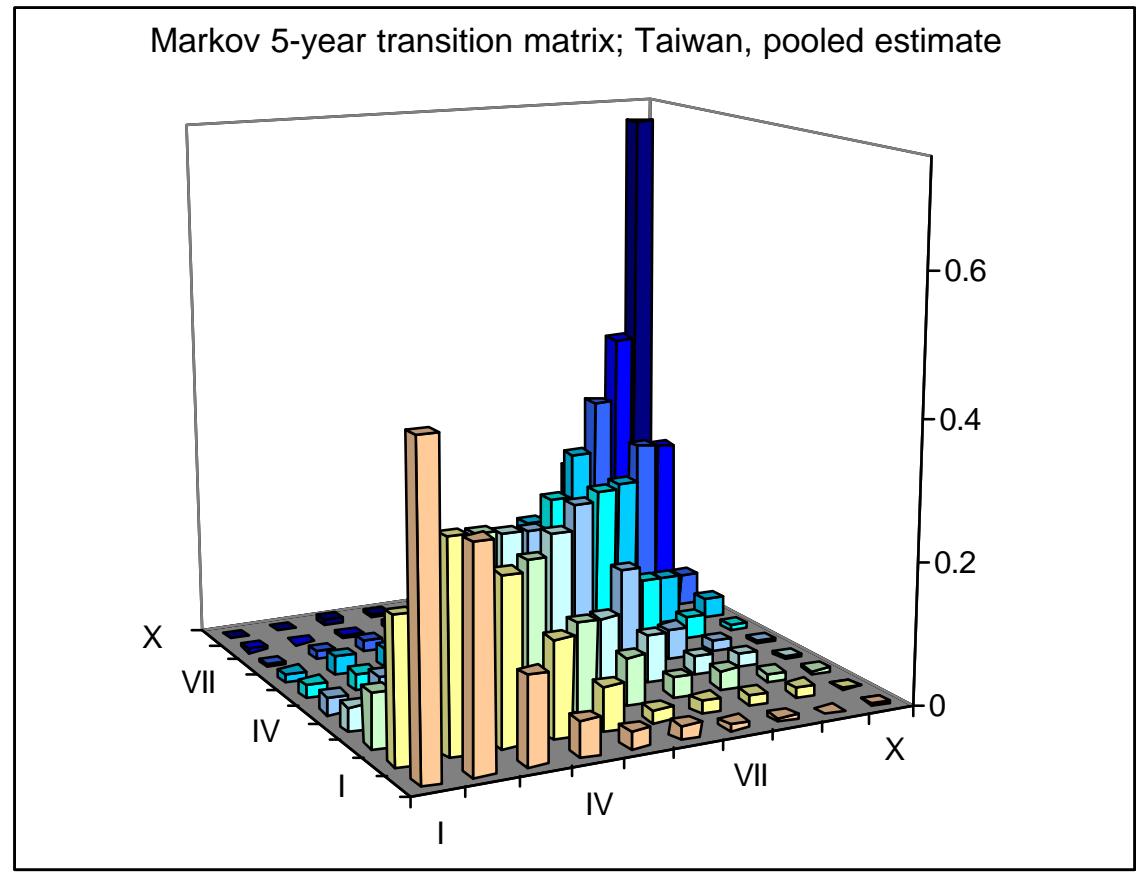

Essentially, we want to know: "given that sector $j$ in country $i$ is in the $k$-th decile of the distribution of the Balassa index in year $t$, what is the probability that sector $j$ in country $i$ is in the $l$-th decile of the distribution in year $t+5$, where $l$ ranges from the first to the $10^{\text {th }}$ decile." We answer this question using Anderson and Goodman's (1957) Maximum Likelihood estimator using the actual decile observations. We estimated these transition probabilities for each country for all years for which observations were available. Table 8 summarizes the pooled regression results for each country. Take China as an example. The table indicates that if a sector is in the first decile of the distribution in some year, the probability is 49.9 percent that it will remain in the first decile after five years, while there is a 25.8 percent chance that the sector will move to the second decile after five years, there is an 11.7 percent chance that it will move to the third decile, etc. The diagonal elements of the table indicate persistence, the probability of remaining in the same decile after five years. For all three countries persistence is high for the first decile (close to 50 percent), then declines monotonically to reach a minimum (for China and Hong Kong in the fourth decile, for Taiwan in the fifth decile), followed by a monotonic increase to the maximum in the tenth decile (ranging from 72.7 percent for Taiwan to 84.7 percent for Hong Kong). This finding of higher persistence at the extreme ends of the distribution, specifically the highest persistence for the category with the highest Balassa index, is similar to findings in earlier studies, although the degree of detail is much better ( 10 categories, rather than 4 or 5). Figure 12 illustrates this finding for Taiwan. 
Table 8 Markov 5-year transition matrices; pooled estimates, deciles

\begin{tabular}{|c|c|c|c|c|c|c|c|c|c|c|}
\hline \multicolumn{11}{|c|}{ Panel a China } \\
\hline & I & II & III & IV & $\mathrm{V}$ & VI & VII & VIII & IX & $\mathrm{X}$ \\
\hline $\mathrm{I}$ & 0.499 & 0.258 & 0.117 & 0.047 & 0.025 & 0.022 & 0.014 & 0.010 & 0.003 & 0.005 \\
\hline II & 0.182 & 0.363 & 0.226 & 0.126 & 0.049 & 0.030 & 0.018 & 0.002 & 0.001 & 0.002 \\
\hline III & 0.107 & 0.198 & 0.276 & 0.204 & 0.120 & 0.053 & 0.029 & 0.007 & 0.006 & 0.000 \\
\hline IV & 0.037 & 0.087 & 0.199 & 0.258 & 0.223 & 0.105 & 0.054 & 0.025 & 0.011 & 0.002 \\
\hline $\mathrm{V}$ & 0.021 & 0.052 & 0.106 & 0.202 & 0.275 & 0.192 & 0.090 & 0.040 & 0.017 & 0.006 \\
\hline VI & 0.007 & 0.027 & 0.044 & 0.104 & 0.209 & 0.292 & 0.189 & 0.096 & 0.030 & 0.002 \\
\hline VII & 0.006 & 0.009 & 0.028 & 0.046 & 0.084 & 0.200 & 0.302 & 0.218 & 0.098 & 0.008 \\
\hline VIII & 0.007 & 0.006 & 0.007 & 0.015 & 0.032 & 0.087 & 0.231 & 0.364 & 0.207 & 0.044 \\
\hline IX & 0.005 & 0.009 & 0.006 & 0.007 & 0.005 & 0.034 & 0.072 & 0.213 & 0.472 & 0.178 \\
\hline $\mathrm{X}$ & 0.000 & 0.001 & 0.000 & 0.004 & 0.002 & 0.002 & 0.018 & 0.039 & 0.172 & 0.762 \\
\hline ergodic & 0.068 & 0.087 & 0.092 & 0.097 & 0.102 & 0.105 & 0.108 & 0.111 & 0.114 & 0.116 \\
\hline \multicolumn{11}{|c|}{ Panel b Hong Kong } \\
\hline & I & II & III & IV & $\mathrm{V}$ & VI & VII & VIII & IX & $\mathrm{X}$ \\
\hline $\mathrm{I}$ & 0.513 & 0.261 & 0.113 & 0.051 & 0.028 & 0.018 & 0.010 & 0.001 & 0.003 & 0.000 \\
\hline II & 0.177 & 0.359 & 0.245 & 0.125 & 0.047 & 0.015 & 0.020 & 0.009 & 0.003 & 0.000 \\
\hline III & 0.075 & 0.175 & 0.291 & 0.228 & 0.116 & 0.054 & 0.037 & 0.018 & 0.007 & 0.000 \\
\hline IV & 0.030 & 0.082 & 0.213 & 0.265 & 0.217 & 0.111 & 0.061 & 0.014 & 0.005 & 0.001 \\
\hline V & 0.012 & 0.052 & 0.079 & 0.215 & 0.268 & 0.220 & 0.107 & 0.034 & 0.012 & 0.003 \\
\hline VI & 0.014 & 0.035 & 0.041 & 0.077 & 0.212 & 0.290 & 0.204 & 0.099 & 0.025 & 0.003 \\
\hline VII & 0.010 & 0.008 & 0.019 & 0.043 & 0.098 & 0.225 & 0.303 & 0.225 & 0.060 & 0.010 \\
\hline VIII & 0.003 & 0.005 & 0.017 & 0.015 & 0.022 & 0.060 & 0.250 & 0.427 & 0.186 & 0.015 \\
\hline IX & 0.003 & 0.000 & 0.001 & 0.009 & 0.015 & 0.028 & 0.040 & 0.188 & 0.583 & 0.135 \\
\hline X & 0.000 & 0.001 & 0.001 & 0.000 & 0.000 & 0.003 & 0.001 & 0.011 & 0.135 & 0.847 \\
\hline ergodic & 0.056 & 0.075 & 0.086 & 0.094 & 0.100 & 0.106 & 0.111 & 0.117 & 0.123 & 0.133 \\
\hline
\end{tabular}

\begin{tabular}{r|cccccccccc}
\multicolumn{2}{l}{ Panel c Taiwan } & & & & & & & & & \\
& I & II & III & IV & V & VI & VII & VIII & IX & X \\
\hline I & 0.453 & 0.309 & 0.124 & 0.051 & 0.025 & 0.020 & 0.009 & 0.006 & 0.000 & 0.002 \\
II & 0.203 & 0.295 & 0.236 & 0.138 & 0.062 & 0.018 & 0.019 & 0.015 & 0.014 & 0.001 \\
III & 0.078 & 0.156 & 0.271 & 0.226 & 0.129 & 0.069 & 0.029 & 0.027 & 0.011 & 0.004 \\
IV & 0.034 & 0.102 & 0.174 & 0.242 & 0.233 & 0.103 & 0.066 & 0.025 & 0.017 & 0.003 \\
V & 0.025 & 0.043 & 0.079 & 0.182 & 0.220 & 0.245 & 0.141 & 0.044 & 0.017 & 0.004 \\
VI & 0.020 & 0.024 & 0.071 & 0.090 & 0.188 & 0.235 & 0.240 & 0.096 & 0.030 & 0.007 \\
VII & 0.012 & 0.026 & 0.028 & 0.052 & 0.103 & 0.182 & 0.277 & 0.223 & 0.071 & 0.026 \\
VIII & 0.005 & 0.013 & 0.017 & 0.034 & 0.047 & 0.095 & 0.158 & 0.330 & 0.256 & 0.046 \\
IX & 0.005 & 0.001 & 0.004 & 0.009 & 0.013 & 0.041 & 0.076 & 0.214 & 0.405 & 0.231 \\
X & 0.000 & 0.001 & 0.005 & 0.005 & 0.011 & 0.012 & 0.017 & 0.037 & 0.189 & 0.722 \\
\hline ergodic & 0.059 & 0.075 & 0.087 & 0.095 & 0.101 & 0.105 & 0.109 & 0.113 & 0.119 & 0.136
\end{tabular}

The diagonal elements of a Markov matrix measure the degree of persistence of individual initial states. The literature, however, has focused on measuring a summary statistic of its inverse, the degree of mobility, for the matrix as a whole. Let $p_{i j}$ denote the probability of 
transition from the $i$-th to the $j$-th decile after five years, and let $P=\left(p_{i j}\right)$ denote the Markov transition matrix as reported in Table 8. Define the mobility index $\mathrm{M}$ as follows ${ }^{9}$ :

$$
M=[n-\operatorname{tr}(P)] /(n-1)
$$

Measured accordingly, the mobility index for the whole sample period for Hong Kong is 0.651, for China is 0.682 , and for Taiwan is 0.728 , suggesting that Taiwan's comparative advantage is slightly more mobile than for China and Hong Kong. Figure 13 shows the evolution of the mobility index over time, based on the estimated individual transition matrices. It displays some variation over time, but no clear pattern or strong peaks, making it impossible to relate the pattern to observed structural changes. Moreover, using this index it does not appear that one country displays consistently more mobility than another.

Figure 13 Evolution of the mobility index, five year transitions*

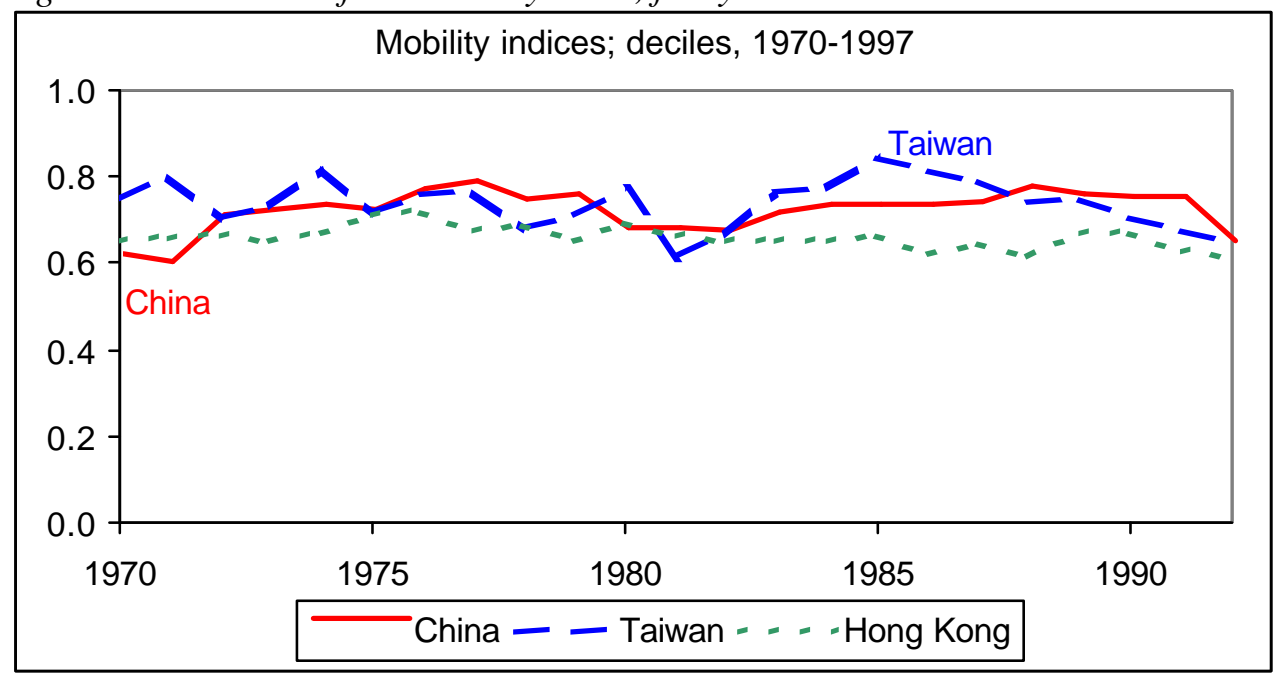

The index is depicted at the first year, the 1970 values therefore refer to the 1970-75 transition, etc.

Although there are formal asymptotic tests available to compare individual Markov transition matrices and determine whether or not these are identical, see Anderson and Goodman (1957), the asymptotic nature of the tests implies that their practical use is limited as equality is most often rejected, certainly as the number of identified categories increases. Appendix II shows, for example, that even the pooled estimate for any of the three Chinese economies reported in Table 8 differs significantly from each of the underlying individually estimated matrices. Hinloopen and Van Marrewijk (2004b) provide a further discussion and explain why we prefer to assess whether or not the Markov transition matrices capture the underlying data-generating process by computing the implied limiting distribution. This 'ergodic'

\footnotetext{
${ }^{9}$ Other mobility indices are also used, generally giving similar results. Since all eigenvalues of the matrices $\mathrm{P}$ are real, the index defined in eq. (7) is identical to: $\left(n-\sum_{m}\left|\lambda_{m}\right|\right) /(n-1)$, where $\lambda_{m}$ are the eigenvalues. See Geweke et al. (1986) and Hinloopen and Van Marrrewijk (2001) for further details.
} 
distribution of a transition matrix, that is the distribution that would result if the process is time stationary, can be simply derived by matrix multiplication. The bottom row in each panel of Table 8 gives the implied ergodic distribution. Since the matrix was constructed on a decile basis, a distribution of 10 percent in each cell would imply a perfect match to stationarity. This is not the case. Instead, for all three Chinese economies the ergodic distribution implies a gradual shift away from the lower towards the higher end of the distribution. It is important to note that this is not an artifact of the data or our estimation method, as similar observations do not generally hold for other countries in our data set. We take it as an indication that the rapid increase in the (per capita) income level of the Chinese economies developed in parallel with an increase of the degree of specialization according to comparative advantage.

\section{The Harmonic-Mass index and p-p plots}

Estimating Markov transition matrices is a useful tool in applied international trade analysis as these matrices give an indication of the degree of mobility and persistence in comparative advantage, both in general and for specific parts of the distribution. A disadvantage of this approach is the need to discretize the space of Balassa index values into distinct discrete cells. In Hinloopen and Van Marrewijk (2004b) we analyze the optimal number of classes to be selected if this procedure is followed. Another option is to continue to treat the Balassa index as a continuous variable and estimate the stochastic kernel, as suggested by Quah (1996, 1997) for analyzing cross-country per capita income convergence. Although leading to fascinating hill-shaped diagrams, there are three practical disadvantages to this approach. First, the data requirements are substantial. One needs a large number of observations over an extended period of time to estimate stochastic kernels, which is the main reason for Redding (2002) to continue estimating Markov matrices. ${ }^{10}$ Second, even if the required data is available, the careful estimation of stochastic kernels is a rather complicated and timeconsuming econometrics exercise. Third, and perhaps most importantly, even if the necessary data is available and time and effort spent to estimate stochastic kernels, the obtained output seems to be of limited practical use. A good case in point is the work of Brasili, Epifani, and Helg (2000), who after taking the time and trouble to estimate stochastic kernels for 14 countries continue with estimating Markov transition matrices to discuss the practical dynamic implications for the trade patterns of these countries.

Acknowledging the principal disadvantages of estimating Markov matrices and the practical disadvantages of estimating stochastic kernels, we advocate a novel approach in applied trade analysis which is practical, easy to use, and avoids the discretization problem. Our method,

\footnotetext{
${ }^{10}$ Clearly, our data set is large enough to estimate stochastic kernels.
} 
outlined in Hinloopen and Van Marrewijk (2004c), is based on pp plots, indicating either probability-probability or percentile-percentile, as suggested by Holmgren (1995) for comparing treatment effects in medicine studies. As explained below, these plots can be made quite easily, even with just limited data available. On the basis of these plots we define an index, taking on values between zero and one, which compares the two distributions. As the objective of this index is to determine to what extent the probability mass of one distribution function is in harmony with another distribution function, we label it the Harmonic-Mass (HM) index.

Figure 14 Cumulative distributions: explaining p-p plots

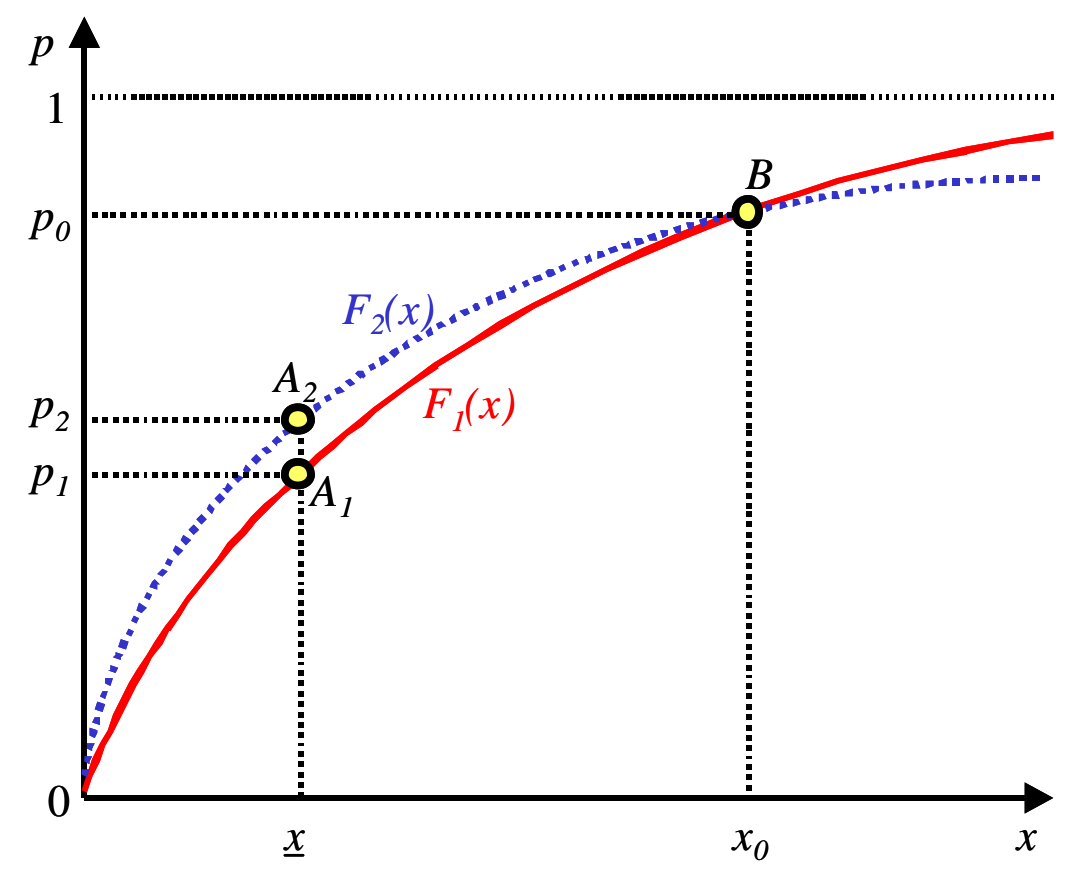

Figure 14 explains the construction of p-p plots, using two cumulative distributions similar to the actual distributions of the Balassa index for China in 1988 and 1993, but modified and simplified slightly for clarity. Let $F_{1}(x)$ and $F_{2}(x)$ be two distribution functions with common support. By definition, the distribution function indicates the probability that a random variable takes on a value smaller than or equal to $x$. As indicated in Figure 14, this probability is higher for distribution function $F_{2}$ than for distribution function $F_{1}$ at $\underline{x}$, more specifically $p_{2}>p_{1}$. We can compare the similarity of the two distribution functions in a compact space by plotting these $p$-values, which can be represented in functional form as $\eta=F_{1}\left(F_{2}^{-1}(p)\right), \quad 0 \leq p \leq 1$. An example is given in Figure 15 for the distribution of the 
Balassa index in China in 1988 and 1993. A p-p plot therefore ranges from [0,1] to [0,1]. If the two distribution functions are identical, the p-p plot coincides with the $45^{\circ}$ line. Obviously the pp plot can cut the diagonal, as occurs three times in Figure 15. This happens, for example, if the distribution functions intersect, as illustrated at point B in Figure 14.

Figure 15 P-P plot of the Balassa index (China 1988-1993) and HM index

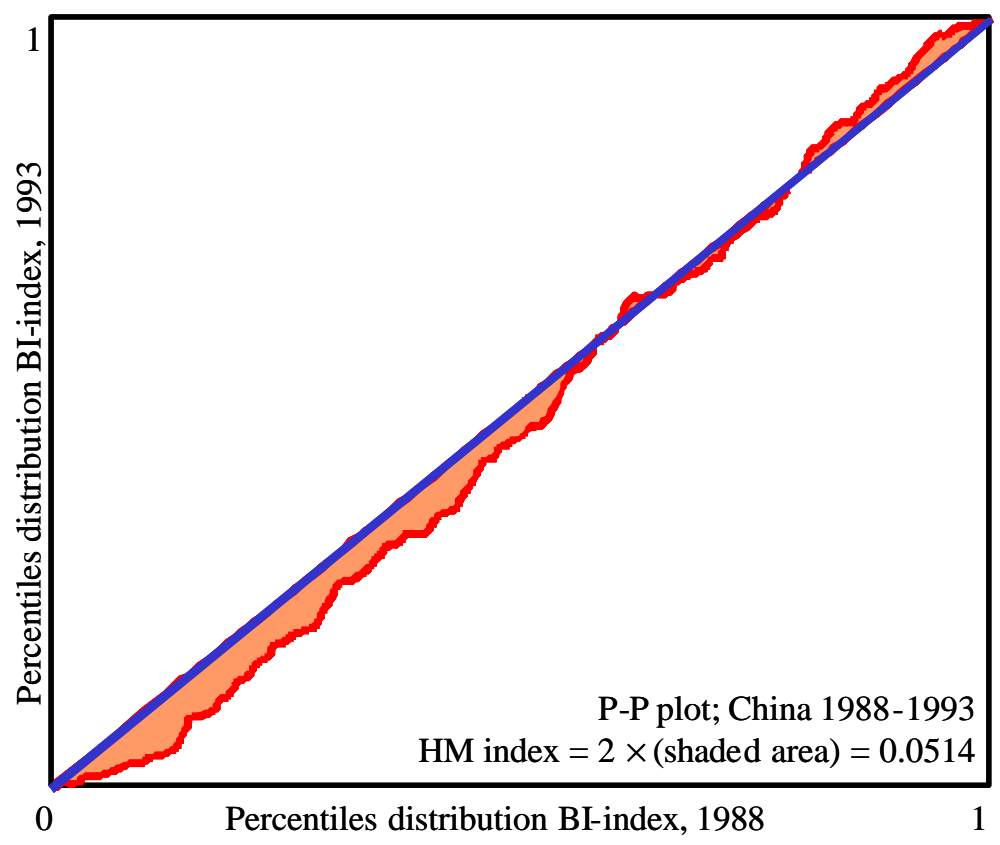

There are several advantages of using p-p plots for comparing distribution functions. First, the comparison is readily available in a compact space (this does not hold, for example, for q $q$ [quantile-quantile] plots). Second, p-p plots allow scale-invariant comparisons, that is the p-p plot is not obscured by outliers but instead focuses attention on the vast majority of data points. Third, Holmgren (1995) proves that the p-p plot contains all the necessary information for making scale-invariant comparisons. Fourth, and in light of our discussion above, there is no need for a discrete approximation. Our focus in this study is on comparing the distribution function of the Balassa index between two distinct time periods in the same country. Since the p-p plot coincides with the diagonal if the two distributions are identical, we can take the deviation between the diagonal and the actual pp plot as a measure of similarity of the distributions. As illustrated in Figure 15, the HM index does just that by calculating the surface area between the diagonal and the p-p plot and multiplying by 2 to normalize to an index that varies from 0 to 1 . More precisely:

$$
H M_{\text {index }}=2 \int_{0}^{1}\left|p-F_{1}\left(F_{2}^{-1}(p)\right)\right| d p
$$


In Hinloopen and Van Marrewijk (2004c), we discuss the general properties of p-p plots and the HM in dex, describe the methods used for derivation and calculation, and apply this to the distribution of the Balassa index for all countries in our data set. Just like there is a need for comparison of a country's trade share in a specific sector with the concomitant share in a group of reference countries to identify comparative advantage, see section 5, there is a need for benchmarking a particular value of the HM index to understand whether this observation, such as the value 0.0514 reported in Figure 15, is high or low. Two options explored further below are available in this respect: (i) benchmarking relative to a group of reference countries and (ii) benchmarking relative to observations in other time periods of the country itself.

\section{Figure 16 HM index distribution for Balassa index; all countries, 4-digits, 5 year difference}

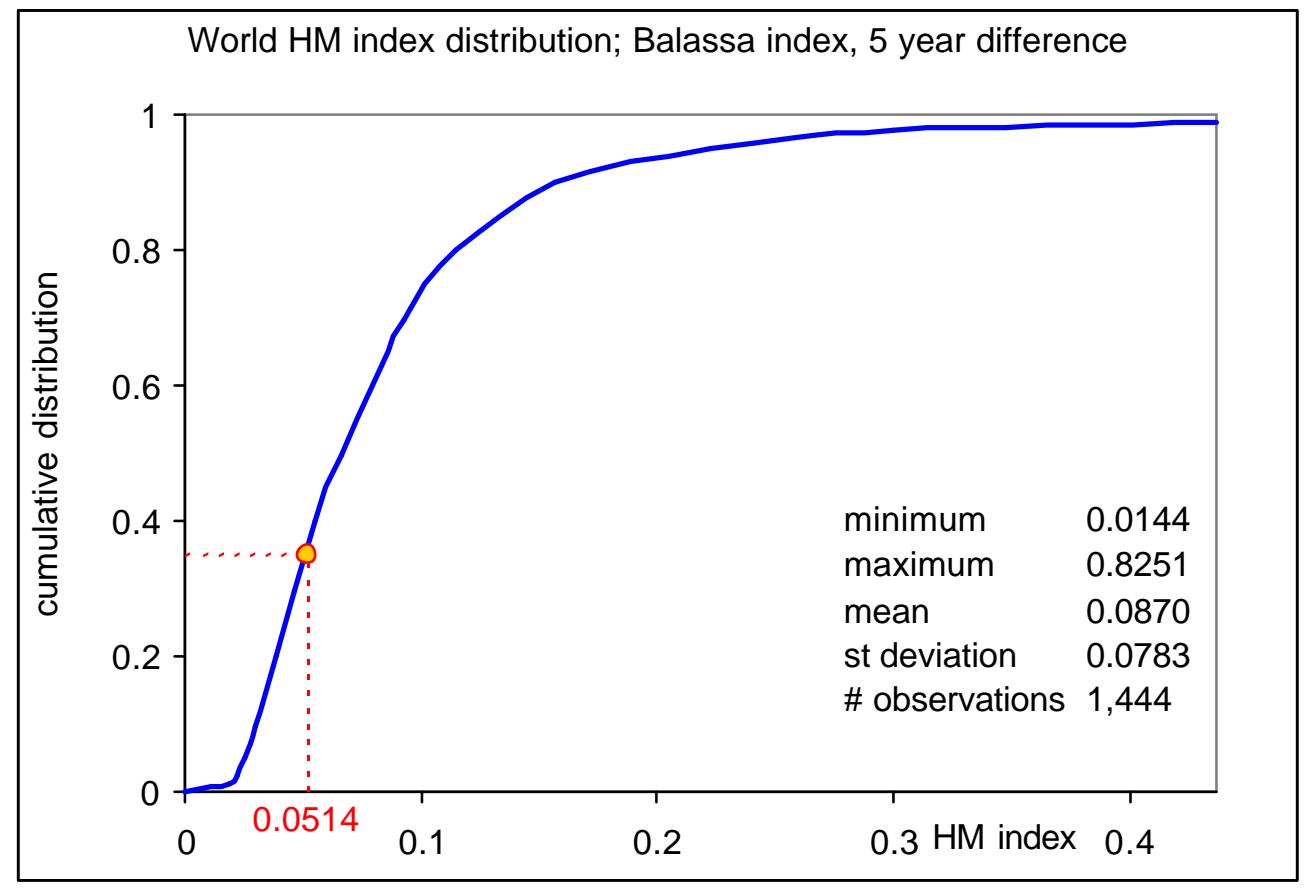

Source: Hinloopen and Van Marrewijk (2004c)

Ad (i) benchmarking relative to a group of reference countries. In Hinloopen and Van Marrewijk (2004c) we calculated the Balassa index for different levels of aggregation for all countries in the data set, and for every year. This gave us the distribution function for each country in each year. We then calculated p-p plots for 1, 2, 3, 4, and 5 years in between the distribution observations, and subsequently the concomitant HM index. This was used, finally, to calculate the world distribution of the HM index for comparison purposes. This is illustrated in Figure 16 for the 4-digit level and 5 year difference in between observations. 
Figure 17 HM index for the Chinese economies, 1970-1997

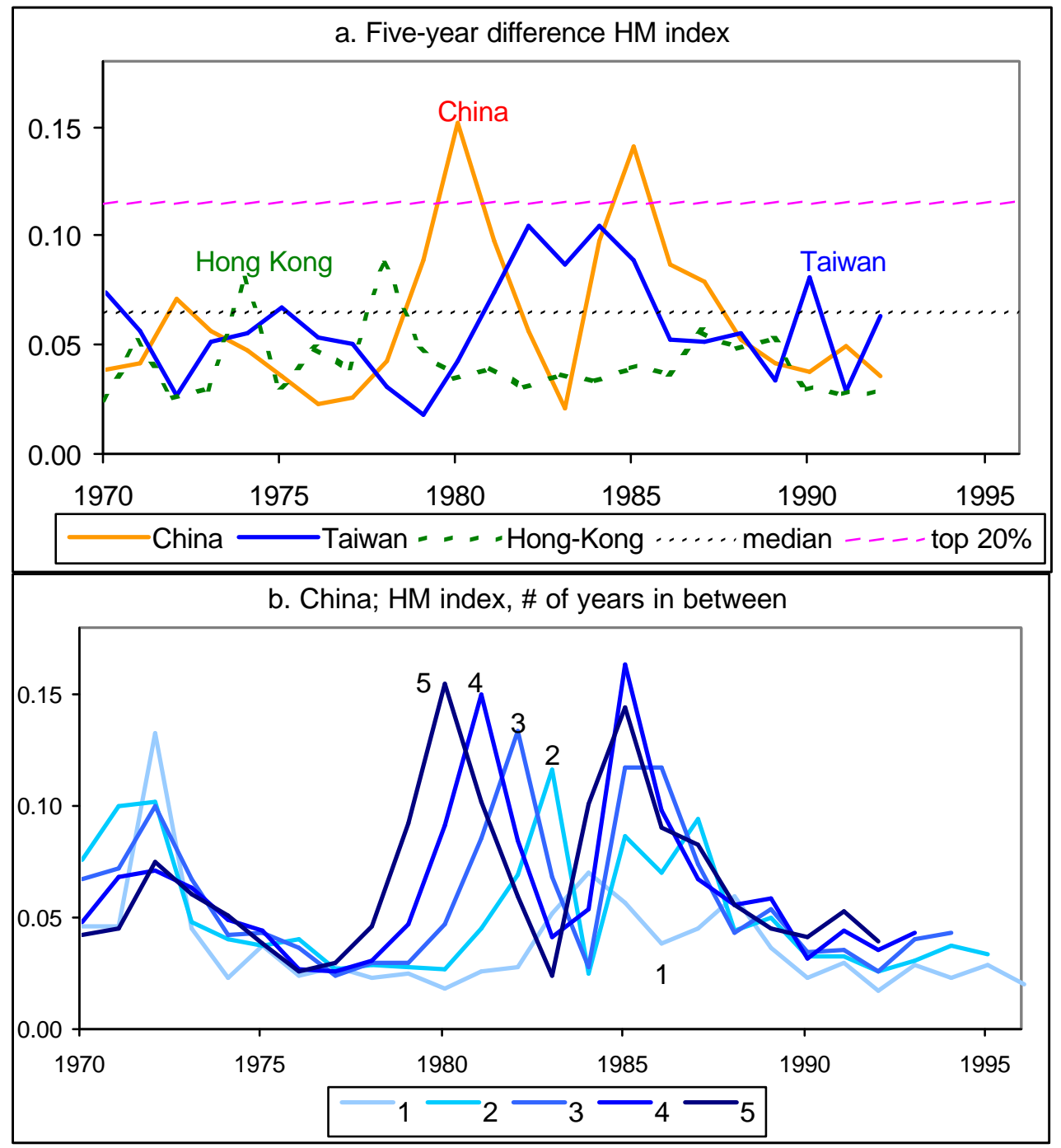

* Median and top $20 \%$ in panel $a$ refer to the global distribution reported in Hinloopen and Van Marrewijk (2004c). The HM index is depicted at the first year, the 1970 values in panel $a$ therefore refer to the 1970-75 transition, etc. Similarly in panel $b$.

Is the reported value of 0.0514 in Figure 15 exceptional, or not? As illustrated in Figure 16, it is not. The value 0.0514 is lower than the world's mean of 0.0870 . About 35 percent of the observations for all countries have a value lower than 0.0514 (equivalently: 65 percent has a higher value), such that this value does not seem to be either exceptionally high or exceptionally low. Figure 16 indicates that the lowest value is 0.0144 and the highest value is 0.8251. The latter is rather misleading, however, as 99 percent of the observations have a value below 0.4376 , indicating that the maximum is an outlier and, consequently, it is better to concentrate on the percentile distribution illustrated in Figure 16. Taking this into consideration, we could argue that a value in the world's top 10- or top 20-percent is 'exceptional'. None of the observations of the HM index on the Chinese economies makes it to the world's top 10 percent and only two observations (the 1980-85 and 1985-90 transitions in China) make it to the world's top 20 percent, as illustrated in panel $a$ of Figure 17. 
Ad (ii) benchmarking relative to observations in other time periods of the country itself. This method is particularly useful if there is a clear and coherent pattern of variation which enables us to identify periods of substantial structural change. More specifically, if there is no such pattern, as is the case for the mobility indices in Figure 13, benchmarking of observations relative to other time periods is not very informative. As illustrated in Figure 17, the HM index may be a very useful tool for identifying periods of substantial structural change. Panel $a$ displays two clear peaks in the HM index for China (the 1980-85 transition and the 1985-90 transition), and a modest peak for Taiwan (the 1982-87 and 1984-89 transitions). On a global scale, the peaks for Taiwan are not exceptional (about the top 25 percent) while the two peaks for China are (about the top 13 percent). Moreover, we will argue in section 10 that Taiwan's peaks in the 1980s are related to China's peaks in those years. For that reason, we focus attention in the remainder on the two peaks for China.

We can get additional information on the type of structural change by taking the timedifference of the comparison into consideration. This is illustrated for China in panel $b$ of Figure 17, displaying the HM index for 1, 2, 3, 4, and 5 year differences. Recall that the reported values in the figure are depicted at the first year of the comparison. We then see a remarkable difference in the nature of the two peaks identified using the five year difference. The 1980 5-year difference peak moves structurally forward by one year (to 1981, 1982, etc.) if we reduce the time difference (to 4 years, 3 years, etc., respectively). The 1985 5-year difference peak, on the other hand, does not move forward if we reduce the time difference, suggesting that 1985 initiated a structural change relative to $1986,1987,1988$, etc.

\section{Chinese structural change, 3-digit}

This section analyzes some details of the structural change in Chinese comparative advantage at the 3-digit level for two main reasons. First, as emphasized by Hinloopen and van Marrewijk (2004a) and in section 4, data coverage is more complete at the 3-digit than the 4 digit level. Second, we can classify most sectors at the 3digit level according to factor intensity on the basis of the International Trade Center's classification, the joint UNCTAD/WTO organization. With some adjustments to go from SITC rev 3 codes to our codes and ranking code 951 (armored fighting vehicles, etc.) as technology intensive, the $3-$ digit sectors are classified according to five broad factor intensity categories as follows:

A. Primary products (83 sectors); e.g. meat, dairy, cereals, fruit, coffee, sand, minerals, oil, natural gas, iron ore, and copper ore.

B. Natural-resource intensive products (21 sectors); e.g. leather, cork, wood, lime, precious stones, pig iron, copper, aluminum, and lead. 
C. Unskilled-labor intensive products (26 sectors); e.g. pipes, various textiles, clothing, glass, pottery, ships, furniture, footwear, and office supplies.

D. Technology intensive products (62 sectors); e.g. various chemic als, medicaments, plastics, engines, generators, machines, tools, pumps, telecommunications and photo equipment, optical equipment, and aircraft.

E. Human-capital intensive products (43 sectors); synthetic colors, pigments, perfumes, cosmetics, rubber and tires, tubes, pipes, various types of steel and iron, cutlery, televisions, radios, cars, watches, and jewellery.

This leaves five 3-digit sectors not classified according to intensity (notably sector 999, nonidentified products), to be ignored in the remainder of this section. The complete classification is listed at www.few.eur.nl/few/people/vanmarrewijk/eta.

Figure 18 Structural change in comparative advantage, category aggregates

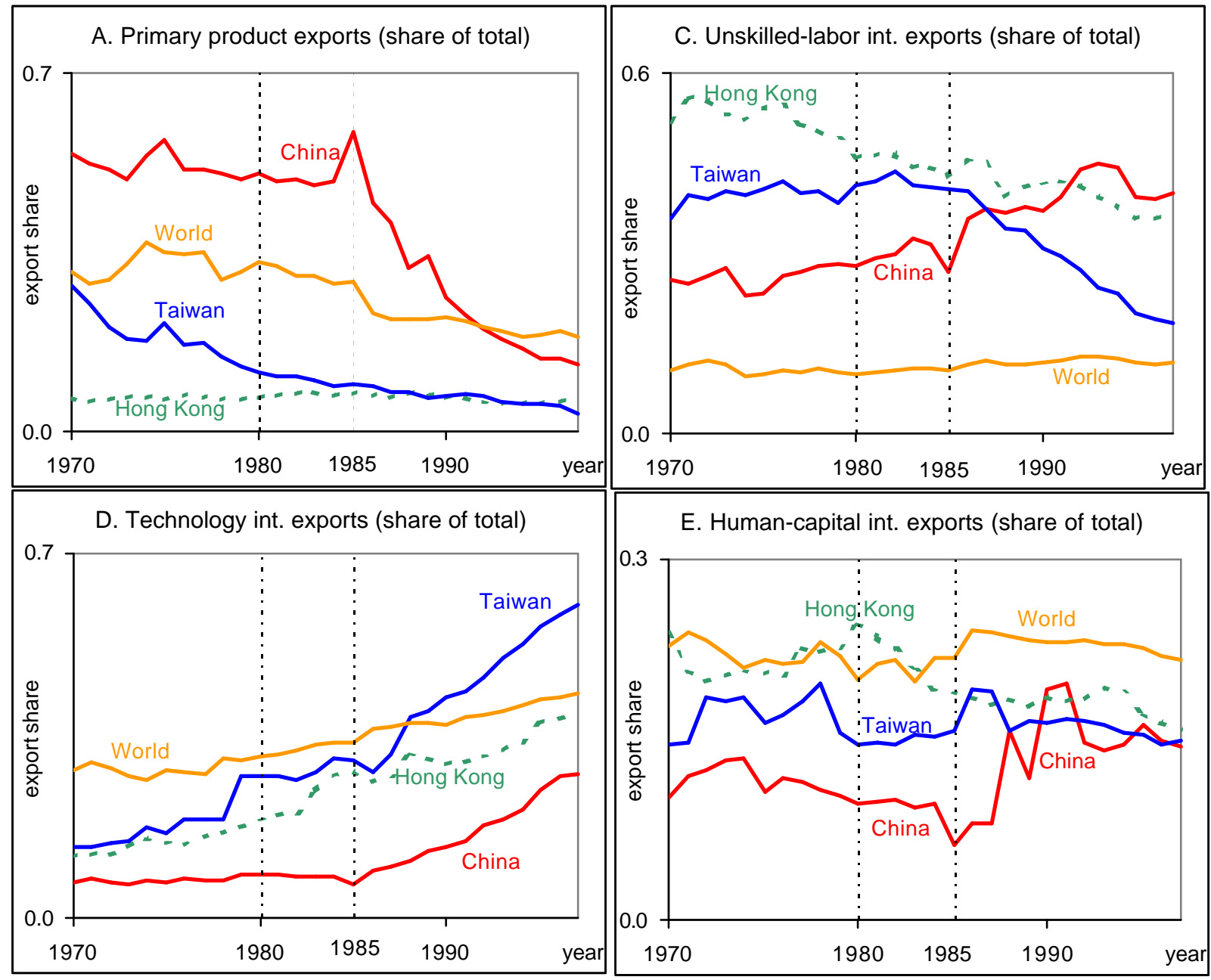

As explained in section 8, one of the advantages of the Harmonic Mass index is its ability to identify periods of rapid structural change. Using 5-year differences, Figure 17a showed that, relative to the benchmark of all other countries in the data set (see Hinloopen and Van Marrewijk, 2004c), only China had two observations in the global top 20 percent, namely the 
1980-85 and the 1985-90 transition. Moreover, as illustrated by Figure 17b using 1-, 2-, 3-, 4-, and 5-year transitions for China only, there are actually three peaks: in 1972, 1980, and 1985.

The first peak, in 1972, is relatively modest using the 5-year difference, but particularly high using the 1-year difference, where it reaches the global top 5 percent. On the one hand it is easy to explain this peak, while on the other hand it remains a puzzle. As discussed in section 3 , in the 1970s a large share of China's trade flows are attributed to 'non-identified products' exported to 'unknown partners'; for the years 1970-74 the exports classified as such are 27.6, 13.7, 0.0, 27.2, and 20.7 percent, respectively. The year 1972 is therefore quite exceptional as it does not contain non-identified products, in contrast to the other years in this period. Why this is the case is unclear, but it affects the distribution of the Balassa index, and this peculiarity is immediately identified by the HM index. ${ }^{11}$

The second peak in the HM index, in 1980, indicates the start of one of the most remarkable and successful policy changes in economic history. Mao's death in September 1976 set off a scramble for succession, leading to the arrest of the Gang of Four and the reinstatement of Deng Xiaoping in August of 1977. In a pivotal meeting in December 1978 the new leadership adopted Economic Reform policies to expand rural incentives, encourage enterprise autonomy, reduce central planning, open up to international trade flows with the outside world, and pass new legal codes in June of 1979. It marks the start of rapidly expanding trade flows; for the years 1976-80 the increase in China's export flows is -5.2, 10.3, 24.6, 40.2, and 41.3 percent, respectively. The third peak in the HM index, in 1985, identifies changes in the structural composition of China's export flows, not only indicating that some years after the policy change towards a more open economy have to pass before these are reflected in the composition, but also reflecting the delayed impact of a second policy change: more openness towards the inflow of foreign capital. Until the year 1982, there are no foreign direct investments into China. This changes in the 1980s. Net inflows of foreign direct investments relative to China's rapidly expanding GDP in the years 1982-88 were: $0.21,0.28,0.49,0.54$, $0.63,0.86$, and 1.04 percent, respectively. The export of intermediate products starts to flourish parallel to these investment flows and continues to this day, again reflected by the HM index.

Figure 18 illustrates the main structural changes for the three Chinese economies in terms of exports for the aggregates for four of the five groups identified above. For the moment we focus on the aggregate level, going into further detail below. For the period under investigation and relative to the world aggregate level, Hong Kong and Taiwan never had a

\footnotetext{
${ }^{11}$ Personal correspondence with Robert Feenstra regarding this matter did not resolve the issue.
} 
comparative advantage in primary products. China, on the other hand, was initially specializing to a large extent in exporting primary products. This changed rapidly after the peak of 58.6 percent of total exports in primary products in 1985, leading to a loss of comparative advantage in 1992, and an export share of 13.1 percent in 1997. The exports of natural resource intensive products, not shown in Figure 18, is modest in relative terms (the highest is Taiwan's 8.2 percent in 1973). Taiwan is the only country which, in 1970-75, achieves a modest comparative advantage in natural resource intensive products.

Table 9 Structural change in Revealed Comparative Advantage (BI > 1), 3-digit level

\begin{tabular}{|c|c|c|c|c|}
\hline product group & \multicolumn{4}{|c|}{ \# of sectors with BI > 1 throughout period (share of group) } \\
\hline \multicolumn{5}{|c|}{ China } \\
\hline & 1970-1979 & 1980-1989 & 1990-1997 & 1970-1997 \\
\hline A primary products & $26(0.31)$ & $25(0.30)$ & $21 \quad(0.25)$ & $15 \quad(0.18)$ \\
\hline B natural resource int. & $3(0.14)$ & $(0.10)$ & $(0.24)$ & $(0.10)$ \\
\hline $\mathrm{C}$ unskilled-labor int. & $17 \quad(0.65)$ & $(0.69)$ & $(0.73)$ & $(0.58)$ \\
\hline D technology int. & $2(0.03)$ & $(0.05)$ & $(0.03)$ & $1 \quad(0.02)$ \\
\hline E human-capital int. & $8 \quad(0.19)$ & $(0.14)$ & $11 \quad(0.26)$ & $4(0.09)$ \\
\hline
\end{tabular}

Hong Kong

\begin{tabular}{l|rrrrrr|rr} 
& \multicolumn{1}{|c}{$1970-1979$} & $1980-1989$ & $1990-1997$ & $1970-1997$ \\
\hline A primary products & 5 & $(0.06)$ & 7 & $(0.08)$ & 2 & $(0.02)$ & 0 & $(0.00)$ \\
B natural resource int. & 1 & $(0.05)$ & 1 & $(0.05)$ & 3 & $(0.14)$ & 0 & $(0.00)$ \\
C unskilled-labor int. & 19 & $(0.73)$ & 21 & $(0.81)$ & 21 & $(0.81)$ & 18 & $(0.69)$ \\
D technology int. & 6 & $(0.10)$ & 10 & $(0.16)$ & 11 & $(0.18)$ & 3 & $(0.05)$ \\
E human-capital int. & 9 & $(0.21)$ & 10 & $(0.23)$ & 8 & $(0.19)$ & 6 & $(0.14)$ \\
\hline
\end{tabular}

Taiwan

\begin{tabular}{|c|c|c|c|c|}
\hline & 1970-1979 & 1980-1989 & 1990-1997 & 1970-1997 \\
\hline A primary products & $\begin{array}{ll}10 & (0.12)\end{array}$ & $\begin{array}{ll}6 & (0.07) \\
\end{array}$ & $\begin{array}{ll}3 & (0.04) \\
\end{array}$ & $\begin{array}{ll}2 & (0.02) \\
\end{array}$ \\
\hline $\mathrm{B} \mathrm{n}$ & $2(0.10)$ & $(0.14)$ & $2(0.10)$ & $(0.05)$ \\
\hline $\mathrm{C}$ un & $17 \quad(0.65)$ & $(0.73)$ & $(0.62)$ & $(0.46)$ \\
\hline D te & $5(0.08)$ & $(0.15)$ & $(0.27)$ & $(0.06)$ \\
\hline E human-capital int. & $4 \quad(0.09)$ & (0.19) & $(0.19)$ & $4 \quad(0.09)$ \\
\hline
\end{tabular}

All three Chinese economies have a comparative advantage in unskilled-labor intensive products. To some extent this is surprising as both Hong Kong and Taiwan have rapidly developed over the period and have reached high income per capita levels. Figure 18 suggests that this rapid development was achieved by specializing on exporting unskilled-labor intensive products, in accordance with the neoclassical theory of comparative advantage. Hong Kong's share of unskilled-labor intensive products declined gradually throughout the period. Taiwan's share first increased and then declined more rapidly than Hong Kong's, particularly from 1986 onwards. China's share of unskilled-labor intensive exports increased, particularly after 1985 . 
Figure 19 Structural change in revealed comparative advantage, 3-digit level
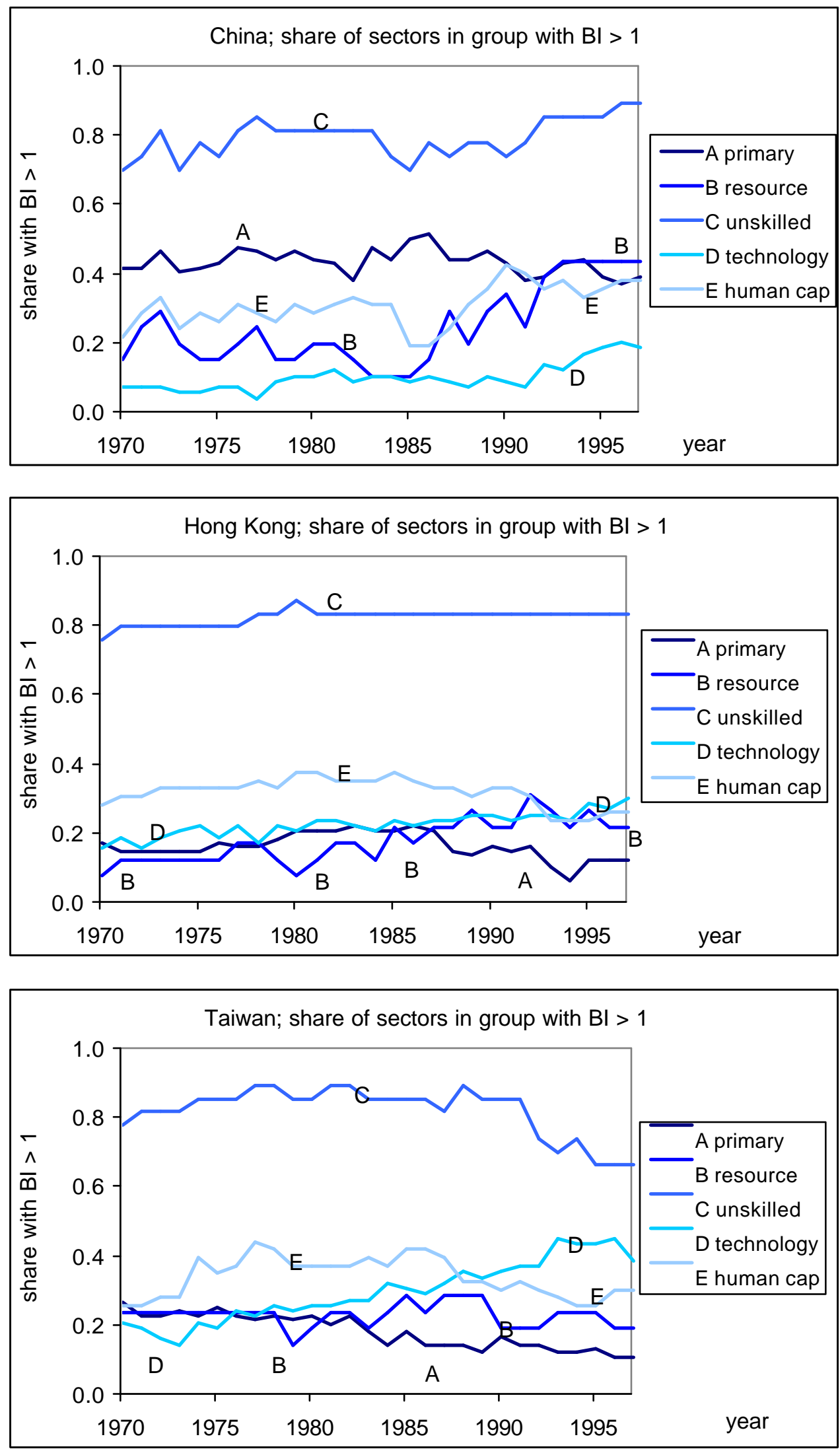
These developments are related. The more gradual decline of unskilled-labor intensive exports in Hong Kong than in Taiwan reflect its role as an entrepôt for China (with a rising share of these products). Moreover, China's opening up to the world economy allows Taiwan to more easily switch from unskilled-labor intensive products to higher value-added products, particularly technology intensive exports. Regarding the latter, we see a gradual improvement in Hong Kong throughout the period, almost reaching comparative advantage in 1997. Developments for technology intensive exports in Taiwan are similar to those in Hong Kong until 1986, after which a period of more rapid expansion begins, leading to comparative advantage from 1988 onwards. Developments of technology intensive exports in China are stable until 1985. Using foreign knowledge incorporated in the expanding foreign direct investments, technology intensive exports from China start to rise rapidly from 1985 onwards. Regarding the last category, human-capital intensive exports, only Hong Kong briefly achieves a period of comparative advantage in the early 1980s. Developments in this category in all three countries are rather stable and mimic those in the world economy. Only China appears to increase its share relative to the other two countries and the world economy from 1985 onwards.

The group aggregates illustrated in Figure 18 are each composed of a number of 3 digit sectors. Obviously, if comparative advantage is achieved at the aggregate level this does not mean that it holds for all its components. Vice versa, if the group aggregate is relatively low, some of the sectors within this group may be strong. Table 9 illustrates these aspects by listing the number of sectors within each group (and the concomitant share of that group) which managed to reach a comparative advantage $(\mathrm{BI} \geq 1)$ throughout the period 1970-97 as a whole and for the three sub-periods 1970-79, 1980-89, and 1990-97. Using this as an indicator, comparative advantage in China is most stable as 37 of the 235 classified 3-digit sectors (16 percent of the total) held on to their comparative advantage throughout the period. Similar numbers for Hong Kong and Taiwan are 27 sectors (11 percent) and 23 sectors (10 percent), respectively. In all three Chinese economies the highest stable share of comparative advantage is in unskilled-labor intensive products: at least 46 percent of the sectors within this group showed a comparative advantage for the entire period. China is relatively strong for a number of primary product sectors (18 percent of the group) and Hong Kong for humancapital intensive sectors (14 percent of the group).

At the sector level, China's stronghold in primary products (think of silk, tea, and vegetables throughout the period, initially of eggs and rice, and ultimately of coal) gradually reduced. China's high grip on unskilled-labor intensive products increased gradually (think particularly of various textiles, pottery, bags, toys, and footwear), as did its grip on natural resource 
intensive products (think of iron, steel, and zinc) and human-capital intensive products (think of radios, cutlery, and trailers) in the 1990s.

Figure 20 Evolution of initial and final top Balassa indices for China*
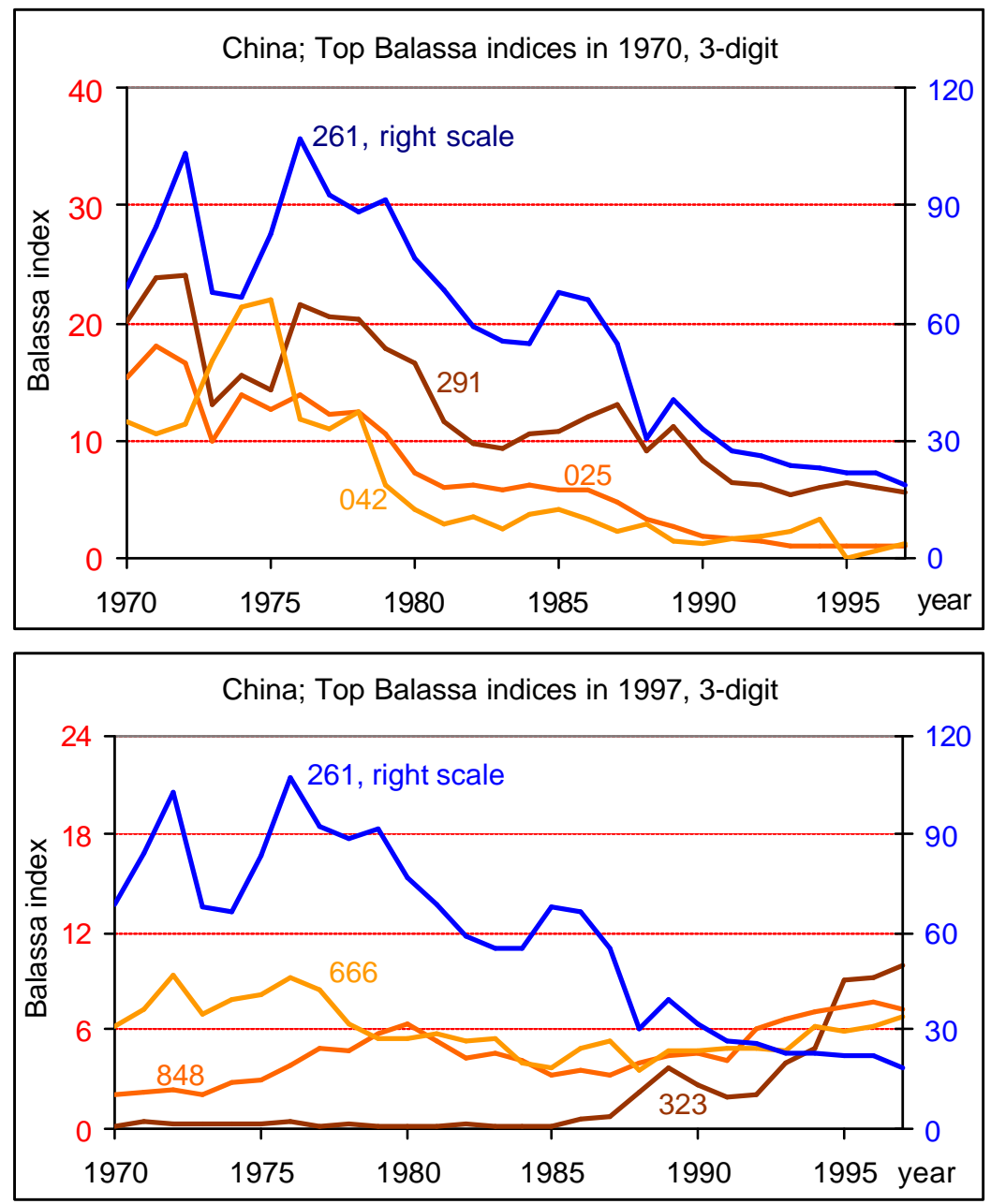

* Left hand scale, unless otherwise specified; 025-eggs and yolks, fresh, dried, or otherwise preserved; 042-rice; 261-Silk; 291 -crude animal materials nes; 323 -briquettes; coke and semi-coke of coal, lignite / peat; 666-pottery; 848-art. of apparel \& clothing accessories, no textile.

Not surprisingly, Hong Kong has no sectors with a comparative advantage in the primary products or natural resource intensive groups throughout the period. Hong Kong's comparative advantage is remarkably concentrated at virtually all unskilled-labor intensive products, with a shift towards technology intensive products over time (think initially of film and ultimately of electric power machinery and optical, medical, and electric equipment). Taiwan's focus has shifted most drastically over time. Its position in primary products virtually disappeared (with fish and crude animal materials remaining, joined by synthetic fibers suitable for spinning since 1977). Its position in unskilled-labor intensive products peaked in the 1980s (think initially of basic textiles and footwear, ultimately of special textile fabrics), as did its position in natural resource intensive products, although at a much lower 
level (think initially of wood, ultimately of leather). Most importantly, however, Taiwan has shifted toward technology intensive products throughout the period, particularly towards office machines, automatic data processing machines, and electric power machinery.

Figure 19, illustrates the developments at the sectoral level within the group aggregates. It shows most clearly that all three Chinese economies have a comparative advantage in virtually all unskilled-labor intensive sectors, most of the time hovering around 80 percent within the group, with a slight upward trend in China and a slight downward trend in Taiwan since 1985. China's large economy is more diversified as it clearly has more sectors achieving a comparative advantage throughout the period than either Hong Kong or Taiwan, both of which show an upward trend in the share of sectors within the technology intensive group with a comparative advantage. Figure 20, finally, illustrates the evolution over time of China's sectors with the highest initial and final Balassa index. Initially, these are all primary products, ultimately, there is one primary product (silk), one natural resource intensive product (coal), and two unskilled-labor intensive products (pottery and apparel).

\section{Conclusions}

We analyze the dynamics of revealed comparative advantage for China, Hong Kong, and Taiwan, with three innovations. First, we use Galtonian regressions to identify the most suitable lag period for analyzing changes in the distribution of comparative advantage. Second, we introduce probability-probability (p-p) plots as an alternative means to avoid the discretization problem associated with estimating Markov transition matrices. Third, we apply the Harmonic Mass (HM) index developed by Hinloopen and Van Marrewijk (2004c) on the basis of p-p plots to identify peculiarities in the data and periods of rapid structural change. Along the way, we also (i) describe basic developments in Chinese export flows, (ii) discuss statistical and stability properties of the distribution of comparative advantage, (iii) estimate decile Markov transition matrices with associated mobility indices, and (iv) give a description of the structural changes in Chinese exports which enabled the rapid development process.

In accordance with our earlier findings for the EU, the distribution of the Balassa index differs markedly from one country to the other. The economies of Taiwan and Hong Kong are more specialized in their exports than China's economy: the share of sectors unable to achieve a comparative advantage in international trade (Balassa index below 1) is on average 73.2 percent for Hong Kong, 70.1 percent for Taiwan, and 61.3 percent for China. Also in accordance with our earlier findings for the EU, the distribution is very skewed to the right for all countries, with a few very high observations, such that the mean is a poor indicator for the statistical properties of the distribution and it is better to focus on the distribution of the 
percentiles and the extent of comparative advantage. Unlike our earlier findings for the EU, however, the distribution of the Balassa index is not very stable over time for the countries considered here. Taiwan, in particular, is increasingly specializing in its exports as the share of sectors with a comparative advantage is gradually declining over time. These changes relative to our European findings reflect, of course, the longer time period under investigation as well as the more dramatic structural changes for the Chinese economies during the sample period. The stability aspects present a problem for the frequently used procedure for dynamic analysis of discretizing the state space into a finite number of cells and estimating Markov transition matrices. We therefore prefer to use the HM index in this respect.

We estimate the degree of persistence in comparative advantage using Galtonian regressions. Balancing the advantages of an improvement in fit against the disadvantages of extending the base period lag, we argue that a five year lag is a suitable lag choice. Based on our regression results, there is some evidence that the dispersion of the distribution diminishes over time for the three Chinese economies in the sample period. There does not seem to be a structural difference in the degree of persistence of comparative advantage for the Chinese economies. We estimate five-year difference Markov transition matrices for the deciles of the distribution using a maximum likelihood estimator. For all three countries persistence is highest at the extreme ends of the distribution, that is at the first and particularly at the tenth decile. Estimating mobility indic es for the Chinese economies for all years in the sample again does not reveal a structural difference in the degree of persistence of comparative advantage. The ergodic distribution for all three Chinese economies implies a gradual shift away from the lower towards the higher end of the decile distribution. We take it as an indication that the rapid increase in per capita income level for the Chinese economies developed in parallel with the degree of specialization according to comparative advantage.

Acknowledging the principal disadvantages of estimating Markov matrices and the practical disadvantages of estimating stochastic kernels, we advocate a novel approach in applied trade analysis which is practical, easy to use, and avoids the discretization problem. Our method is based on probability-probability (p-p) plots. These plots can be made quite easily, even with just limited data available, and can be used to define an index, taking on values between zero and one, which compares the two distributions. As the objective of this index is to determine to what extent the probability mass of one distribution function is in harmony with another distribution function, we label it the Harmonic-Mass (HM) index. Benchmarking the evolution of the HM index relative to all other countries in the world and to the country itself in time, indicates drastic structural change in China, particularly in 1980 and 1985, a more modest, related structural change in Taiwan in the mid 1980s, and a rather peculiar peak in 
China in 1972. In sharp contrast to the standard mobility indices, therefore, the HM index is useful for identifying structural change or data peculiarities. In particular, we relate the 1972 peak to the disappearance of the non-identified products category in that year, the 1980 peak to China's start of opening up to international trade flows, and the 1985 peak to the inflow of foreign direct investments and structural changes in the composition of export flows, related to an increase in unskilled-labor intensive exports, the rise in technology intensive exports (associated with intermediate goods and foreign direct investments), and the drastic relative decline in primary product exports. At the same time, Taiwan's unskilled-labor intensive exports start to fall and its technology intensive exports start to rise even more rapidly, as also reflected by a peak in its HM index. We argue, therefore, that Taiwan benefited considerably from China's opening up to international trade flows as it eased the transition from unskilledlabor intensive exports towards technology intensive exports.

At the sector level, China's stronghold in primary products gradually reduced and its high grip on unskilled-labor intensive products increased, as did its grip on natural resource intensive products and human-capital intensive products in the 1990s. Not surprisingly, Hong Kong has no sectors with a comparative advantage in the primary products or natural resource intensive groups throughout the period. Hong Kong's comparative advantage is remarkably concentrated at virtually all unskilled-labor intensive products, with a shift towards technology intensive products over time. Taiwan's focus has shifted most drastically. Its position in primary products virtually disappeared. Its position in unskilled-labor intensive products peaked in the $1980 \mathrm{~s}$, as did its position in natural resource intensive products, although at a much lower level. Most importantly, however, Taiwan has shifted towards technology intensive products throughout the period. Taiwan, therefore, appears to be the most specialized of the three Chinese economies. As explained in the introduction, however, Hong Kong's reported comparative advantage to a substantial extent reflects developments in China's comparative advantage as a result of its entrepôt role. Hong Kong's true comparative advantage may therefore more closely resemble Taiwan's than reflected in our analysis. 


\section{References}

Anderson, T.W., and L.A. Goodman (1957), "Statistical inference about Markov chains," The Annals of Mathematical Statistics, 28 (1), 89-110.

Amiti, M. (1999), “Specialization patterns in Europe," Weltwirtschaftliches Archiv, 135, 573593.

Balassa, B. (1965), "Trade liberalization and 'revealed' comparative advantage," The Manchester School of Economic and Social Studies 33: 92-123.

Bojnec, S. (2001), “Trade and revealed comparative advantage measures: regional and central and east European agricultural trade," Eastern European Economics, 39 (2), 72-98.

Bowen, H. P., A. Hollander, and J.-M. Viaene (1998), Applied international trade analysis, MacMillan, London.

Chotikapanich, D., and W. Griffiths (2000), “On calculation of the extended Gini coefficient," Working Paper No. 2000-1, University of New England.

Deckers, W. (2004), "China, globalisation and the World Trade Organisation," Journal of Contemporary Asia 34 (1): 102-119.

Feenstra, R. C. (2000), World trade flows; 1980 - 1997, Institute of Governmental Affairs, University of California, Davis.

Feenstra, R.C., W. Hai, W.T. Woo, and S. Yao (1999), "Discrepancies in international trade data: an application to China-Hong Kong entrepôt trade," American Economic Review, May: 338-343.

Feenstra, R., R. Lipsey, and H. Bowen (1997), "World trade flows, 1970 - 1992, with production and tariff data," NBER Working Paper No. 5910.

Fung, K.C. (1998), "Accounting for Chinese trade: some national and regional considerations," in: R.E. Baldwin, J.D. Richardson, and R.E. Lipsey (eds.), Geography and ownership, NBER and University of Chicago Press, 173-200.

Fung, K.C., and L.J. Lau (2001), "New estimates of the United States - China bilateral trade balances," Journal of the Japanese and International Economies 15 (1): 102-130.

Fertö, I., and L.J. Hubbard (2003), "Revealed comparative advantage and competitiveness in Hungarian Agri-food sectors," World Economy, 26 (2), 247-259.

Geweke, J., R.C. Marshall, and G.A. Zarkin (1986), "Mobility indices in continuous time Markov chains," Econometrica 54: 1407 - 1423.

Hart, P. (1995), "Galtonian regression across countries and the convergence of productivity", Oxford Bulletin of Economics and Statistics, 57, No. 3, 287 - 293.

Hillman, A.L. (1980), "Observations on the relation between 'revealed comparative advantage' and comparative advantage as indicated by pre-trade relative prices," Weltwirtschaftliches Archiv, 116, No. 2, 315 - 321. 
Hinloopen, J., and C. van Marrewijk (2001), "On the empirical distribution of the Balassa index", Weltwirtschaftliches Archiv, 137, No. 1, 1- 35.

Hinloopen, J., and C. van Marrewijk (2004a), "Empirical relevance of the Hillman condition and comparative advantage," Tinbergen Institute Working Paper 04-019/2.

Hinloopen, J., and C. van Marrewijk (2004b), "Measuring trade dynamics," Tinbergen Institute, mimeo.

Hinloopen, J., and C. van Marrewijk (2004c), "P-P plots and the Harmonic Mass index: an application to comparative advantage," Tinbergen Institute, mimeo.

Hinloopen, J., and C. van Marrewijk (2004d), "Sectors, competition, comparative advantage, and the HM index," Tinbergen Institute, mimeo.

Holmgren, E.B. (1995), “The P-P plot as a method of comparing treatment effects,” Journal of the American Statistical Association, 90 (429), 360-365.

Lerman, R.I., and S. Yitzhaki (1989), "Improving the accuracy of estimates of Gini coefficients," Journal of Econometrics 42, 43-47.

Liesner, H.H. (1958), “The European Common Market and British industry,” Economic Journal 68: 302-316.

Marchese, S., and F. Nadal De Simone (1989), "Monotonicity of indices of 'revealed' comparative advantage: empirical evidence on Hillman's condition," Weltwirtschaftiches Archiv 125, 158 - 167.

Porter, M. (1990), The competitive advantage of nations, MacMillan, London.

Proudman, J. and S. Redding (1998), "Persistence and mobility in international trade," in: J. Proudman and S. Redding (eds.), Openness and growth, Bank of England, Chapter 2.

Proudman, J. and S. Redding (2000), "Evolving patterns of international trade," Review of International Economics, 8 (3), pp. 373-396.

Quah, D.T. (1996), "Empirics for economic growth and convergence," European Economic Review, 90, pp. 1353-1375.

Quah, D.T. (1997), "Empirics for growth and distribution: stratification, polarization, and convergence clubs," Journal of Economic Growth, 2, pp. 27-59.

Redding, S. (2002), “Specialization dynamics," Journal of International Economics, 58, pp. 299-334.

Tse, A, S. Lym, O. Yau, J. Lee, and R. Chow (2003), "Market orientation and business performance in a Chinese business environment," Journal of Business Research 56 (3): 227-239.

Vollrath, T. L. (1991), "A theoretical evaluation of alternative trade intensity measures of revealed comparative advantage", Weltwirtschaftliches Archiv, 127, pp. 265 - 280.

Yoshimatsu, H. (2002), "Social demand, state capability and globalization: Japan - China trade friction over safeguards," Pacific Review 15 (3): 381-408. 


\section{Appendix I Data}

The primary source for our trade data are the World Import and Export data as provided by the Center for International Data, University of California, Davis (CID/UCD). We have merged two separate data sets issued by CID/UCD, the first covering the years 1970 through 1993 (see Feenstra, Lipsey and Bowen, 1997) and the second covering the years 1980 through 1997 (see Feenstra, 2000). For the overlapping years the data from the latter source are used.

The data set contains bilateral trade flows between 183 trading partners, including n.e.s. (not elsewhere specified) regions for trade flows that could not be classified further than within a broad geographical region (such as "Middle East", or "North Africa"), an "Areas n.e.s." region for trade flows that cannot be attributed to any country or to any of the used broad geographical regions but that do come from a well-defined geographical region, and an "Unknown Partner" category for trade flows that could not be attributed at all due to various reasons (see Feenstra, 2000). This leaves us with 167 genuine countries.

The bilateral trade flows are decomposed into 1,249 sectors, comprising 747 genuine 4-digit sectors, based on SITC (Standard International Trade Classification), rev. 2. The remaining 502 sectors refer to aggregates at the 1-, 2-, or 3-digit level, and a "Non-identified products" category. Accordingly, restricting attention to lower levels of aggregation, which has the advantage of enabling more detailed analysis, comes at a cost in terms of a reduction in total trade covered by the data. In particular, the 4-digit subset contains $60.39 \%$ of all trade, the 3digit subset covers $99.46 \%$ of all trade, and the 2-digit subset comprises $99.67 \%$ of all trade (see Hinloopen and Van Marrewijk, 2004a). The loss in trade coverage going from the 3-digit level to the 4-digit level is therefore quite substantial.

The data were first compiled by Statistics Canada and made available through the CID/UCD (see Feenstra, 2000). The former makes use of various sources (according to Statistics Canada $87 \%$ of all trade flows is based on independent sources of both imports and exports, while $98 \%$ is based on reports of at least one side of trade), yielding a rather complete coverage of world trade flows. The CID/UCD transforms the data such that trade flows for all years, all countries, and all industry groups are consistent and presented in a unified manner.

Each observation in the raw data consists of four entries: importing country, exporting country, sector, and size of the trade flow (in 1,000 US \$). The data are thus classified according to the importing country. This is not to say that the data are based on import sources only, as explained above. After merging the two separate datasets we have created a 
second dataset by "inverting" the data, in that all trade is classified according to the exporting country.

Non-trade data sources used for information regarding the Chinese economies are:

- World Bank Development Indicators CD-Rom (2002) for

- GDP in constant 1995 US dollar (China, Hong Kong, and world)

- Export as a percent of GDP (China and Hong Kong)

- Population (China and Hong Kong)

- Maddison (2001), The World Economy: A Millennial Perspective, OECD, for

- Population (Taiwan)

- Taiwan Statistical Office www.stat.gov.tw for

- GDP in constant 1996 NT dollar (Taiwan)

- Export as a percent of GDP (Taiwan)

Taiwan's index of GDP per capita relative to the world average was calculated as follows. First, Taiwan's GDP in constant 1996 NT dollar was divided by the population. The result was expressed as an index $(1960=100)$. Second, world GDP per capita in constant 1995 US dollar was expressed as an index $(1960=100)$. Third, the ratio of these two indexes was expressed as an index $(1960=100)$. 


\section{Appendix II Additional information}

This appendix provides additional information and figures on the dynamics of Chinese comparative advantage. See the paper for discussion, explanation, methodology, and details.

Figure Al Geographic distribution, highest export markets in 1970 (\% of total)

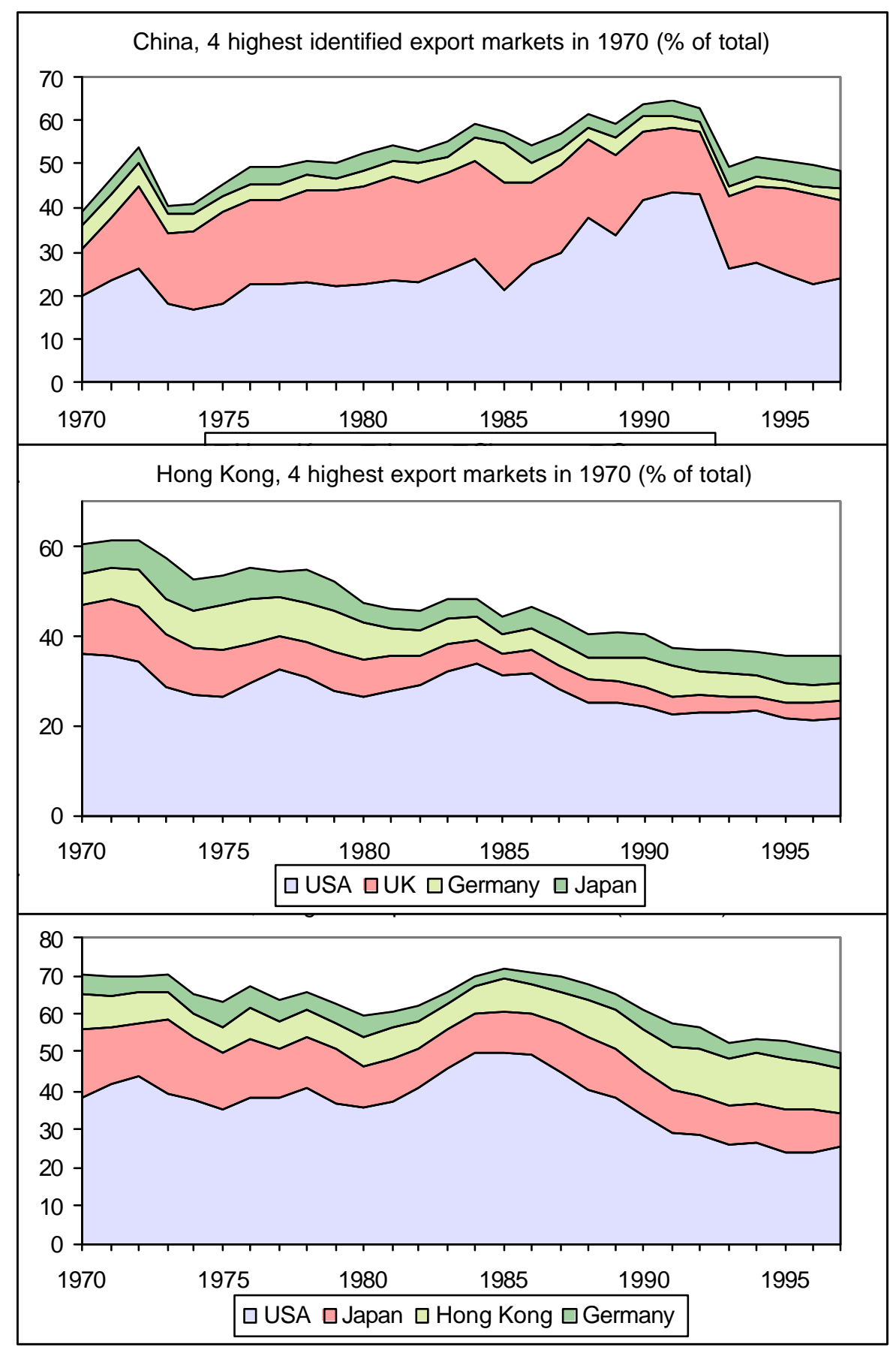


Table A1 Largest export markets in 1970 (\% of total exports)

\begin{tabular}{lr|lr|lr}
\hline \hline China & export & Hong Kong & export & Taiwan & export \\
\hline Hong Kong & 19.9 & USA & 36.4 & USA & 38.4 \\
Japan & 10.9 & UK & 10.7 & Japan & 17.5 \\
Singapore & 5.4 & Germany & 6.7 & Hong Kong & 9.4 \\
Germany & 3.3 & Japan & 6.7 & Germany & 5.4 \\
Malaysia & 3.3 & Singapore & 3.8 & Canada & 3.5 \\
UK & 3.0 & Canada & 2.9 & Singapore & 2.9 \\
France & 3.0 & Australia & 2.9 & South Korea & 2.4 \\
Italy & 2.7 & Indonesia & 2.6 & Thailand & 2.0 \\
Sri Lanka & 2.2 & Taiwan & 2.0 & Malaysia & 1.8 \\
Tanzania & 1.6 & Sweden & 1.7 & Vietnam & 1.8 \\
& & & &
\end{tabular}

Table A2 Four highest identified 4-digit sectors in 1970, value

\begin{tabular}{r|lrr}
\hline \hline \multirow{2}{*}{ SITC } & \multicolumn{3}{c}{ export (\% of total) } \\
& China & 1970 & 1997 \\
\hline 0422 & Rice semi-milled or wholly milled, broken rice & 3.702 & 0.128 \\
2613 & Raw silk (not thrown) & 3.124 & 0.152 \\
6522 & Cotton fabrics, woven, bleach. merceriz. dyed, printed & 2.931 & 1.243 \\
2919 & Other materials of animal origin, n.e.s & 2.929 & 0.364 \\
\hline & Hong Kong & & \\
\hline 8999 & Manufactured goods, n.e.s. & 7.213 & 0.635 \\
8942 & Children's toys, indoor games, etc. & 6.312 & 6.357 \\
8429 & Other outer garments of textile fabrics & 5.712 & 2.038 \\
8451 & Jerseys, pull-overs, twin sets, cardigans, knitted & 5.037 & 2.217 \\
\hline & Taiwan & 5.973 & 0.031 \\
\hline 0565 & Vegetables, prepared or preserved, n.e.s. & 5.071 & 0.083 \\
6342 & Plywood consisting of sheets of wood & 4.241 & 0.049 \\
6521 & Cotton fabrics, woven, unbleached, not mercerized & 3.859 & 0.537 \\
8451 & Jerseys, pull-overs, twin sets, cardigans, knitted & &
\end{tabular}


Figure A2 Relative developments for 4 highest 4-digit sectors in 1970, value

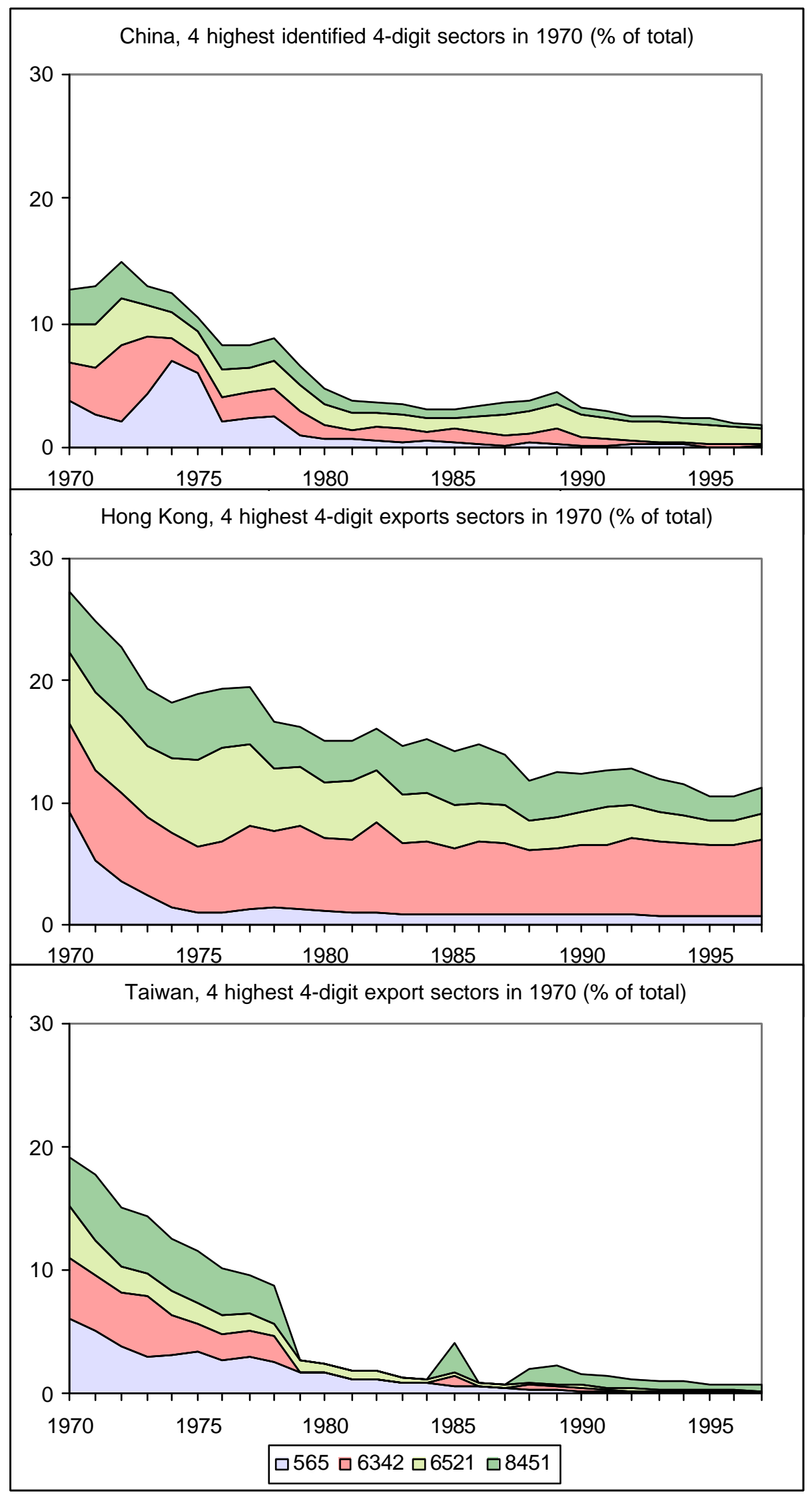


Table A3a. The empirical cumulative probability density function of the Balassa index for China, all sample years (1970-1997). ${ }^{a}$

\begin{tabular}{|c|c|c|c|c|c|c|c|c|c|c|c|c|c|c|}
\hline $\begin{array}{r}\text { Year } \\
\text { indicator }\end{array}$ & 1970 & 1971 & 1972 & 1973 & 1974 & 1975 & 1976 & 1977 & 1978 & 1979 & 1980 & 1981 & 1982 & 1983 \\
\hline p-1 & 0.003 & 0.003 & 0.004 & 0.002 & 0.001 & 0.003 & 0.003 & 0.002 & 0.003 & 0.001 & 0.002 & 0.002 & 0.001 & 0.002 \\
\hline p-2.5 & 0.007 & 0.007 & 0.009 & 0.006 & 0.003 & 0.006 & 0.005 & 0.006 & 0.008 & 0.003 & 0.004 & 0.004 & 0.005 & 0.005 \\
\hline p-5 & 0.013 & 0.014 & 0.018 & 0.009 & 0.010 & 0.011 & 0.014 & 0.013 & 0.013 & 0.009 & 0.009 & 0.008 & 0.008 & 0.010 \\
\hline $\mathrm{p}-10$ & 0.022 & 0.032 & 0.032 & 0.017 & 0.022 & 0.024 & 0.031 & 0.034 & 0.032 & 0.025 & 0.024 & 0.020 & 0.022 & 0.022 \\
\hline p-25 & 0.087 & 0.103 & 0.134 & 0.074 & 0.079 & 0.088 & 0.113 & 0.123 & 0.122 & 0.116 & 0.107 & 0.105 & 0.097 & 0.105 \\
\hline p-50 & 0.457 & 0.697 & 0.641 & 0.441 & 0.471 & 0.463 & 0.628 & 0.553 & 0.541 & 0.543 & 0.541 & 0.503 & 0.453 & 0.479 \\
\hline p-75 & 1.864 & 2.491 & 2.428 & 1.792 & 1.856 & 2.066 & 2.581 & 2.374 & 2.229 & 2.000 & 2.075 & 1.936 & 1.846 & 2.140 \\
\hline p-90 & 8.338 & 12.776 & 7.989 & 4.831 & 5.629 & 5.810 & 6.193 & 6.142 & 7.451 & 7.169 & 7.520 & 6.430 & 6.586 & 7.523 \\
\hline p-95 & 16.290 & 22.605 & 17.895 & 11.407 & 12.894 & 13.789 & 15.057 & 14.701 & 13.554 & 14.107 & 15.991 & 12.807 & 12.080 & 15.662 \\
\hline p-97.5 & 26.081 & 32.147 & 29.118 & 16.154 & 20.833 & 22.600 & 23.988 & 25.228 & 24.017 & 24.842 & 24.601 & 21.221 & 19.391 & 26.446 \\
\hline p-99 & 56.682 & 73.740 & 41.347 & 22.866 & 31.617 & 38.369 & 29.833 & 45.504 & 36.379 & 37.036 & 39.772 & 31.999 & 30.262 & 40.706 \\
\hline Max & 81.390 & 96.961 & 109.788 & 79.445 & 83.999 & 92.750 & 121.664 & 131.557 & 103.303 & 112.140 & 89.644 & 79.361 & 74.032 & 65.148 \\
\hline Mean & 3.457 & 4.366 & 3.584 & 2.326 & 2.651 & 2.936 & 3.331 & 3.395 & 3.163 & 3.384 & 3.214 & 2.734 & 2.584 & 3.159 \\
\hline Std & 9.745 & 11.742 & 9.570 & 6.678 & 7.839 & 8.566 & 10.282 & 10.915 & 8.634 & 10.449 & 9.190 & 7.016 & 6.727 & 7.953 \\
\hline Obs & 470 & 501 & 518 & 541 & 552 & 552 & 557 & 566 & 577 & 578 & 570 & 582 & 564 & 577 \\
\hline Sk & 2272 & 2237 & 3253 & 4894 & 4266 & 3749 & 5832 & 5558 & 4331 & 4798 & 3795 & 3584 & 3619 & 2171 \\
\hline Kur & 22172 & 20625 & 54772 & 108358 & 73192 & 57836 & 137732 & 119832 & 85465 & 84286 & 54802 & 63186 & 59346 & 17188 \\
\hline Nor & 24444 & 22863 & 58025 & 113252 & 77458 & 61585 & 143564 & 125391 & 89796 & 89084 & 58597 & 66770 & 62965 & 19359 \\
\hline$B I-1$ & 0.604 & 0.553 & 0.562 & 0.632 & 0.611 & 0.609 & 0.569 & 0.588 & 0.605 & 0.611 & 0.607 & 0.612 & 0.638 & 0.622 \\
\hline$B I-2$ & 0.755 & 0.687 & 0.699 & 0.776 & 0.755 & 0.743 & 0.702 & 0.721 & 0.735 & 0.751 & 0.744 & 0.758 & 0.752 & 0.737 \\
\hline$B I-4$ & 0.851 & 0.810 & 0.813 & 0.884 & 0.875 & 0.853 & 0.835 & 0.841 & 0.820 & 0.832 & 0.833 & 0.842 & 0.851 & 0.828 \\
\hline$B I-8$ & 0.896 & 0.874 & 0.900 & 0.926 & 0.931 & 0.922 & 0.917 & 0.915 & 0.903 & 0.908 & 0.909 & 0.919 & 0.918 & 0.901 \\
\hline
\end{tabular}

${ }^{a}$ The Balassa index is based on annual bilateral export flows of 182 countries for the period 1970 through 1997; p- $z$ reports the Balassa index for the $z$-th percentile, for $z=1,2.5,5,10,25,50,75,90,95,97.5$, and 99; $\max =$ maximum; std $=$ standard deviation; obs $=$ number of observations; sk $=$ skewness, kur $=$ kurtosis; nor = normality; $B I-z$ reports the share of industries with a Balassa index lower than $z$, for $z=1,2,4,8$. 
Table A3a (continued). The empirical cumulative probability density function of the Balassa index for China, all sample years (1970 - 1997). ${ }^{a}$

\begin{tabular}{|c|c|c|c|c|c|c|c|c|c|c|c|c|c|c|}
\hline $\begin{array}{r}\text { year } \\
\text { indicator }\end{array}$ & 1984 & 1985 & 1986 & 1987 & 1988 & 1989 & 1990 & 1991 & 1992 & 1993 & 1994 & 1995 & 1996 & 1997 \\
\hline p-1 & 0.002 & 0.001 & 0.002 & 0.001 & 0.001 & 0.002 & 0.002 & 0.001 & 0.001 & 0.003 & 0.001 & 0.001 & 0.002 & 0.001 \\
\hline p-2.5 & 0.004 & 0.002 & 0.005 & 0.005 & 0.003 & 0.006 & 0.008 & 0.006 & 0.006 & 0.015 & 0.008 & .005 & 0.003 & 0.006 \\
\hline p-5 & 0.010 & 0.007 & 0.010 & 0.011 & 0.008 & 0.015 & 0.015 & 0.014 & 0.029 & 0.030 & 0.018 & 0.022 & 0.023 & 0.027 \\
\hline p-10 & 0.024 & 0.017 & 0.022 & 0.024 & 0.023 & 0.036 & 0.032 & 0.038 & 0.050 & 0.059 & 0.052 & 0.049 & 0.054 & 0.060 \\
\hline & 095 & 0.071 & 0.107 & 122 & 0.121 & 152 & 0.155 & 0.126 & 0.176 & 0.169 & 0.159 & 0.172 & 0.186 & 0.200 \\
\hline p-50 & 0.537 & 0.442 & 0.538 & 0.567 & 0.450 & 0.622 & 0.574 & 0.564 & 0.555 & 0.594 & 0.570 & 0.540 & 0.575 & 0.598 \\
\hline p-75 & 2.865 & 2.675 & 3.155 & 3.190 & 1.823 & 2.129 & 1.958 & 1.791 & 1.924 & 1.911 & 2.039 & 2.137 & 2.076 & 2.064 \\
\hline p-90 & 9.805 & 12.282 & 14.124 & 12.421 & 5.462 & 5.450 & 4.548 & 4.469 & 4.206 & 4.457 & 4.329 & 4.310 & 4.438 & 4.254 \\
\hline p-95 & .055 & 30.585 & 26.127 & 24.768 & 9.262 & 10.490 & 8.354 & 7.173 & 7.103 & 6.982 & 6.832 & 6.413 & 6.256 & 6.158 \\
\hline p-97.5 & .948 & 43.250 & 42.916 & 39.758 & 12.062 & 14.423 & 10.981 & 9.191 & 8.661 & 8.637 & 8.260 & 8.556 & 8.146 & 7.714 \\
\hline p-99 & .370 & 64.718 & 60.203 & 51.946 & 15.514 & 16.850 & 13.942 & 13.352 & 11.312 & 10.975 & 10.341 & 10.493 & 10.578 & 10.810 \\
\hline Max & 75.848 & 77.032 & 77.471 & 72.481 & 46.408 & 44.384 & 39.466 & 39.319 & 35.969 & 25.634 & 24.097 & 22.164 & 22.412 & 19.204 \\
\hline Mean & 4.023 & 4.594 & 4.844 & 4.422 & 1.917 & 2.129 & 1.862 & 1.713 & 1.663 & 1.629 & 1.634 & 1.592 & 1.609 & 1.572 \\
\hline Std & 9.708 & 11.388 & 11.351 & 10.276 & 4.088 & 4.303 & 3.862 & 3.536 & 3.138 & 2.811 & 2.763 & 2.511 & 2.458 & 2.287 \\
\hline Obs & 555 & 546 & 560 & 573 & 459 & 459 & 457 & 461 & 469 & 467 & 469 & 476 & 471 & 470 \\
\hline Sk & 1493 & 1307 & 1280 & 1338 & 2334 & 1903 & 2263 & 2488 & 2348 & 1417 & 1299 & 951 & 946 & 670 \\
\hline Kur & & 5502 & 5255 & 5661 & 460 & 1088 & 30953 & 37779 & 38485 & 13215 & 11554 & 6149 & 7026 & 2889 \\
\hline Nor & 9109 & 6809 & 6535 & 6999 & 40794 & 25991 & 33216 & 40267 & 40833 & 14632 & 12852 & 7101 & 7972 & 3559 \\
\hline$B I-1$ & 0.589 & 0.597 & 0.575 & 0.569 & 0.632 & 0.606 & 0.619 & 0.646 & 0.633 & 0.632 & 0.620 & 0.618 & 0.607 & 0.594 \\
\hline$B I-2$ & 0.694 & 0.709 & 0.686 & 0.689 & 0.765 & 0.741 & 0.755 & 0.772 & 0.755 & 0.758 & 0.740 & 0.742 & 0.735 & 0.743 \\
\hline$B I-4$ & 0.802 & 0.813 & 0.780 & 0.796 & 0.871 & 0.856 & 0.871 & 0.887 & 0.889 & 0.893 & 0.885 & 0.880 & 0.875 & 0.885 \\
\hline$B I-8$ & 0.876 & 0.859 & 0.854 & 0.857 & 0.935 & 0.937 & 0.945 & 0.952 & 0.964 & 0.964 & 0.966 & 0.968 & 0.968 & 0.977 \\
\hline
\end{tabular}

\footnotetext{
${ }^{a}$ The Balassa index is based on annual bilateral export flows of 182 countries for the period 1970 through 1997; p- $z$ reports the Balassa index for the $z$-th percentile, for $z=1,2.5,5,10,25,50,75,90,95,97.5$, and 99; $\max =$ maximum; std $=$ standard deviation; obs $=$ number of observations; sk $=$ skewness, kur $=$ kurtosis; nor = normality; $B I-z$ reports the share of industries with a Balassa index lower than $z$, for $z=1,2,4,8$.
} 
Table A3b. The empirical cumulative probability density function of the Balassa index for Taiwan, all sample years (1970-1997). ${ }^{a}$

\begin{tabular}{|c|c|c|c|c|c|c|c|c|c|c|c|c|c|c|}
\hline $\begin{array}{r}\text { Year } \\
\text { indicator }\end{array}$ & 1970 & 1971 & 1972 & 1973 & 1974 & 1975 & 1976 & 1977 & 1978 & 1979 & 1980 & 1981 & 1982 & 1983 \\
\hline p-1 & 0.003 & 0.002 & 0.001 & 0.003 & 0.001 & 0.003 & 0.002 & 0.001 & 0.001 & 0.001 & 0.001 & 0.000 & 0.000 & 0.001 \\
\hline & 0.008 & 008 & 0.008 & 0.004 & 0.004 & 0.005 & 0.005 & 0.003 & 0.003 & 0.001 & 0.001 & 0.001 & 0.001 & 0.001 \\
\hline-5 & 0.021 & 0.014 & 0.014 & 0.008 & 0.010 & 0.011 & 0.009 & 0.008 & 0.006 & 0.003 & 0.004 & .002 & 0.002 & 0.004 \\
\hline $\mathrm{p}-10$ & 0.032 & 0.030 & 0.028 & 0.023 & 0.025 & 0.028 & 0.018 & 0.017 & 0.014 & 0.009 & 0.011 & 0.007 & 0.008 & 0.011 \\
\hline p-25 & 0.111 & 0.120 & 0.087 & 0.099 & 0.089 & 0.117 & 0.097 & 0.089 & 0.079 & 0.077 & 0.078 & 0.070 & 0.072 & 0.085 \\
\hline p-50 & 30 & 0.398 & 354 & 0.353 & 0.362 & 0.386 & 0.383 & 0.377 & 0.366 & 0.369 & 0.351 & 0.366 & 0.360 & 0.390 \\
\hline p-75 & 2.166 & 2.005 & & 1.772 & 1.916 & 1.872 & 1.885 & 1.845 & 1.622 & 1.464 & 1.555 & 1.434 & 1.527 & 1.500 \\
\hline 90 & 250 & 6.031 & 4.458 & 4.503 & 5.877 & 5.254 & 5.100 & 5.494 & 5.474 & 4.166 & 4.590 & 4.145 & 4.448 & 4.689 \\
\hline 95 & 125 & 10.476 & 6.804 & 7.922 & 9.116 & 9.883 & 7.998 & 9.054 & 8.751 & 8.146 & 8.587 & 7.636 & 8.062 & 7.970 \\
\hline 97.5 & 674 & 16.621 & 12.846 & 11.524 & 6.060 & 15.050 & 3.169 & 13.318 & 13.351 & 1.974 & 12.370 & 2.122 & 1.151 & 0.639 \\
\hline p-99 & .015 & .611 & 15.550 & 13.458 & 16.608 & 17.454 & 15.187 & 21.254 & 17.051 & 18.124 & 18.977 & 18.941 & 17.201 & 16.484 \\
\hline Max & 4.909 & 154.802 & 90.835 & 20.254 & 40.646 & 25.524 & 54.911 & 81.302 & 65.740 & 32.191 & 35.158 & 38.579 & 38.956 & 30.562 \\
\hline Mean & 926 & 293 & 1.857 & 1.622 & 12 & 1.863 & 1.866 & 2.055 & 1.875 & 1.636 & 1.718 & 1.695 & 1.655 & 1.630 \\
\hline Std & 14.724 & 13.346 & 5.706 & 3.046 & 3.938 & 3.604 & 4.125 & 5.515 & 4.507 & 3.534 & 3.738 & 3.830 & 3.675 & 3.350 \\
\hline Obs & 418 & 454 & 469 & 460 & 463 & 469 & 493 & 504 & 501 & 400 & 392 & 398 & 395 & 384 \\
\hline Sk & 4439 & 6033 & 9134 & 734 & 1338 & 782 & 3137 & 5898 & 4423 & 1207 & 1210 & 1600 & 1727 & 1148 \\
\hline Kur & 0390 & 144448 & 29694 & 2294 & 12342 & 2460 & 76091 & 204090 & 147835 & 8828 & 9363 & 17426 & 22295 & 9151 \\
\hline Nor & 104829 & 150480 & 438828 & 3028 & 13680 & 3242 & 79228 & 209988 & 152258 & 10035 & 10572 & 19026 & 24022 & 10299 \\
\hline$B I-1$ & 0.636 & 0.654 & 0.691 & 0.707 & 0.680 & 0.691 & 0.675 & 0.673 & 0.677 & 0.700 & 0.689 & 0.686 & 0.691 & 0.693 \\
\hline$B I-2$ & 739 & 0.747 & 0.761 & 0.763 & 0.758 & 0.755 & 0.755 & 0.758 & 0.778 & 0.795 & 0.793 & 0.799 & 0.787 & 0.789 \\
\hline$B I-4$ & 0.830 & 0.841 & 0.866 & 0.861 & 0.860 & 0.857 & 0.862 & 0.863 & 0.878 & 0.895 & 0.890 & 0.889 & 0.889 & 0.883 \\
\hline BI-8 & 0.897 & 0.930 & 0.962 & 0.952 & 0.942 & 0.938 & 0.949 & 0.944 & 0.938 & 0.945 & 0.944 & 0.950 & 0.947 & 0.951 \\
\hline
\end{tabular}

${ }^{\mathrm{a}}$ The Balassa index is based on annual bilateral export flows of 182 countries for the period 1970 through 1997; p- $z$ reports the Balassa index for the $z$-th percentile, for $z=1,2.5,5,10,25,50,75,90,95,97.5$, and 99; $\max =$ maximum; std $=$ standard deviation; obs $=$ number of observations; sk $=$ skewness, kur $=$ kurtosis; nor = normality; $B I-z$ reports the share of industries with a Balassa index lower than $z$, for $z=1,2,4,8$. 
Table A3b (continued). The empirical cumulative probability density function of the Balassa index for Taiwan, all sample years (1970 - 1997). ${ }^{a}$

\begin{tabular}{|c|c|c|c|c|c|c|c|c|c|c|c|c|c|c|}
\hline $\begin{array}{r}\text { year } \\
\text { indicator }\end{array}$ & 1984 & 1985 & 1986 & 1987 & 1988 & 1989 & 1990 & 1991 & 1992 & 1993 & 1994 & 1995 & 1996 & 1997 \\
\hline p-1 & 0.001 & 0.000 & 0.001 & 0.000 & 0.001 & 0.000 & 0.001 & 0.002 & 0.001 & 0.001 & 0.001 & 0.000 & 0.001 & 0.000 \\
\hline $\mathrm{p}-2.5$ & 0.002 & 0.001 & 0.002 & 0.001 & 0.003 & 0.001 & 0.003 & 0.003 & 0.002 & 0.002 & 0.002 & 0.001 & 0.001 & 0.001 \\
\hline p-5 & 0.003 & 0.003 & 0.004 & 0.002 & 0.005 & 0.005 & 0.006 & 0.006 & 0.006 & 0.005 & 0.004 & 0.004 & 0.003 & 0.003 \\
\hline p-10 & 0.012 & 0.013 & 0.012 & 0.010 & 0.015 & 0.012 & 0.015 & 0.016 & 0.017 & 0.016 & 0.011 & 0.014 & 0.012 & 0.009 \\
\hline p-25 & 0.088 & 0.084 & 0.072 & 0.066 & 0.055 & 0.062 & 0.081 & 0.082 & 0.080 & 0.084 & 0.067 & 0.074 & 0.065 & 0.056 \\
\hline p-50 & 0.375 & 0.434 & 0.334 & 0.301 & 0.309 & 0.333 & 0.368 & 0.370 & 0.375 & 0.393 & 0.334 & 0.382 & 0.307 & 0.286 \\
\hline p-75 & 1.428 & 1.810 & 1.317 & 1.267 & 1.191 & 1.055 & 1.254 & 1.245 & 1.163 & 1.287 & 1.005 & 1.146 & 0.934 & 0.895 \\
\hline p-90 & 4.002 & 4.728 & 3.867 & 3.529 & 2.994 & 3.083 & 3.458 & 3.714 & 3.444 & 3.630 & 2.615 & 3.049 & 2.250 & 2.170 \\
\hline p-95 & 7.574 & 7.661 & 6.065 & 6.346 & 4.715 & 4.779 & 5.637 & 5.849 & 5.955 & 6.609 & 3.915 & 6.107 & 3.465 & 3.608 \\
\hline p-97.5 & 10.841 & 10.768 & 8.313 & 7.481 & 6.931 & 6.291 & 7.517 & 8.115 & 10.361 & 16.684 & 5.884 & 10.237 & 5.369 & 5.392 \\
\hline p-99 & 14.213 & 14.108 & 11.003 & 10.683 & 11.584 & 10.309 & 14.664 & 20.253 & 25.461 & 30.624 & 9.576 & 25.939 & 6.734 & 8.628 \\
\hline Max & 30.710 & 50.828 & 22.523 & 15.024 & 42.734 & 37.487 & 46.400 & 39.894 & 41.352 & 39.427 & 30.013 & 37.543 & 31.829 & 25.261 \\
\hline Mean & 1.555 & 1.788 & 1.324 & 1.196 & 1.181 & 1.099 & 1.400 & 1.440 & 1.582 & 1.748 & 1.028 & 1.520 & 0.942 & 0.933 \\
\hline Std & 3.192 & 4.125 & 2.510 & 2.192 & 2.862 & 2.421 & 3.655 & 3.591 & 4.344 & 4.770 & 2.327 & 4.171 & 2.339 & 2.308 \\
\hline Obs & 387 & 408 & 393 & 409 & 545 & 519 & 545 & 550 & 535 & 542 & 510 & 509 & 467 & 475 \\
\hline $\mathrm{Sk}$ & 1213 & 3635 & 905 & 645 & 6067 & 5530 & 6093 & 3951 & 3305 & 2609 & 4203 & 2898 & 5977 & 3888 \\
\hline Kur & 10844 & 93069 & 5939 & 2119 & 211424 & 224729 & 175580 & 70817 & 41197 & 22731 & 99761 & 32177 & 195314 & 73841 \\
\hline Nor & 12057 & 96704 & 6844 & 2764 & 217491 & 230259 & 181673 & 74768 & 44502 & 25340 & 103963 & 35075 & 201290 & 77728 \\
\hline$B I-1$ & 0.690 & 0.659 & 0.700 & 0.724 & 0.730 & 0.740 & 0.706 & 0.707 & 0.720 & 0.714 & 0.745 & 0.723 & 0.762 & 0.773 \\
\hline$B I-2$ & 0.798 & 0.762 & 0.817 & 0.824 & 0.831 & 0.844 & 0.828 & 0.825 & 0.830 & 0.821 & 0.863 & 0.843 & 0.887 & 0.893 \\
\hline$B I-4$ & 0.897 & 0.870 & 0.903 & 0.912 & 0.934 & 0.934 & 0.908 & 0.904 & 0.914 & 0.906 & 0.951 & 0.925 & 0.955 & 0.962 \\
\hline$B I-8$ & 0.956 & 0.956 & 0.967 & 0.978 & 0.983 & 0.988 & 0.978 & 0.973 & 0.963 & 0.961 & 0.986 & 0.965 & 0.991 & 0.987 \\
\hline
\end{tabular}

${ }^{\mathrm{a}}$ The Balassa index is based on annual bilateral export flows of 182 countries for the period 1970 through 1997; p- $z$ reports the Balassa index for the $z$-th percentile, for $z=1,2.5,5,10,25,50,75,90,95,97.5$, and 99; $\max =$ maximum; std $=$ standard deviation; obs $=$ number of observations; sk $=$ skewness, kur $=$ kurtosis; nor $=$ normality; $B I-z$ reports the share of industries with a Balassa index lower than $z$, for $z=1,2,4,8$. 
Table A3c. The empirical cumulative probability density function of the Balassa index for Hong Kong, all sample years (1970 - 1997). ${ }^{a}$

\begin{tabular}{|c|c|c|c|c|c|c|c|c|c|c|c|c|c|c|}
\hline $\begin{array}{r}\text { Year } \\
\text { indicator }\end{array}$ & 1970 & 1971 & 1972 & 1973 & 1974 & 1975 & 1976 & 1977 & 1978 & 1979 & 1980 & 1981 & 1982 & 1983 \\
\hline p-1 & 0.003 & 0.003 & 0.002 & 0.002 & 0.002 & 0.001 & 0.001 & 0.002 & 0.002 & 0.001 & 0.001 & 0.001 & 0.001 & 0.001 \\
\hline $\mathrm{p}-2.5$ & 008 & 0.005 & 0.005 & 0.004 & 0.004 & 0.003 & 0.003 & 0.004 & 0.004 & 0.003 & 0.003 & 0.002 & .004 & 0.004 \\
\hline p-5 & 0.013 & 0.008 & 0.010 & 0.006 & 0.010 & 0.008 & 0.006 & 0.007 & 0.009 & 0.004 & 0.005 & 0.005 & 0.008 & 0.012 \\
\hline$p-10$ & 0.021 & 0.016 & 0.015 & 0.015 & 0.019 & 0.014 & 0.012 & 0.013 & 0.019 & 0.014 & 0.013 & 0.018 & 0.020 & 0.025 \\
\hline p-25 & 0.057 & 0.056 & 0.052 & 0.048 & 0.080 & 0.052 & 0.051 & 0.053 & 0.055 & 0.054 & 0.072 & 0.070 & 0.084 & 0.096 \\
\hline $\mathrm{p}-50$ & 216 & 0.220 & 0.219 & 0.227 & 0.292 & 0.258 & 0.217 & 0.245 & 0.224 & 0.258 & 0.310 & 0.360 & 0.359 & 0.380 \\
\hline p-75 & 1.010 & 0.918 & 0.935 & 0.929 & 1.086 & 1.098 & 1.050 & 1.070 & 1.070 & 1.033 & 1.171 & 1.213 & 1.287 & 1.284 \\
\hline p-90 & 87 & 5.595 & 5.168 & 5.635 & 5.998 & 130 & 4.718 & 5.203 & 384 & 4.936 & 4.895 & 5.140 & 5.029 & 4.954 \\
\hline p-95 & .031 & 2.724 & 4.904 & 14.104 & 16.496 & 15.565 & 12.164 & 12.603 & 10.398 & 8.484 & 8.246 & 8.574 & 8.034 & 7.926 \\
\hline p-97.5 & 864 & .160 & 326 & 16.809 & 21.291 & .392 & 18.029 & 17.480 & 16.877 & 4.351 & 3.269 & 1.191 & 12.010 & 1.295 \\
\hline p-99 & .977 & 20.235 & 18.416 & 16.905 & 21.336 & 23.225 & 22.961 & 20.407 & 23.014 & 23.412 & 21.248 & 18.040 & 17.159 & 14.619 \\
\hline Max & .591 & 44.873 & 34.365 & 31.161 & 28.170 & 26.364 & 25.053 & 27.622 & 29.765 & 27.049 & 26.390 & 23.613 & 22.756 & 21.305 \\
\hline Mean & 1.954 & 1.954 & 1.861 & 1.793 & 2.115 & 2.090 & 1.862 & 1.825 & 1.750 & 1.664 & 1.651 & 1.630 & 1.570 & 1.557 \\
\hline Std & 5.147 & 4.942 & 4.521 & 4.243 & 4.921 & 4.999 & 4.482 & 4.330 & 4.234 & 3.970 & 3.763 & 3.409 & 3.271 & 3.059 \\
\hline Obs & 397 & 394 & 398 & 418 & 418 & 428 & 423 & 426 & 426 & 434 & 431 & 430 & 435 & 428 \\
\hline Sk & 1547 & 1042 & 815 & 770 & 676 & 738 & 815 & 872 & 1091 & 1114 & 1085 & 900 & 1003 & 818 \\
\hline Kur & 3715 & 6453 & 2950 & 2379 & 1442 & 1671 & 2294 & 2862 & 5209 & 5249 & 5272 & 3745 & 4790 & 3159 \\
\hline Nor & 20262 & 7495 & 3765 & 3150 & 2118 & 2409 & 3109 & 3734 & 6299 & 6363 & 6357 & 4645 & 5793 & 3977 \\
\hline$B I-1$ & 0.748 & 0.759 & 0.754 & 0.761 & 0.739 & 0.738 & 0.740 & 0.737 & 0.735 & 0.742 & 0.724 & 0.726 & 0.708 & 0.708 \\
\hline$B I-2$ & 0.841 & 0.840 & 0.834 & 0.840 & 0.825 & 0.822 & 0.832 & 0.831 & 0.831 & 0.836 & 0.828 & 0.809 & 0.807 & 0.806 \\
\hline$B I-4$ & 0.882 & 0.883 & 0.884 & 0.890 & 0.878 & 0.886 & 0.887 & 0.885 & 0.890 & 0.889 & 0.886 & 0.884 & 0.883 & 0.881 \\
\hline BI-8 & 0.929 & 0.929 & 0.927 & 0.921 & 0.911 & 0.911 & 0.920 & 0.932 & 0.937 & 0.947 & 0.940 & 0.942 & 0.947 & 0.951 \\
\hline
\end{tabular}

${ }^{\mathrm{a}}$ The Balassa index is based on annual bilateral export flows of 182 countries for the period 1970 through 1997; p- $z$ reports the Balassa index for the $z$-th percentile, for $z=1,2.5,5,10,25,50,75,90,95,97.5$, and 99; $\max =$ maximum; std = standard deviation; obs = number of observations; sk $=$ skewness, kur $=$ kurtosis; nor $=$ normality; $B I-z$ reports the share of industries with a Balassa index lower than $z$, for $z=1,2,4,8$. 
Table A3c (continued). The empirical cumulative probability density function of the Balassa index for Hong Kong, all sample years (1970 - 1997). ${ }^{a}$

\begin{tabular}{|c|c|c|c|c|c|c|c|c|c|c|c|c|c|c|}
\hline $\begin{array}{r}\text { year } \\
\text { indicator }\end{array}$ & 1984 & 1985 & 1986 & 1987 & 1988 & 1989 & 1990 & 1991 & 1992 & 1993 & 1994 & 1995 & 1996 & 1997 \\
\hline p-1 & 0.001 & 0.001 & 0.001 & 0.001 & 0.001 & 0.001 & 0.001 & 0.001 & 0.001 & 0.000 & 0.001 & 0.000 & 0.000 & 0.000 \\
\hline & 0.003 & 0.004 & 0.002 & 0.002 & 0.003 & 0.001 & 0.002 & 0.002 & 0.002 & 0.001 & 0.002 & 0.001 & 0.003 & 0.001 \\
\hline p-5 & 0.011 & 0.008 & 0.007 & 0.006 & 0.006 & 0.011 & 0.006 & 0.006 & 0.005 & 0.005 & 0.005 & 0.005 & 0.006 & 0.004 \\
\hline p-10 & 0.023 & 0.021 & 0.021 & 0.018 & 0.018 & 022 & 0.018 & 0.018 & 0.018 & 0.014 & 0.015 & 0.013 & 0.016 & 0.017 \\
\hline p-25 & 0.078 & 0.099 & 0.094 & 0.077 & 0.086 & 0.092 & 0.086 & 0.089 & 0.101 & 0.100 & 0.107 & 0.100 & 0.109 & 0.093 \\
\hline p-50 & 52 & 426 & 0.391 & 0.402 & & 397 & 0.379 & 0.381 & 41 & 337 & 345 & 0.360 & 0.381 & 0.364 \\
\hline p-75 & 162 & 1.262 & 1.143 & 181 & 1.215 & 1.273 & 1.203 & 1.107 & 1.102 & 0.999 & 0.977 & 1.058 & 1.067 & 1.119 \\
\hline 90 & 501 & 4.309 & 3.923 & 3.725 & 3.545 & 3.367 & 3.341 & 3.313 & 3.078 & 2.932 & 2.683 & 2.713 & 2.802 & 2.877 \\
\hline p-95 & 7.278 & 6.723 & 6.761 & 6.194 & 5.654 & 5.549 & 5.417 & 5.018 & 4.108 & 3.874 & 3.822 & 3.738 & 3.850 & 3.671 \\
\hline 97.5 & .347 & .440 & 8.418 & 8.191 & 7.970 & 7.881 & 6.813 & 5.722 & 5.125 & 4.934 & 4.780 & 4.761 & 4.948 & 4.803 \\
\hline p-99 & 14.660 & 12.694 & 1.930 & 1.790 & 11.812 & 9.092 & 8.975 & 9.505 & 7.261 & 7.551 & 7.214 & 7.040 & 8.134 & 7.789 \\
\hline Max & .306 & 16.981 & 15.560 & 15.688 & 15.110 & 14.281 & 14.636 & 13.981 & 12.287 & 11.253 & 11.346 & 11.552 & 11.644 & 11.873 \\
\hline Mean & 1.442 & 1.433 & 1.306 & 1.250 & 1.205 & 1.171 & 1.113 & 1.060 & 0.973 & 0.937 & 0.914 & 0.938 & 0.962 & 0.950 \\
\hline Std & 2.804 & 2.665 & 2.414 & 2.266 & 2.127 & 1.988 & 1.914 & 1.781 & 1.561 & 1.484 & 1.436 & 1.486 & 1.500 & 1.489 \\
\hline Obs & 432 & 440 & 439 & 442 & 450 & 447 & 450 & 447 & 453 & 445 & 450 & 453 & 447 & 449 \\
\hline Sk & 771 & 718 & 725 & 743 & 776 & 664 & 721 & 730 & 705 & 683 & 734 & 719 & 695 & 753 \\
\hline Kur & 2536 & 2108 & 2196 & 2460 & 2854 & 2006 & 2555 & 2864 & 2861 & 2581 & 3198 & 2993 & 2895 & 3550 \\
\hline Nor & 3307 & 2826 & 2921 & 3203 & 3630 & 2670 & 3275 & 3594 & 3566 & 3264 & 3932 & 3712 & 3589 & 4304 \\
\hline$B I-1$ & 0.727 & 0.711 & 0.718 & 0.710 & 0.718 & 0.711 & 0.709 & 0.727 & 0.733 & 0.751 & 0.762 & 0.742 & 0.736 & 0.731 \\
\hline$B I-2$ & 0.813 & 0.818 & 0.829 & 0.837 & 0.838 & 0.834 & 0.853 & 0.850 & 0.852 & 0.856 & 0.853 & 0.848 & 0.839 & 0.849 \\
\hline$B I-4$ & 0.889 & 0.882 & 0.907 & 0.914 & 0.916 & 0.926 & 0.920 & 0.922 & 0.940 & 0.951 & 0.956 & 0.956 & 0.951 & 0.960 \\
\hline$B I-8$ & 0.961 & 0.955 & 0.961 & 0.973 & 0.976 & 0.975 & 0.982 & 0.987 & 0.991 & 0.991 & 0.993 & 0.993 & 0.989 & 0.991 \\
\hline
\end{tabular}

\footnotetext{
${ }^{a}$ The Balassa index is based on annual bilateral export flows of 182 countries for the period 1970 through 1997; $\mathrm{p}-z$ reports the Balassa index for the $z$-th percentile, for $z=1,2.5,5,10,25,50,75,90,95,97.5$, and 99; $\max =$ maximum; std $=$ standard deviation; obs $=$ number of observations; sk $=$ skewness, kur $=$ kurtosis; nor = normality; $B I-z$ reports the share of industries with a Balassa index lower than $z$, for $z=1,2,4,8$.
} 
Table A4a China; share of 4-digit sectors (\%) with Balassa index > 1, 2, 4, and 8*

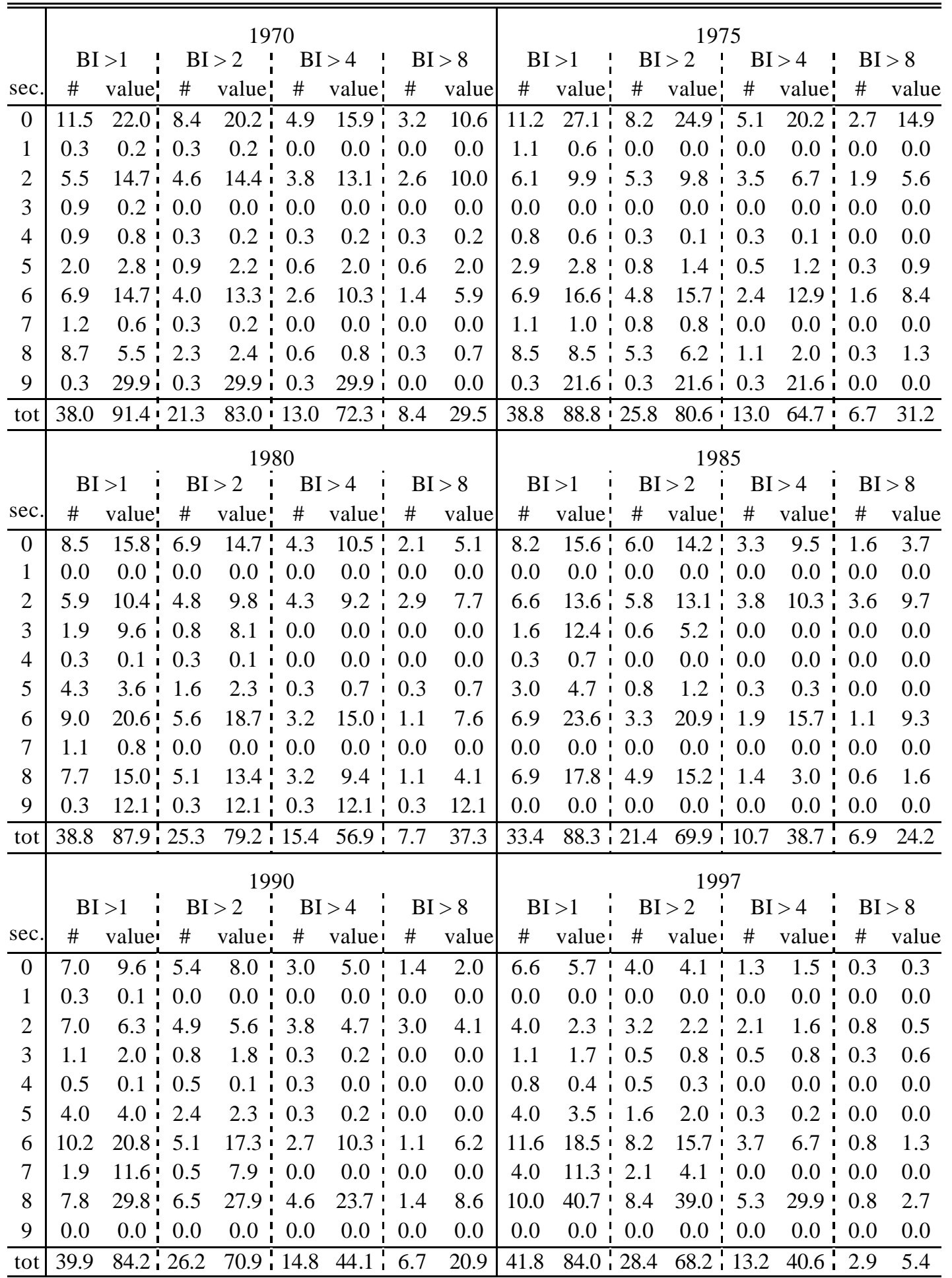

* The table lists the share for a Balassa index above 1, 2, 4, and 8, for 4-digit sectors organized along the 1-digit sector composition, both as a percentage of the total number of sectors and as a percentage of the export value; $0=$ food and live animals; $1=$ beverages and tobacco; $2=$ crude materials; $3=$ mineral fuels $; 4=$ animal $\&$ vegetable oils; $5=$ chemicals; $6=$ manufactured goods; 7 $=$ machinery $\&$ transport eq.; $8=$ misc. manufactured articles; $9=$ comm. not classified elsewhere. 
Table A4b Hong Kong; share of 4-digit sectors (\%) with Balassa index > 1, 2, 4, and 8*

\begin{tabular}{|c|c|c|c|c|c|c|c|c|c|c|c|c|c|c|c|c|}
\hline \multirow[b]{3}{*}{ sec. } & \multicolumn{8}{|c|}{1970} & \multicolumn{8}{|c|}{1975} \\
\hline & \multicolumn{2}{|c|}{ BI $>1$} & \multicolumn{2}{|c|}{$\mathrm{BI}>2$} & \multicolumn{2}{|c|}{$\mathrm{BI}>4$} & \multicolumn{2}{|c|}{ BI $>8$} & \multicolumn{2}{|c|}{ BI > 1} & \multicolumn{2}{|c|}{$\mathrm{BI}>2$} & \multicolumn{2}{|c|}{$\mathrm{BI}>4$} & \multicolumn{2}{|c|}{$\mathrm{BI}>8$} \\
\hline & $\#$ & value', & $\#$ & value', & \# & value' & \# & value & $\#$ & value', & $\#$ & value' & $\#$ & valuei' & \# & value \\
\hline 0 & 2.1 & 0.7 & 0.6 & 0.2 & 0.6 & $0.2:$ & 0.0 & 0.0 & 1.7 & 0.5 & 0.9 & 0.1 & 0.0 & 0.0 & 0.0 & 0.0 \\
\hline 1 & 0.3 & 0.4 & 0.3 & 0.4 & 0.0 & 0.0 & 0.0 & 0.0 & 0.3 & 0.3 & 0.3 & 0.3 & 0.0 & 0.0 & 0.0 & 0.0 \\
\hline 2 & 2.4 & 1.9 & 1.5 & 1.6 & 0.6 & 0.8 & 0.3 & 0.6 & 1.7 & 1.7 & 1.7 & 1.7 & 0.9 & 1.3 & 0.6 & 1.1 \\
\hline 3 & 0.0 & $0.0 \mathrm{i}$ & 0.0 & 0.0 & 0.0 & 0.0 & 0.0 & 0.0 & 0.0 & $0.0 \mathrm{i}$ & 0.0 & 0.0 & 0.0 & 0.0 & 0.0 & 0.0 \\
\hline 4 & 0.0 & $0.0 !$ & 0.0 & $0.0 !$ & 0.0 & 0.0 & 0.0 & 0.0 & 0.0 & 0.0 ' & 0.0 & $0.0:$ & 0.0 & 0.0 & 0.0 & 0.0 \\
\hline 5 & 1.8 & 2.9 & 0.9 & 1.8 & 0.3 & 0.1 & 0.0 & 0.0 & 2.0 & 2.5 & 0.9 & $1.1 !$ & 0.3 & 0.1 & 0.0 & 0.0 \\
\hline 6 & 6.1 & 19.1 ' & 3.3 & $17.6 !$ & 2.4 & $15.9 !$ & 1.2 & 7.5 & 6.6 & $17.9 !$ & 3.7 & 16.4 ' & 2.0 & $10.3 !$ & 1.4 & 9.1 \\
\hline 7 & 1.2 & $3.2 !$ & 0.9 & 3.0 & 0.6 & 2.7 & 0.0 & 0.0 & 2.9 & $5.3 \mathrm{i}$ & 1.7 & 4.7 & 0.9 & 3.8 & 0.0 & 0.0 \\
\hline 8 & 10.6 & $61.2 i$ & 8.8 & 59.4 & 8.5 & 59.2 & 6.4 & 53.0 & 11.1 & 61.9 i & 9.7 & 60.2 & 8.8 & 59.1 & 7.7 & 55.0 \\
\hline 9 & 0.0 & 0.0 & 0.0 & 0.0 & 0.0 & 0.0 & 0.0 & 0.0 & 0.0 & 0.0 & 0.0 & 0.0 & 0.0 & 0.0 & 0.0 & 0.0 \\
\hline \multirow[t]{3}{*}{ tot } & 24.6 & $89.3 !$ & 16.4 & $84.1 !$ & 13.0 & 78.7! & 7.9 & 61.1 & 26.2 & I' & 18.8 & $84.6 !$ & 12.8 & $74.6 !$ & 9.7 & 65.2 \\
\hline & \multicolumn{8}{|c|}{1980} & \multicolumn{8}{|c|}{1985} \\
\hline & \multicolumn{2}{|c|}{ BI >1 } & \multicolumn{2}{|c|}{$\mathrm{BI}>2$} & \multicolumn{2}{|c|}{$\mathrm{BI}>4$} & \multicolumn{2}{|c|}{$\mathrm{BI}>8$} & \multicolumn{2}{|c|}{ BI $>1$} & \multicolumn{2}{|c|}{$\mathrm{BI}>2$} & B & 4 & & $>8$ \\
\hline sec. & \# & value, & \# & value, & & value, & \# & value & \# & value! & \# & value! & \# & value, & \# & value \\
\hline 0 & 1.2 & 0.6 & 0.6 & 0.1 i & 0.0 & 0.0 & 0.0 & 0.0 & 1.4 & 0.9 i & 0.9 & 0.4 i & 0.3 & 0.2 & 0.0 & 0.0 \\
\hline 1 & 0.3 & 0.3 & 0.0 & 0.0 & 0.0 & 0.0 & 0.0 & 0.0 & 0.3 & 1.0 & 0.3 & 1.0 & 0.3 & 1.0 & 0.0 & 0.0 \\
\hline 2 & 2.9 & 2.3 & 2.0 & 1.9 & 0.9 & 1.4 & 0.3 & 0.8 & 3.4 & 2.2 & 2.5 & 2.0 & 2.0 & 1.8 & 0.9 & 0.9 \\
\hline 3 & 0.0 & 0.0 & 0.0 & 0.0 & 0.0 & 0.0 & 0.0 & 0.0 & 0.0 & 0.0 & 0.0 & 0.0 & 0.0 & 0.0 & 0.0 & 0.0 \\
\hline 4 & 0.0 & $0.0 \vdots$ & 0.0 & 0.0 & 0.0 & 0.0 & 0.0 & 0.0 & 0.0 & $0.0 \mathrm{i}$ & 0.0 & $0.0 \vdots$ & 0.0 & 0.0 & 0.0 & 0.0 \\
\hline 5 & 1.7 & $1.2 !$ & 0.3 & $0.2 !$ & 0.0 & 0.0 & 0.0 & 0.0 & 2.0 & $1.5 !$ & 0.0 & $0.0 \vdots$ & 0.0 & 0.0 & 0.0 & 0.0 \\
\hline 6 & 8.1 & $16.1 '$ & 4.4 & 12.0 I & 1.7 & 7.9 & 1.2 & 6.5 & 7.3 & $15.1 '$ & 4.0 & $12.4 !$ & 2.3 & 8.7 & 0.0 & 0.0 \\
\hline 7 & 2.9 & $9.4 !$ & 1.2 & 6.1 & 0.9 & 5.9 & 0.0 & 0.0 & 3.1 & 14.9 & 1.7 & 12.1 & 0.6 & 3.2 & 0.3 & 1.3 \\
\hline 8 & 10.8 & $59.6 !$ & 10.2 & 59.4 ' & 8.7 & 56.7 & 5.5 & 49.6 & 11.0 & ' & 9.6 & $49.7 !$ & 7.9 & 46.3 & 4.2 & 39.4 \\
\hline 9 & 0.0 & 0.0 & 0.0 & 0.0 & 0.0 & 0.0 & 0.0 & 0.0 & 0.0 & 0.0 & 0.0 & 0.0 & 0.0 & 0.0 & 0.0 & 0.0 \\
\hline tot & 27.9 & 89.4 ' & 18.6 & 79.7 & 12.2 & '71.8 & 7.0 & 56.9 & 28.5 & 87.4 i & 18.9 & $77.6 !$ & 13.3 & 61.1 & 5.4 & 41.7 \\
\hline & & & & & & & & & & & & 199 & & & & \\
\hline & BI & & BI & & & $>4$ & & 8 & BI & $>1$ & & {$[>2$} & & $>4$ & & $>8$ \\
\hline sec. & \# & value, & \# & value! & \# & value! & \# & value & \# & value! & \# & value! & \# & value! & \# & value \\
\hline 0 & 1.1 & $0.7 !$ & 0.3 & $0.2 !$ & 0.3 & 0.2 & 0.0 & 0.0 & 0.8 & $0.6 !$ & 0.3 & $\begin{array}{l:}0.1 \\
0.1\end{array}$ & 0.0 & 0.0 & 0.0 & 0.0 \\
\hline 1 & 0.3 & $2.1 !$ & 0.3 & 2.1 ' & 0.3 & 2.1 & 0.0 & 0.0 & 0.3 & $0.8:$ & 0.0 & $0.0:$ & 0.0 & 0.0 & 0.0 & 0.0 \\
\hline 2 & 3.6 & $1.6 !$ & 1.7 & 1.0 & 1.1 & 0.7 & 0.3 & 0.4 & 3.3 & 1.1 & 0.8 & 0.3 ' & 0.6 & 0.3 & 0.0 & 0.0 \\
\hline 3 & 0.3 & 0.0 & 0.0 & 0.0 & 0.0 & 0.0 & 0.0 & 0.0 & 0.3 & 1.2 & 0.0 & 0.0 & 0.0 & 0.0 & 0.0 & 0.0 \\
\hline 4 & 0.3 & 0.1 & 0.0 & 0.0 i & 0.0 & 0.0 & 0.0 & 0.0 & 0.6 & 0.2 & 0.0 & 0.0 & 0.0 & 0.0 & 0.0 & 0.0 \\
\hline 5 & 1.9 & $1.5 \mathrm{I}$ & 0.3 & $0.1 \quad$ & 0.0 & 0.0 & 0.0 & 0.0 & 0.6 & 0.7 & 0.0 & 0.01 & 0.0 & 0.0 & 0.0 & 0.0 \\
\hline 6 & 8.1 & 16.3 & 3.6 & 11.5 & 0.8 & 4.5 & 0.0 & 0.0 & 7.2 & 13.1 & 3.3 & 9.3 & 0.3 & 2.3 & 0.0 & 0.0 \\
\hline 7 & 3.9 & $15.5 !$ & 1.7 & $9.5 !$ & 0.6 & 2.5 & 0.0 & 0.0 & 4.5 & $22.2 !$ & 3.1 & $13.3 !$ & 0.3 & $1.6:$ & 0.0 & 0.0 \\
\hline 8 & 10.6 & $49.5 !$ & 7.8 & ' & 5.8 & 40.8 ' & 1.7 & 23.5 & 10.3 & 43.1 ' & 7.8 & 39.0 ' & 2.8 & $23.7 !$ & 0.8 & 13.9 \\
\hline 9 & 0.0 & 0.0 i & 0.0 & i & 0.0 & $\begin{array}{l:}0.0 \\
\end{array}$ & 0.0 & 0.0 & 0.0 & 0.0 i & 0.0 & 0.01 & 0.0 & 0.01 & 0.0 & 0.0 \\
\hline tot & 30.0 & $87.1 \mathrm{i}$ & 15.6 & i & 8.9 & 50.7 i & 1.9 & 23.9 & 27.9 & ו & 15.3 & 62.0 & 3.9 & ו & 0.8 & 13.9 \\
\hline
\end{tabular}

* The table lists the share for a Balassa index above 1, 2, 4, and 8, for 4-digit sectors organized along the 1-digit sector composition, both as a percentage of the total number of sectors and as a percentage of the export value; $0=$ food and live animals; $1=$ beverages and tobacco; $2=$ crude materials; 3 = mineral fuels; $4=$ animal $\&$ vegetable oils; $5=$ chemicals; $6=$ manufactured goods; 7 $=$ machinery $\&$ transport eq.; $8=$ misc. manufactured articles; $9=$ comm. not classified elsewhere. 
Table A4c Taiwan; share of 4-digit sectors (\%) with Balassa index > 1, 2, 4, and $8^{*}$

\begin{tabular}{|c|c|c|c|c|c|c|c|c|c|c|c|c|c|c|c|c|}
\hline \multirow[b]{3}{*}{ sec. } & \multicolumn{8}{|c|}{1970} & \multicolumn{8}{|c|}{1975} \\
\hline & \multicolumn{2}{|c|}{$\mathrm{BI}>1$} & \multicolumn{2}{|c|}{$\mathrm{BI}>2$} & \multicolumn{2}{|c|}{ BI $>4$} & \multicolumn{2}{|c|}{ BI $>8$} & \multicolumn{2}{|c|}{ BI $>1$} & \multicolumn{2}{|c|}{$\mathrm{BI}>2$} & \multicolumn{2}{|c|}{ BI $>4$} & \multicolumn{2}{|c|}{$\mathrm{BI}>8$} \\
\hline & $\#$ & value, & $\#$ & value, & $\#$ & value! & $\#$ & value & $\#$ & value! & $\#$ & value! & $\#$ & value! & $\#$ & value \\
\hline 0 & 7.1 & $25.6 !$ & 5.6 & $25.0 !$ & 4.0 & $22.2 !$ & 3.1 & 17.4 & 6.4 & 21.0 & 4.8 & $19.1 !$ & 3.1 & $12.1 !$ & 2.2 & 8.0 \\
\hline 1 & 0.0 & 0.0 ' & 0.0 & 0.0 ' & 0.0 & $0.0:$ & 0.0 & 0.0 & 0.0 & $0.0:$ & 0.0 & $0.0:$ & 0.0 & 0.0 & 0.0 & 0.0 \\
\hline 2 & 2.8 & 4.2 & 2.2 & 3.7 & 0.6 & 0.4 & 0.0 & 0.0 & 2.0 & 1.5 & 0.8 & 0.5 & 0.0 & 0.0 & 0.0 & 0.0 \\
\hline 3 & 0.3 & 0.3 & 0.0 & 0.0 & 0.0 & 0.0 & 0.0 & 0.0 & 0.0 & 0.0 & 0.0 & 0.0 & 0.0 & 0.0 & 0.0 & 0.0 \\
\hline 4 & 0.0 & $0.0 \mathrm{i}$ & 0.0 & $0.0 \mathrm{i}$ & 0.0 & $0.0 i$ & 0.0 & 0.0 & 0.0 & 0.0 & 0.0 & 0.0 & 0.0 & 0.0 & 0.0 & 0.0 \\
\hline 5 & 1.6 & $1.0 !$ & 0.6 & $0.6:$ & 0.3 & 0.4 & 0.0 & 0.0 & 1.4 & 0.4 & 0.6 & $0.2:$ & 0.0 & 0.0 & 0.0 & 0.0 \\
\hline 6 & 8.4 & $27.2 !$ & 6.2 & $24.9 !$ & 2.5 & $16.3 !$ & 1.2 & 12.6 & 9.0 & $24.3 !$ & 6.7 & $22.9 !$ & 4.2 & $18.5 !$ & 1.1 & 7.4 \\
\hline 7 & 3.7 & $6.9 !$ & 1.6 & 3.3 & 0.0 & 0.0 & 0.0 & 0.0 & 3.4 & $8.3 !$ & 3.1 & $8.1:$ & 0.6 & 1.5 & 0.0 & 0.0 \\
\hline 8 & 9.9 & $24.6 !$ & 8.1 & 23.1 ' & 6.8 & $21.9 !$ & 2.2 & 12.0 & 10.9 & $32.7 !$ & 10.4 & $32.5 !$ & 7.3 & $27.5 !$ & 2.2 & 15.7 \\
\hline 9 & 0.0 & 0.0 & 0.0 & 0.0 & 0.0 & 0.0 & 0.0 & 0.0 & 0.0 & 0.0 & 0.0 & $0.0:$ & 0.0 & 0.0 & 0.0 & 0.0 \\
\hline \multirow[t]{3}{*}{ tot } & 33.9 & 89.8 i & 24.2 & 80.5 ' & 14.3 & ' & 6.5 & 41.9 & 33.1 & 88.3 & 26.3 & $83.2 !$ & 15.1 & יו & 5.6 & 31.1 \\
\hline & \multicolumn{8}{|c|}{1980} & \multicolumn{8}{|c|}{1985} \\
\hline & \multicolumn{2}{|c|}{$\mathrm{BI}>1$} & \multicolumn{2}{|c|}{$\mathrm{BI}>2$} & \multicolumn{2}{|c|}{$\mathrm{BI}>4$} & \multicolumn{2}{|c|}{$\mathrm{BI}>8$} & \multicolumn{2}{|c|}{$\mathrm{BI}>1$} & \multicolumn{2}{|c|}{$\mathrm{BI}>2$} & BI & $>4$ & B & 8 \\
\hline sec. & \# & value! & \# & value! & \# & value! & \# & value & \# & value & \# & value! & & value! & \# & value \\
\hline 0 & 4.7 & $9.3 !$ & 3.2 & $8.2 !$ & 1.9 & $\begin{array}{ll}6.2 ! \\
\end{array}$ & 1.3 & 5.2 & 4.5 & 5.3 & 3.3 & 4.9 & 2.1 & 4.0 & 0.0 & 0.0 \\
\hline 1 & 0.0 & ' & 0.0 & 0.0 ' & 0.0 & $\begin{array}{l:}0.0 \\
\end{array}$ & 0.0 & 0.0 & 0.0 & 0.0 & 0.0 & 0.0 & 0.0 & 0.0 & 0.0 & 0.0 \\
\hline 2 & 1.6 & $0.6 !$ & 1.0 & 0.4 & 0.3 & 0.0 & 0.3 & 0.0 & 1.5 & 0.8 & 0.6 & 0.6 & 0.0 & 0.0 & 0.0 & 0.0 \\
\hline 3 & 0.0 & ' & 0.0 & ' ' & 0.0 & $\begin{array}{l:}0.0 \\
\end{array}$ & 0.0 & 0.0 & 0.3 & 0.2 & 0.0 & 0.0 & 0.0 & 0.0 & 0.0 & 0.0 \\
\hline 4 & 0.0 & 0.0 & 0.0 & 0.0 & 0.0 & 0.0 & 0.0 & 0.0 & 0.0 & 0.0 & 0.0 & 0.0 & 0.0 & 0.0 & 0.0 & 0.0 \\
\hline 5 & 1.0 & 0.3 & 0.0 & 0.0 & 0.0 & 0.0 i & 0.0 & 0.0 & 0.3 & 0.0 & 0.3 & 0.0 i & 0.3 & 0.0 & 0.0 & 0.0 \\
\hline 6 & 12.0 & 22.1 & 8.2 & 19.1 & 3.8 & 16.0 & 0.6 & 5.5 & 11.8 & 22.8 & 8.1 & 19.7 & 4.2 & $15.2 \vdots$ & 1.5 & 5.1 \\
\hline 7 & 4.7 & '23.0' & 2.5 & ' & 1.6 & $17.3 !$ & 1.0 & 15.2 & 5.7 & 20.8 & 3.6 & 17.8: & 1.8 & 10.7 & 0.3 & 2.7 \\
\hline 8 & 7.9 & $33.6 !$ & 7.3 & 33.5 ! & 4.7 & $30.6 !$ & 3.2 & 27.3 & 11.1 & $35.2 !$ & 9.3 & $33.7 !$ & 6.3 & $29.7 !$ & 3.0 & 17.5 \\
\hline 9 & 0.0 & ' & 0.0 & 0.0 ' & 0.0 & 0.0 & 0.0 & 0.0 & 0.0 & 0.0 & 0.0 & $0.0:$ & 0.0 & $0.0:$ & 0.0 & 0.0 \\
\hline tot & 31.9 & 88.8 i & 22.1 & 81.3 & 12.3 & $70.2 i$ & 6.3 & 53.2 & 35.2 & 85.1 & 25.3 & 76.7 & 14.8 & i & 4.8 & 25.3 \\
\hline & & & & & & & & & & & & 199 & & & & \\
\hline & BI & & BI & & & 4 & & $>8$ & & $>1$ & & I > & & I $>4$ & & $>8$ \\
\hline sec. & \# & value! & \# & value! & \# & value! & \# & value & \# & value & \# & value! & \# & value! & \# & value \\
\hline 0 & 3.3 & I & 1.9 & 5.2 ! & 1.1 & $\begin{array}{l:}4.0 \\
\end{array}$ & 0.0 & 0.0 & 0.8 & 1.6 & 0.3 & 'ו & 0.0 & 0.0 & 0.0 & 0.0 \\
\hline 1 & 0.0 & ' & 0.0 & ' ' & 0.0 & 0.0 & 0.0 & 0.0 & 0.0 & 0.0 & 0.0 & : & 0.0 & 0.0 & 0.0 & 0.0 \\
\hline 2 & 1.6 & 0.7 ' & 0.5 & 0.4 ' & 0.0 & $\begin{array}{l:}0.0 \\
0.0\end{array}$ & 0.0 & 0.0 & 0.8 & 0.6 & 0.3 & $0.3:$ & 0.0 & 0.0 & 0.0 & 0.0 \\
\hline 3 & 0.0 & 0.0 & 0.0 & 0.0 ' & 0.0 & 0.0 & 0.0 & 0.0 & 0.0 & 0.0 & 0.0 & 0.0 & 0.0 & 0.0 & 0.0 & 0.0 \\
\hline 4 & 0.0 & 0.0 & 0.0 & 0.0 & 0.0 & 0.0 & 0.0 & 0.0 & 0.0 & 0.0 & 0.0 & 0.0 & 0.0 & 0.0 & 0.0 & 0.0 \\
\hline 5 & 0.0 & 0.0 & 0.0 & 0.0 & 0.0 & 0.0 & 0.0 & 0.0 & 0.5 & 0.8 & 0.0 & 0.0 & 0.0 & 0.0 & 0.0 & 0.0 \\
\hline 6 & 9.2 & 21.1 & 5.2 & 15.6 & 2.7 & 11.3 & 0.3 & 0.6 & 7.8 & 16.8 & 2.7 & 11.3 & 1.1 & 6.5 & 0.0 & 0.0 \\
\hline 7 & 5.4 & 27.3 ' & 3.0 & '18.1' & 1.4 & 7.11 & 0.3 & 3.5 & 5.9 & 32.2 & 2.4 & 20.3 & 1.1 & 3.6 & 0.3 & 2.6 \\
\hline 8 & 8.7 & ו' & 5.4 & 24.3 ! & 2.4 & $14.4 !$ & 0.3 & 3.2 & 4.9 & 12.1 & 2.7 & '5.6 & 0.3 & 0.4 & 0.0 & 0.0 \\
\hline 9 & 0.0 & 0.0 ' & 0.0 & ' & 0.0 & 0.0 & 0.0 & 0.0 & 0.3 & $14.2 !$ & 0.3 & $14.2 !$ & 0.3 & $14.2 !$ & 0.0 & 0.0 \\
\hline tot & 28.2 & $82.8 !$ & 16.0 & 63.5 & 7.6 & 36.8 & 0.8 & 7.3 & 20.8 & 78.1 & 8.6 & $52.6 !$ & 2.7 & $24.7 !$ & 0.3 & 2.6 \\
\hline
\end{tabular}

* The table lists the share for a Balassa index above 1, 2, 4, and 8, for 4-digit sectors organized along the 1-digit sector composition, both as a percentage of the total number of sectors and as a percentage of the export value; $0=$ food and live animals; $1=$ beverages and tobacco; $2=$ crude materials; $3=$ mineral fuels; $4=$ animal $\&$ vegetable oils; $5=$ chemicals; $6=$ manufactured goods; 7 $=$ machinery $\&$ transport eq.; $8=$ misc. manufactured articles; $9=$ comm. not classified elsewhere. 
Figure A3 Development of sectoral distribution of comparative advantage, value
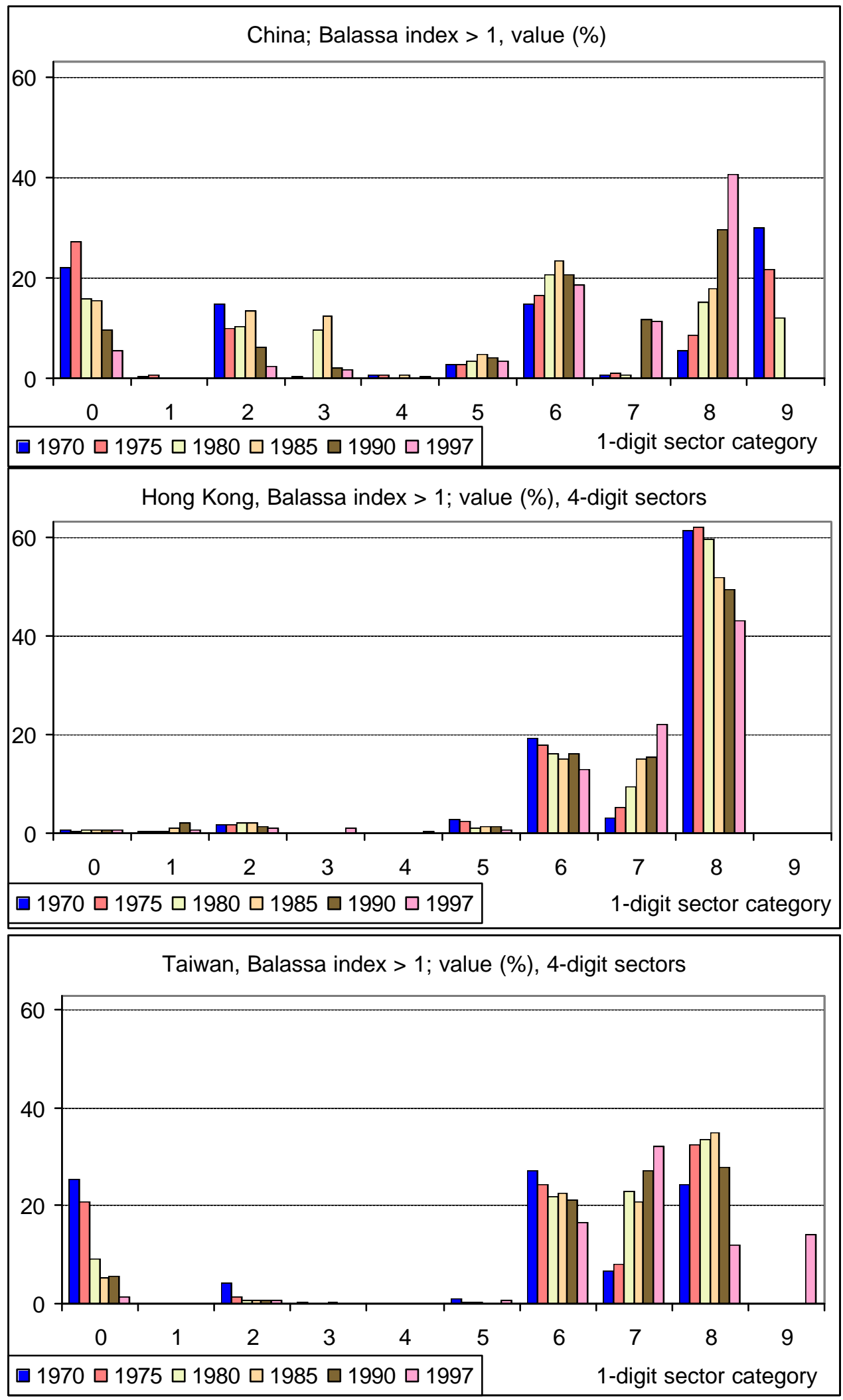
Table A5 Galtonian regressions of the Balassa index for the Chinese economies, lag 15-27

\begin{tabular}{|c|c|c|c|c|c|c|c|c|}
\hline \multicolumn{2}{|l|}{ lag } & China & Taiwan & Hong Kong & lag & China & Taiwan & Hong Kong \\
\hline & $\beta$ & 0.58 & 0.55 & 0.57 & $\beta$ & 0.43 & 0.47 & 0.50 \\
\hline & $\mathrm{t}$-value & 51.69 & 50.12 & 58.38 & t-value & 28.11 & 27.81 & 31.91 \\
\hline \multirow[t]{5}{*}{15} & & 0.69 & 0.64 & 0.71 & $22 ?$ & 0.59 & 0.54 & 0.62 \\
\hline & Adj. $R^{2}$ & 0.47 & 0.42 & 0.51 & Adj. $R^{2}$ & 0.35 & 0.32 & 0.39 \\
\hline & \# obs. & 4679 & 4336 & 4346 & \# obs. & 2135 & 2063 & 1985 \\
\hline & $\beta$ & 0.55 & 0.54 & 0.56 & $\beta$ & 0.41 & 0.46 & $\overline{0.49}$ \\
\hline & t-value & 49.03 & 47.26 & 55.67 & t-value & 24.37 & 24.52 & 29.33 \\
\hline \multirow[t]{5}{*}{16} & & 0.67 & 0.63 & 0.69 & $23 ?$ & 0.57 & 0.52 & 0.60 \\
\hline & Adj. $R^{2}$ & 0.45 & 0.41 & 0.48 & Adj. $\mathrm{R}^{2}$ & 0.32 & 0.29 & 0.37 \\
\hline & \# obs. & 4317 & 4027 & 4001 & \# obs. & 1783 & 1717 & 1649 \\
\hline & $\beta$ & 0.53 & 0.52 & 0.54 & $\beta$ & 0.39 & 0.44 & $\overline{0.46}$ \\
\hline & t-value & 44.55 & 44.09 & 51.74 & t-value & 19.34 & 19.82 & 25.66 \\
\hline \multirow[t]{5}{*}{17} & & 0.66 & 0.61 & 0.68 & $24 ?$ & 0.53 & 0.49 & 0.58 \\
\hline & Adj. $R^{2}$ & 0.43 & 0.39 & 0.47 & Adj. $\mathrm{R}^{2}$ & 0.29 & 0.27 & 0.34 \\
\hline & \# obs. & 3947 & 3753 & 3660 & \# obs. & 1419 & 1370 & 1311 \\
\hline & $\beta$ & 0.51 & 0.51 & 0.54 & $\beta$ & 0.36 & 0.40 & 0.44 \\
\hline & t-value & 42.43 & 42.87 & 49.96 & t-value & 15.32 & 15.00 & 20.63 \\
\hline \multirow[t]{5}{*}{18} & & 0.64 & 0.61 & 0.68 & $25 ?$ & 0.51 & 0.45 & 0.56 \\
\hline & Adj. $R^{2}$ & 0.41 & 0.39 & 0.46 & Adj. $\mathrm{R}^{2}$ & 0.26 & 0.23 & 0.32 \\
\hline & \# obs. & 3576 & 3465 & 3327 & \# obs. & 1062 & 1019 & 977 \\
\hline & $\beta$ & 0.49 & 0.51 & 0.53 & $\beta$ & 0.36 & 0.38 & $\overline{0.45}$ \\
\hline & t-value & 40.46 & 40.58 & 45.32 & $\mathrm{t}$-value & 12.48 & 11.05 & 16.55 \\
\hline \multirow[t]{5}{*}{19} & & 0.63 & 0.59 & 0.67 & $26 ?$ & 0.50 & 0.41 & 0.55 \\
\hline & Adj. $R^{2}$ & 0.40 & 0.37 & 0.45 & Adj. $R^{2}$ & 0.25 & 0.20 & 0.31 \\
\hline & \# obs. & 3215 & 3138 & 2989 & \# obs. & 700 & 671 & 656 \\
\hline & $\beta$ & 0.46 & 0.49 & 0.52 & $\bar{\beta}$ & 0.36 & 0.39 & $\overline{0.44}$ \\
\hline & t-value & 36.02 & 36.75 & 40.49 & $\mathrm{t}$-value & 9.41 & 7.93 & 10.67 \\
\hline \multirow[t]{5}{*}{20} & & 0.61 & 0.57 & 0.65 & $27 ?$ & 0.50 & 0.43 & 0.53 \\
\hline & Adj. $R^{2}$ & 0.38 & 0.35 & 0.42 & Adj. $\mathrm{R}^{2}$ & 0.25 & 0.22 & 0.29 \\
\hline & \# obs. & 2857 & 2780 & 2651 & \# obs. & 353 & 329 & 327 \\
\hline & $\beta$ & 0.44 & 0.47 & 0.51 & & & & \\
\hline & t-value & 31.35 & 32.41 & 35.39 & & & & \\
\hline \multirow[t]{3}{*}{21} & & 0.60 & 0.55 & 0.63 & & & & \\
\hline & Adj. $R^{2}$ & 0.36 & 0.33 & 0.40 & & & & \\
\hline & \# obs. & 2500 & 2417 & 2314 & & & & \\
\hline
\end{tabular}


Figure A4 Chinese Markov 5-year transition matrices, deciles

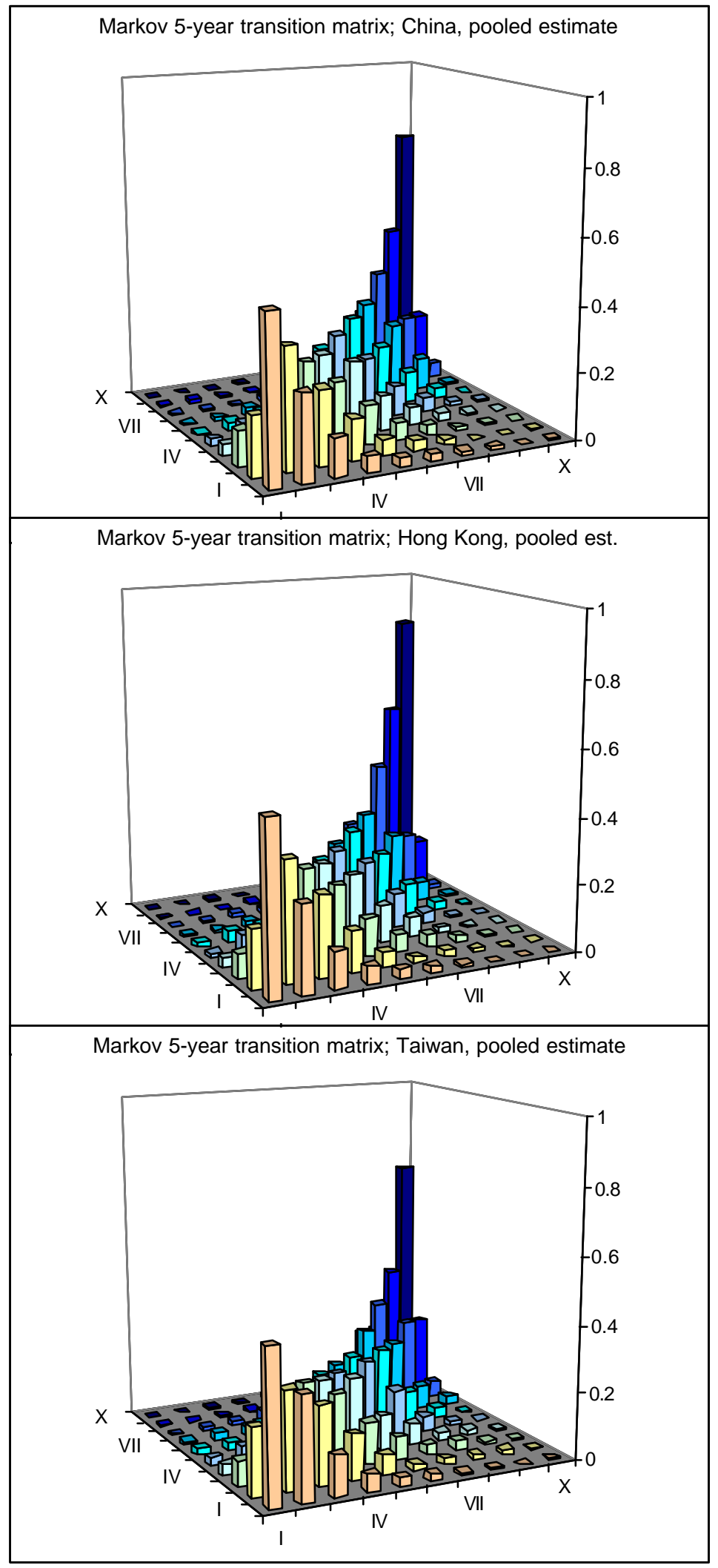


Table A6 Markov 5-year transition matrices; pooled estimates, quintiles

\begin{tabular}{|c|c|c|c|c|c|}
\hline \multicolumn{6}{|c|}{ Panel a China } \\
\hline & I & II & III & IV & V \\
\hline I & 0.648 & 0.260 & 0.063 & 0.023 & 0.006 \\
\hline II & 0.214 & 0.468 & 0.251 & 0.058 & 0.010 \\
\hline III & 0.054 & 0.228 & 0.484 & 0.207 & 0.027 \\
\hline IV & 0.014 & 0.048 & 0.202 & 0.557 & 0.179 \\
\hline V & 0.008 & 0.008 & 0.022 & 0.171 & 0.791 \\
\hline Ergodic & 0.161 & 0.190 & 0.206 & 0.217 & 0.226 \\
\hline \multicolumn{6}{|c|}{ Panel b Hong Kong } \\
\hline & I & II & III & IV & V \\
\hline I & 0.652 & 0.270 & 0.054 & 0.021 & 0.003 \\
\hline II & 0.181 & 0.498 & 0.249 & 0.065 & 0.007 \\
\hline III & 0.056 & 0.206 & 0.495 & 0.222 & 0.021 \\
\hline IV & 0.013 & 0.047 & 0.202 & 0.602 & 0.136 \\
\hline V & 0.002 & 0.006 & 0.023 & 0.121 & 0.849 \\
\hline Ergodic & 0.139 & 0.184 & 0.207 & 0.227 & 0.243 \\
\hline \multicolumn{6}{|c|}{ Panel c Taiwan } \\
\hline & I & II & III & IV & V \\
\hline I & 0.621 & 0.281 & 0.063 & 0.025 & 0.009 \\
\hline II & 0.185 & 0.456 & 0.268 & 0.074 & 0.017 \\
\hline III & 0.056 & 0.211 & 0.444 & 0.260 & 0.029 \\
\hline IV & 0.028 & 0.065 & 0.214 & 0.494 & 0.198 \\
\hline V & 0.004 & 0.012 & 0.039 & 0.172 & 0.773 \\
\hline Ergodic & 0.141 & 0.187 & 0.208 & 0.224 & 0.241 \\
\hline
\end{tabular}


Table A7 - Mobility index values, five year transitions, 1970 - 1997

\begin{tabular}{|c|c|c|c|c|c|c|}
\hline \multirow[b]{2}{*}{ transition } & \multicolumn{2}{|c|}{ China } & \multicolumn{2}{|c|}{ Taiwan } & \multicolumn{2}{|c|}{ Hong Kong } \\
\hline & quintiles & deciles & quintiles & deciles & quintiles & deciles \\
\hline $1970-75$ & 0.392 & 0.593 & 0.550 & 0.750 & 0.515 & 0.648 \\
\hline $1971-76$ & 0.422 & 0.573 & 0.587 & 0.799 & 0.499 & 0.659 \\
\hline $1972-77$ & 0.492 & 0.681 & 0.504 & 0.707 & 0.500 & 0.662 \\
\hline 1973-78 & 0.524 & 0.693 & 0.560 & 0.736 & 0.526 & 0.649 \\
\hline 1974-79 & 0.513 & 0.707 & 0.666 & 0.818 & 0.521 & 0.668 \\
\hline $1975-80$ & 0.503 & 0.691 & 0.613 & 0.718 & 0.557 & 0.711 \\
\hline 1976-81 & 0.559 & 0.743 & 0.608 & 0.757 & 0.551 & 0.719 \\
\hline $1977-82$ & 0.584 & 0.761 & 0.591 & 0.763 & 0.505 & 0.677 \\
\hline 1978-83 & 0.542 & 0.715 & 0.536 & 0.681 & 0.499 & 0.688 \\
\hline 1979-84 & 0.604 & 0.731 & 0.581 & 0.713 & 0.498 & 0.650 \\
\hline $1980-85$ & 0.499 & 0.653 & 0.654 & 0.771 & 0.505 & 0.690 \\
\hline $1981-86$ & 0.428 & 0.653 & 0.444 & 0.617 & 0.465 & 0.664 \\
\hline $1982-87$ & 0.460 & 0.647 & 0.496 & 0.666 & 0.468 & 0.651 \\
\hline 1983-88 & 0.516 & 0.684 & 0.617 & 0.763 & 0.470 & 0.651 \\
\hline 1984-89 & 0.514 & 0.707 & 0.595 & 0.778 & 0.429 & 0.651 \\
\hline $1985-90$ & 0.550 & 0.703 & 0.690 & 0.841 & 0.475 & 0.665 \\
\hline 1986-91 & 0.575 & 0.703 & 0.608 & 0.812 & 0.439 & 0.621 \\
\hline 1987-92 & 0.589 & 0.713 & 0.595 & 0.787 & 0.413 & 0.644 \\
\hline 1988-93 & 0.609 & 0.749 & 0.557 & 0.743 & 0.484 & 0.612 \\
\hline 1989-94 & 0.553 & 0.731 & 0.550 & 0.745 & 0.459 & 0.671 \\
\hline 1990-95 & 0.554 & 0.724 & 0.475 & 0.703 & 0.466 & 0.671 \\
\hline 1991-96 & 0.548 & 0.721 & 0.469 & 0.672 & 0.457 & 0.628 \\
\hline 1992-97 & 0.446 & 0.621 & 0.446 & 0.646 & 0.477 & 0.614 \\
\hline mean & 0.521 & 0.691 & 0.565 & 0.739 & 0.486 & 0.659 \\
\hline st. dev & 0.060 & 0.048 & 0.068 & 0.057 & 0.036 & 0.027 \\
\hline
\end{tabular}


To test the equality of different Markov transition probabilities we apply Anderson and Goodman's (1957) test statistic, which under the null hypothesis $p_{i j}=\tilde{p}_{i j}$ for each state $i$ has an asymptotic distribution: $\quad \sum_{j} n_{i}^{*} \frac{\left(p_{i j}-\tilde{p}_{i j}\right)^{2}}{\tilde{p}_{i j}} \sim \mathrm{X}^{2}(m-1), \quad n_{i}^{*} \equiv \sum_{t=0}^{T-1} n_{i}(t)$

where $m$ is the number of states, $p_{i j}$ are the estimated probabilities, $\tilde{p}_{i j}$ are the probabilities under the null, and $n_{i}(t)$ denotes the number of sectors in cell $i$ at time $t$. Table A6 gives the test statistics when comparing individually estimated transition matrices for an individual country with the pooled estimate for that country reported in Table 6 of the paper and Table A5 above. Equality of all individual matrices relative to the benchmark is rejected, at least suggesting that this asymptotic theory is not very useful for practical applications in this field.

Table A8 Test statistic for equality of Markov transition matrices

\begin{tabular}{|c|c|c|c|c|c|c|}
\hline & Chine & & Taiwa & & Hon & Kong \\
\hline & $\#$ cells $=5$ & $\#$ cells $=10$ & $\#$ cells $=5$ & $\#$ cells $=10$ & $\#$ cells $=5$ & $\#$ cells $=10$ \\
\hline 70-75 v benchmark & 74.85 & 174.85 & 58.94 & 240.08 & 36.63 & 133.48 \\
\hline 71-76 v benchmark & 44.61 & 156.17 & 26.03 & 167.37 & 28.98 & 169.04 \\
\hline 72-77 v benchmark & 38.64 & 125.69 & 16.08 & 104.84 & 65.28 & 147.69 \\
\hline 73-78 v benchmark & 21.41 & 122.15 & 21.73 & 127.94 & 59.23 & 190.58 \\
\hline 74-79 v benchmark & 29.00 & 164.20 & 99.60 & 254.87 & 45.22 & 164.66 \\
\hline 75-80 v benchmark & 44.40 & 128.30 & 92.42 & 256.24 & 57.67 & 221.01 \\
\hline 76-81 v benchmark & 51.03 & 153.30 & 51.08 & 199.77 & 69.43 & 169.32 \\
\hline $77-82 \mathrm{v}$ benchmark & 54.58 & 167.91 & 52.29 & 205.89 & 79.62 & 272.73 \\
\hline $78-83$ v benchmark & 20.92 & 129.71 & 48.26 & 168.88 & 38.68 & 152.55 \\
\hline 79-84 v benchmark & 53.41 & 189.21 & 36.09 & 136.27 & 25.71 & 103.61 \\
\hline $80-85$ v benchmark & 27.16 & 107.41 & 102.08 & 244.57 & 15.75 & 110.53 \\
\hline $81-86 \mathrm{v}$ benchmark & 45.11 & 161.93 & 50.34 & 119.29 & 13.14 & 83.99 \\
\hline $82-87 \mathrm{v}$ benchmark & 31.16 & 134.59 & 22.78 & 94.79 & 22.14 & 123.13 \\
\hline $83-88$ v benchmark & 26.60 & 122.72 & 35.72 & 248.58 & 17.93 & 105.07 \\
\hline $84-89$ v benchmark & 21.97 & 125.63 & 44.53 & 200.03 & 24.48 & 124.84 \\
\hline $85-90 \mathrm{v}$ benchmark & 21.81 & 126.36 & 93.39 & 264.77 & 25.05 & 114.90 \\
\hline 86-91 v benchmark & 20.98 & 167.95 & 43.10 & 144.86 & 15.36 & 85.05 \\
\hline $87-92$ v benchmark & 24.21 & 167.49 & 34.60 & 159.57 & 27.93 & 121.44 \\
\hline $88-93$ v benchmark & 45.19 & 168.22 & 29.16 & 138.57 & 18.10 & 134.36 \\
\hline 89-94 v benchmark & 39.05 & 171.13 & 34.56 & 139.12 & 25.99 & 111.90 \\
\hline 90-95 v benchmark & 55.15 & 178.83 & 42.84 & 134.55 & 34.02 & 179.88 \\
\hline 91-96 v benchmark & 57.76 & 208.02 & 37.32 & 109.67 & 21.13 & 127.24 \\
\hline 92-97 v benchmark & 24.46 & 120.17 & 56.47 & 139.58 & 35.97 & 170.09 \\
\hline
\end{tabular}


Figure A5 HM index for the Balassa index of the Chinese economies
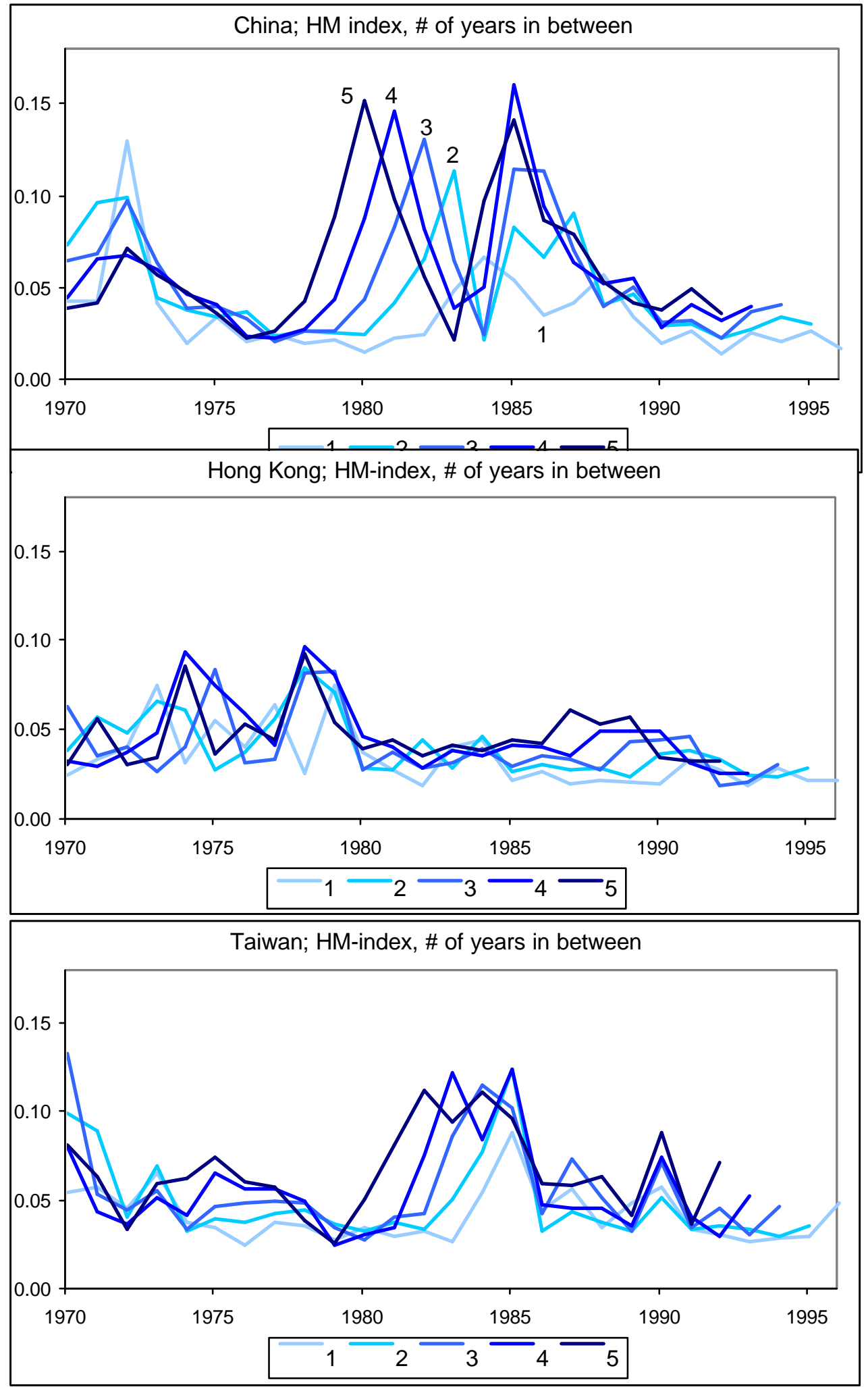
Figure A6 China; $p$-p plots and percentile distribution, 4-digit sectors
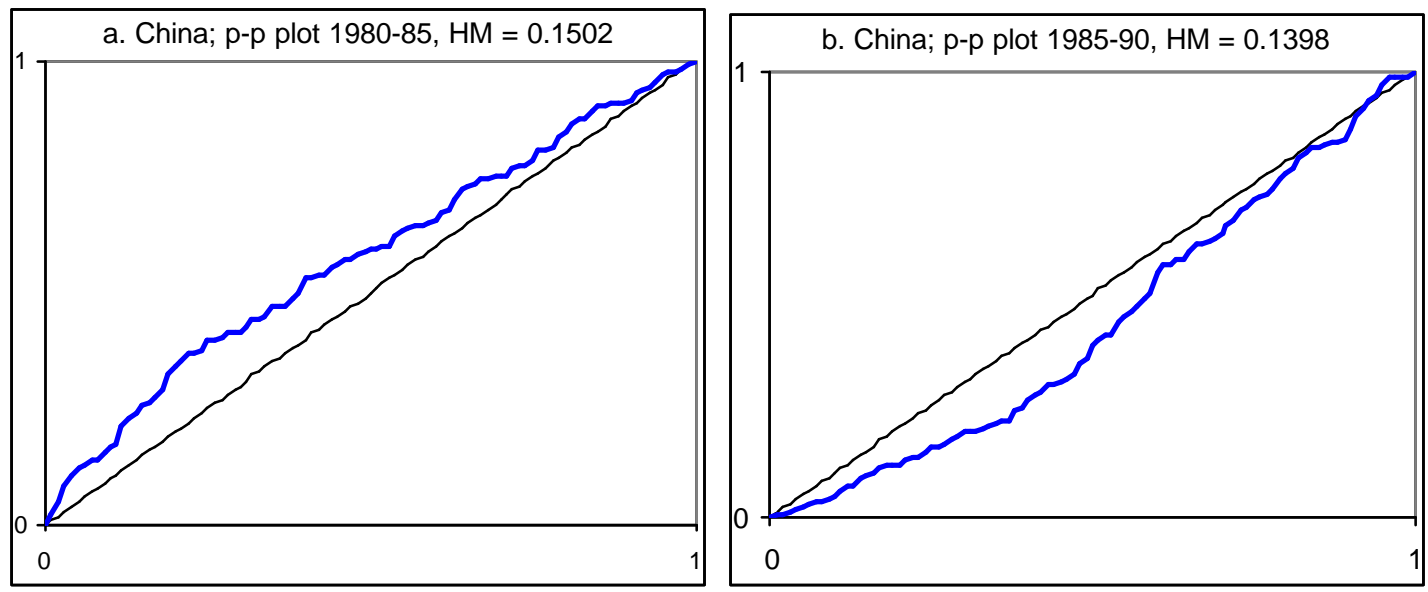

c. China; BI percentile distribution, logarithmic scale From top to bottom: $99 ; 97.5 ; 95 ; 90 ; 75 ; 50$ percent

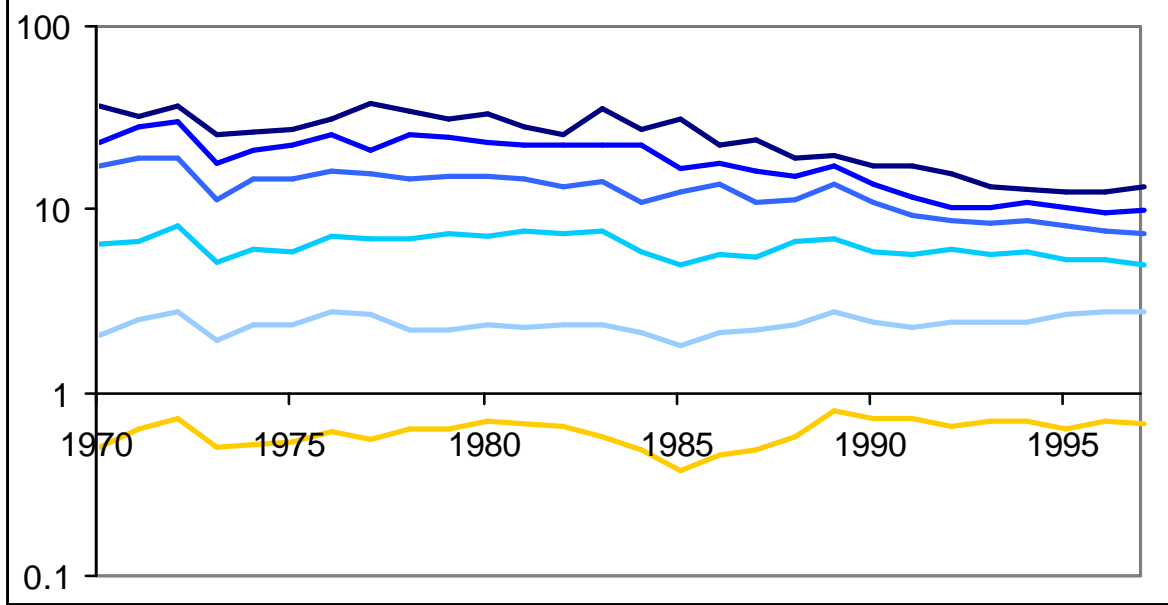

